IAN KOSCIALKOWSKI FIORE

MODELAGEM MATEMÁTICA DE UM REATOR INDUSTRIAL DE ALQUILAÇÃO DE BUTENOS UTILIZANDO HF COMO CATALISADOR 
IAN KOSCIALKOWSKI FIORE

MODELAGEM MATEMÁTICA DE UM REATOR INDUSTRIAL DE ALQUILAÇÃO DE BUTENOS UTILIZANDO HF COMO CATALISADOR 


\section{MODELAGEM MATEMÁTICA DE UM REATOR INDUSTRIAL DE ALQUILAÇÃO DE BUTENOS UTILIZANDO HF COMO CATALISADOR}

Dissertação apresentada à Escola Politécnica da Universidade de São Paulo para obtenção do título de mestre em Engenharia

Área de Concentração:

Engenharia Química

Orientador: Prof. Dr. Reinaldo Giudici 
Este exemplar foi revisado e alterado em relação à versão original, sob responsabilidade única do autor e com a anuência de seu orientador. São Paulo, 25 de abril de 2012

Assinatura do autor:

Assinatura do orientador:

FICHA CATALOGRÁFICA

Fiore, lan Koscialkowski

Modelagem matemática de um reator industrial de alquilação de butenos utilizando HF como catalisador / I.K. Fiore. -- São Paulo, 2012.

$115 \mathrm{p}$.

Dissertação (Mestrado) - Escola Politécnica da Universidade de São Paulo. Departamento de Engenharia Química.

1. Reatores químicos (Modelagem matemática) 2. Alquilação I. Universidade de São Paulo. Escola Politécnica. Departamento de Engenharia Química II. t. 
Dedico esse trabalho a todos que me auxiliam a traçar meus caminhos. 


\section{AGRADECIMENTOS}

Gostaria de agradecer aos professores Reinaldo Giudici e Galo Antônio Carrillo Le Roux pelo suporte prestado a mim durante a execução desse trabalho. $O$ primeiro, orientador do trabalho, por todo auxilio na definição de como abordar o tema proposto e das rotas de solução a seguir. Ao segundo pelo apoio no uso do software MATLAB, e suas funcionalidades.

Agradeço a Petrobras por fomentar a execução do trabalho, disponibilizar a estrutura do CETAI (Centro de Excelência em Tecnologia de Automação Industrial) e fornecer, sem restrições, todos os dados necessários ao projeto.

Ao meu grande amigo Claudio Neves Borges, companheiro incansável durante todo o período de mestrado e, principalmente durante período das disciplinas.

Não poderia deixar de agradecer minha família (pai, mãe, e meu irmão) sempre presente em todos os momentos importantes da minha vida. Em especial minha querida Aline por me incentivar a entrar no programa de mestrado e entender os muitos momentos de distância. 
Pesquisei, estudei, meditei, e comparei impressos e manuscritos, tradições orais e papéis do Estado. Esforcei-me para tirar a limpo a verdade, separando-a do que pudesse obscurecê-la. Com o andar dos tempos e o encontro de novos subsídios, haverá de certo o que modificar e depurar ainda nesta história. Na atualidade, porém, e auxiliando-me com as luzes que pude colher, julgo que a devo publicar como a senti, compreendi e imaginei. João Manuel Pereira da Silva (1817 - 1898). 


\section{RESUMO}

No contexto de refino de petróleo, alquilação é o processo pelo qual se produz uma corrente de hidrocarbonetos chamada de alquilado, na faixa da gasolina, a partir de olefinas leves (propeno, butenos) e isobutano. A demanda por alquilado como corrente integrante do "pool" de gasolinas de uma refinaria tem aumentado ao longo das duas últimas décadas devido a diversos fatores, sendo o principal a adoção de normas mais restritivas para a qualidade de combustíveis automotivos. No presente trabalho foi desenvolvido e validado um modelo matemático fenomenológico capaz de representar adequadamente as reações químicas envolvidas no processo de alquilação catalítica que utiliza ácido fluorídrico como catalisador, bem como estimar o rendimento de produto e subprodutos da reação e a qualidade do alquilado, representada pelo teor de tri-metil-pentanos (TMP) e di-metil-hexanos (DMH) no alquilado. A construção do modelo foi baseada em balanços de massa e energia no conjunto reacional, utilizando mecanismos cinéticos disponíveis na literatura, sendo os seus parâmetros cinéticos estimados por regressão não linear a partir de literatura. $\mathrm{O}$ modelo foi validado com dados obtidos em uma unidade industrial de propriedade da Petrobrás, localizada em Cubatão. Os resultados obtidos permitem afirmar que o modelo apresentou boa resposta para a identificação do consumo de reagentes e rendimento de produtos. Sua resposta tendeu a subestimar a quantidade de frações pesadas do alquilado.

Palavras-chave: Alquilação, ácido fluorídrico, modelagem matemática. 


\begin{abstract}
Alkylation is the process which light hydrocarbons (like butenes and iso-bute) are transformed into heavier hydrocarbons, called alkylate. The alkylate demand as a gasoline component has been growing since the middle 90's, mostly due to more severe quality requirements for gasoline. This work proposes a mathematical model that accounts for the main chemical reactions for a HF Alkylation Unit. The alkylate yield and quality, described by its composition, are also represented as well. This model as based on mass and energy balances for the alkylation reactor, using the most accepted kinetic mechanism available at literature. The model constants were estimated by non-linear regression with available data from literature. The model validation was performed comparing the simulation results with data collected at an industrial Alkylation unit at Cubatão, Brazil, without further parameter adjustment. The results show a good model response for the consumption of reagents and alky yield. The model, however, underpredicts the yield of heavier fractions.
\end{abstract}

Key-words: Alkylation, hydrofluoric acid, mathematical modeling. 


\section{LISTA DE FIGURAS}

Figura 1.1: (a) Distribuição da produção de alquilado em diversas regiões; (b) Evolução da produção de alquilado (Hydrocarbon Publishing, 2008).

Figura 3.1: Metodologia utilizada para elaboração do trabalho.

Figura 3.2: Fluxograma simplificado da unidade industrial em estudo.

Figura 4.1: Diagrama de blocos simplificado de uma refinaria de petróleo - adaptado de http://en.wikipedia.org/wiki/File:RefineryFlow.png (acessado em 23/10/2010).....31

Figura 4.2: Diagrama de blocos de uma unidade de alquilação por HF. 35

Figura 4.3: Fluxograma simplificado da seção de preparo de carga. 36

Figura 4.4: Fluxograma simplificado da seção de reação. 37

Figura 4.5: Fluxograma simplificado da seção de recuperação de ácido. 38

Figura 4.6: Fluxograma simplificado da seção de fracionamento. 39

Figura 4.7: Fluxograma simplificado da seção de tratamento de propano e n-butano.

Figura 4.8: Fluxograma simplificado da seção de tratamento de alquilado. 40

Figura 4.9: Reator de alquilação com circulação de ácido por gravidade, modelo Conoco Phillips (GARY e HANDWERK, 2002) 42

Figura 4.10: Esquema reações de alquilação.

Figura 4.11: Distribuição dos hidrocarbonetos nos derivados do petróleo (http://labvirtual.eq.uc.pt acessado em 06/11/2010)...

Figura 4.12: Influência da temperatura de reação na qualidade do alquilado (MAKOVEK e HASKELL, 1977). 52

Figura 4.13: Acidez de HAMMETT para o HF (CUPIT et al, 1961). 54

Figura 4.14: Influência da quantidade de água no ácido na composição (HUTSON e HAYS, 1977) e octanagem do alquilado.

Figura 4.15: Influência do tipo de olefina na composição (HUTSON e HAYS, 1977) e octanagem do alquilado. 57

Figura 4.16: Isômeros do DMH e TMP com diferentes olefinas (HUTSON e HAYS, 1977) 57

Figura 4.17: Efeito da relação iC4/olefina sobre a qualidade do alquilado obtido a partir de buteno-2 (HUTSON, 1978). 
Figura 4.18: Efeito da relação iC4/olefina sobre o PFE do alquilado e sobre a produção de ASO (HUTSON, 1978)

Figura 5.1: Volume de controle utilizado para a obtenção do modelo fenomenológico.

Figura 5.2: Metodologia utilizada para a construção do modelo fenomenológico. ....64 Figura 5.3: Função acidez de HAMMETT para o HF em função da quantidade de água na solução. Comparação com os dados para o ácido sulfúrico (linha contínua: ácido sulfúrico; linha tracejada: ácido fluorídrico). (HYMAN et al, 1957). .66

Figura 5.4: Comparação do rendimento em alquilado obtido experimentalmente e através do modelo proposto.

Figura 5.5A: Gráfico de paridade para o rendimento em alquilado.

Figura 5.5B: Análise de resíduos para o rendimento em alquilado. 85

Figura 5.6: Comparação do rendimento em alquilado pesado obtido

experimentalmente e pelo modelo proposto 85

Figura 5.7: Gráfico de paridade para o rendimento em alquilado pesado. 86

Figura 5.8: Análise de resíduos para o rendimento em alquilado pesado. 86

Figura 5.9: Comparação do rendimento em subproduto obtido experimentalmente e pelo modelo proposto. .87

Figura 5.10: Gráfico de paridade para o rendimento em subproduto (ASO). 87

Figura 5.11: Análise de resíduos para o rendimento em subproduto (ASO). 88

Figura 5.12: Comparação da relação entre TMP e DMH obtido experimentalmente e pelo modelo proposto. .89

Figura 5.13: Gráfico de paridade para a relação entre TMP e DMH. .......................90

Figura 5.14: Análise de resíduos para a relação entre TMP e DMH. .90

Figura 5.12: Gráfico de paridade para o consumo de olefinas: comparação entre dados industriais e modelo proposto. 92

Figura 5.13: Gráfico de paridade para o consumo de i-butano: comparação entre dados industriais e modelo proposto.

Figura 5.14: Análise de resíduos para a o consumo de i-butano: comparação entre dados industriais e dados obtidos pelo modelo proposto.

Figura 5.15: Gráfico de paridade para o rendimento em alquilado: comparação entre dados industriais e modelo proposto.

Figura 5.16: Gráfico de paridade para a composição do alquilado: comparação entre dados industriais e modelo proposto. 
Figura 5.17: Gráfico de paridade para o rendimento em frações pesadas do alquilado: comparação entre dados industriais e modelo proposto.

Figura 5.18: Análise de resíduos para a o rendimento em alquilado pesado:

comparação entre dados industriais e dados obtidos pelo modelo proposto. 96

Figura 5.19: Dependência do rendimento em alquilado pesado com a temperatura: dados industriais.

Figura 5.20: Perfil ao logo do reator para: (a) concentração de reagentes; (b) concentração de intermediários; (c) concentração de produtos e subprodutos; (d) temperatura. 


\section{LISTA DE TABELAS}

Tabela 1.1: Impacto das propriedades da gasolina no motor e no meio ambiente. ..16 Tabela 1.2: Principais restrições ambientais impostas à gasolina na Europa (EURO V) e Brasil.

Tabela 1.3: Propriedades das frações do petróleo utilizadas na formulação de gasolinas.

Tabela 2.1: Otimizadores comerciais e ganhos esperados com sua utilização. .......21

Tabela 2.2: Aplicação de modelos matemáticos na engenharia de processos. ........22

Tabela 3.1: Descrição dos equipamentos apresentados na Figura 4.1 ....................28

Tabela 3.2: Dados industriais disponíveis para construção do modelo.....................29

Tabela 4.1: Capacidade de unidades de alquilação no mundo.................................32

Tabela 4.2: Propriedades dos principais componentes do alquilado........................50

Tabela 4.3: Influência do teor de água no HF na composição do alquilado (\% wt)...54 Tabela 4.4: Consumo de olefinas e rendimento de alquilado para diferentes olefinas.

Tabela 4.5: Composição do alquilado para diferentes olefinas @ iC4/olefina =13:1.58 Tabela 4.6: Influência da relação iC4/olefina sobre o alquilado produzido a partir de

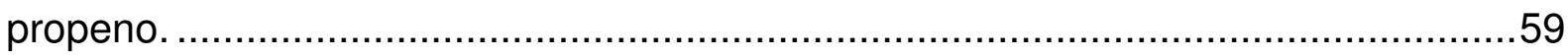

Tabela 5.1: Constantes cinéticas para o modelo proposto.....................................82

Tabela 5.2: Dados industriais necessários para avaliar adesão do modelo matemático. 


\section{SUMÁRIO}

1 INTRODUÇÃO

2 OBJETIVOS

2.1 Objetivo Geral

2.2 Objetivos Específicos

3 MATERIAIS E MÉTODOS

4 REVISÃO BIBLIOGRÁFICA

4.1 Processo de Alquilação

4.2 Alquilação com Ácido Fluorídrico

4.2.1 Reator por gravidade

4.2.2 Mecanismo da Reação de Alquilação

4.2.3 Qualidade do Produto

4.2.4 Dados experimentais e variáveis operacionais

5 RESULTADOS E DISCUSSÃO

5.1 Modelagem Matemática

5.1.1 Dissociação do Ácido Fluorídrico

5.1.2 Cinética de Reação

5.2 Calibração do Modelo Fenomenológico

5.3 Comparação com Dados Industriais

6 SUGESTÕES DE TRABALHOS FUTUROS

7 CONCLUSÕES 


\section{INTRODUÇÃO}

No contexto de refino de petróleo, Alquilação é o processo pelo qual se produz uma corrente de hidrocarbonetos, chamada de alquilado, na faixa da gasolina com elevada octanagem (RON e MON), baixa pressão de vapor Reid (PVR), baixo teor de enxofre e isenta de aromáticos e olefinas.

A demanda por alquilado como corrente integrante do pool de gasolinas de uma refinaria tem aumentado ao longo da última década devido a diversos fatores, sendo os principais: a adoção de normas mais restritivas para emissão veiculares, refletindo diretamente na especificação dos combustíveis, e a proibição do uso de MTBE (metil terc butil éter) na gasolina. (Hydrocarbon Publishing, 2008)

Ao redor do mundo, os governos têm modificado suas legislações que regem a especificação dos combustíveis no sentido de restringir o teor de determinadas substâncias (contaminantes) que, quando queimadas no motor, aumentam as emissões atmosféricas dos veículos. O alvo principal é a redução dos teores de monóxido de carbono (CO), hidrocarbonetos, óxidos de enxofre $\left(\mathrm{SO}_{\mathrm{x}}\right)$ e óxidos de nitrogênio $\left(\mathrm{NO}_{\mathrm{x}}\right)$ no exausto dos veículos. No caso da gasolina essas mudanças são traduzidas pela redução no teor de enxofre, compostos nitrogenados, olefinas e aromáticos (principalmente o benzeno), além de aumentar a octanagem do combustível e reduzir sua PVR (pressão de vapor Reid). A Tabela 1.1 apresenta de maneira resumida o impacto de cada uma dessas propriedades da gasolina no motor e no meio ambiente.

As exigências ambientais estabelecidas na Europa e em alguns estados dos Estados Unidos (como Califórnia) estão entre as mais restritivas do mundo, portanto o combustível a ser utilizado nessas regiões tem regulamentação igualmente rigorosa. As normas norte americanas servem como tendência para a especificação brasileira por este ser o maior consumidor mundial de gasolina, e um potencial importador da gasolina brasileira. A Tabela 1.2 mostra as principais restrições impostas à gasolina com a entrada em vigor do EURO V na Europa e compara com 
a especificação atual no Brasil, ainda bastante atrasada. Em 2014 está prevista a entrada em vigência da fase L6 do PROCONVE (programa de controle da poluição do ar por veículos automotores), do governo federal, que pretende reduzir a diferença entre a especificação do Brasil em relação à do resto do mundo.

A formulação de gasolinas com qualidade compatível com a frota de automóveis existente (principalmente fora do Brasil) que atenda todas as restrições ambientais impostas precisa ser avaliada cuidadosamente e, em muitos casos, representa um desafio para as refinarias devido à qualidade das correntes disponíveis para compor o pool do produto acabado.

A nafta de craqueamento catalítico (FCC), disponível em grande volume, é a principal corrente que compõe a gasolina, porém, por apresentar um elevado teor de olefinas, aromáticos (incluindo benzeno) e enxofre, tem restrições quanto à quantidade máxima a ser dosada. Essa mesma corrente pode passar por um hidrotratamento para remoção de enxofre, permitindo um maior volume desta na gasolina acabada, porém o teor de olefinas e aromáticos não permitem seu uso irrestrito.

A nafta de destilação direta apresenta um baixo teor de contaminantes, porém sua octanagem é muito baixa, o que não permite seu uso em larga escala. $O$ reformado é bastante utilizado como corrente para aumento de octanagem e tem seu uso restringido pelo teor máximo de aromáticos na gasolina. As principais propriedades das correntes que compõe o pool de gasolina aparecem listadas na Tabela 1.3. 
Tabela 1.1: Impacto das propriedades da gasolina no motor e no meio ambiente.

\begin{tabular}{|c|c|c|c|c|}
\hline Propriedade & Direção & Impacto positivo no motor & Impacto negativo no motor & Impacto no meio ambiente \\
\hline Octanagem & Aumento & $\begin{array}{l}\text { Evita detonação prematura. } \\
\text { Aumenta taxa de compressão. } \\
\text { Aumenta potência do motor. } \\
\text { Aumenta eficiência do motor. }\end{array}$ & NA & $\begin{array}{l}\text { A maior parte dos aditivos para aumento } \\
\text { de octanagem são substâncias } \\
\text { perigosas (como chumbo, aromáticos e } \\
\text { olefinas). }\end{array}$ \\
\hline $\begin{array}{l}\text { Teor de } \\
\text { olefinas }\end{array}$ & Aumento & $\begin{array}{l}\text { Aumenta octanagem da } \\
\text { gasolina. }\end{array}$ & $\begin{array}{l}\text { Grande ocorrência de depósitos no } \\
\text { motor devido à geração de goma. }\end{array}$ & $\begin{array}{l}\text { Emissão de ozônio e gases que causam } \\
\text { smog fotoquímico. }\end{array}$ \\
\hline $\begin{array}{l}\text { Teor de } \\
\text { aromáticos }\end{array}$ & Aumento & $\begin{array}{l}\text { Aumenta octanagem da } \\
\text { gasolina. }\end{array}$ & $\begin{array}{l}\text { Leva a ocorrência de depósitos no } \\
\text { motor e queima incompleta do } \\
\text { combustível. }\end{array}$ & $\begin{array}{l}\text { Emissão de monóxido de carbono (CO) } \\
\text { e gases que causam smog fotoquímico. } \\
\text { Emissões fugitivas de benzeno pelo } \\
\text { combustível. }\end{array}$ \\
\hline $\begin{array}{l}\text { Teor de } \\
\text { enxofre }\end{array}$ & Aumento & NA & $\begin{array}{l}\text { Reduz eficiência do motor por } \\
\text { afetar a detonação. } \\
\text { Maior taxa de corrosão. }\end{array}$ & $\begin{array}{l}\text { Emissão de dióxido e trióxido de enxofre } \\
\left(\mathrm{SO}_{2} \text { e } \mathrm{SO}_{3}\right) \text { que causam chuva ácida. } \\
\text { Reduz eficiência dos catalisadores que } \\
\text { removem } \mathrm{NO}_{x} \text {. }\end{array}$ \\
\hline PVR & NA & $\begin{array}{l}\text { Baixa PVR: melhor partida a } \\
\text { frio. }\end{array}$ & $\begin{array}{l}\text { Alta PVR: queima incompleta e } \\
\text { maior formação de depósitos no } \\
\text { motor. }\end{array}$ & $\begin{array}{l}\text { Baixa PVR: maior emissão fugitiva de } \\
\text { hidrocarbonetos pelo combustível. } \\
\text { Alta PVR: emissão de hidrocarbonetos } \\
\text { não queimados e CO. }\end{array}$ \\
\hline
\end{tabular}

(adaptado de BUI, 2007)

http://www.cheresources.com/greengas.shtml (acessado em 17/10/2010) 
Tabela 1.2: Principais restrições ambientais impostas à gasolina na Europa (EURO V) e Brasil.

\begin{tabular}{cccc}
\hline Propriedade & & Especificação EURO V & Brasil \\
\hline Enxofre & $\mathrm{ppm}$ (massa) & 10 & 1000 \\
Olefinas & $\%$ vol & 10 & 25 \\
Aromáticos & $\%$ vol & 35 & 40 \\
Benzeno & $\%$ vol & 1 & NA \\
\hline
\end{tabular}

(DAUZACKER e PALOMBO, 2003)

Um aditivo que costumava ser largamente utilizado para aumentar a octanagem da gasolina era o MTBE, porém seu uso foi proibido nos Estados Unidos (EUA), Europa e outras regiões do mundo devido a questões ambientais. Com a proibição do MTBE como aditivo na gasolina, empresas de todo o mundo estão buscando outras correntes com elevada octanagem para substituí-lo. As alternativas mais comuns são o etanol, o ETBE (etil terc butil éter), iso-octano e o alquilado. $O$ primeiro aparece como uma opção bastante utilizada ao redor do mundo, incluindo o Brasil, por apresentar elevada octanagem sem as restrições ambientais do MTBE. Porém seu uso implica no aumento da PVR na gasolina, o que aumenta as emissões de hidrocarbonetos por evaporação (emissões fugitivas).

O uso do ETBE como corrente para aumento da octanagem tem como principal vantagem em relação ao etanol o fato de não aumentar significantemente a PVR da gasolina. Nos EUA, o uso de tal corrente não é muito difundido devido incertezas quanto a sua proibição, assim como o caso do MTBE, em um futuro próximo. Já Europa e Japão anunciaram planos de aumentar sua produção de ETBE nos próximos anos. (Hydrocarbon Publishing, 2008) 
Tabela 1.3: Propriedades das frações do petróleo utilizadas na formulação de gasolinas.

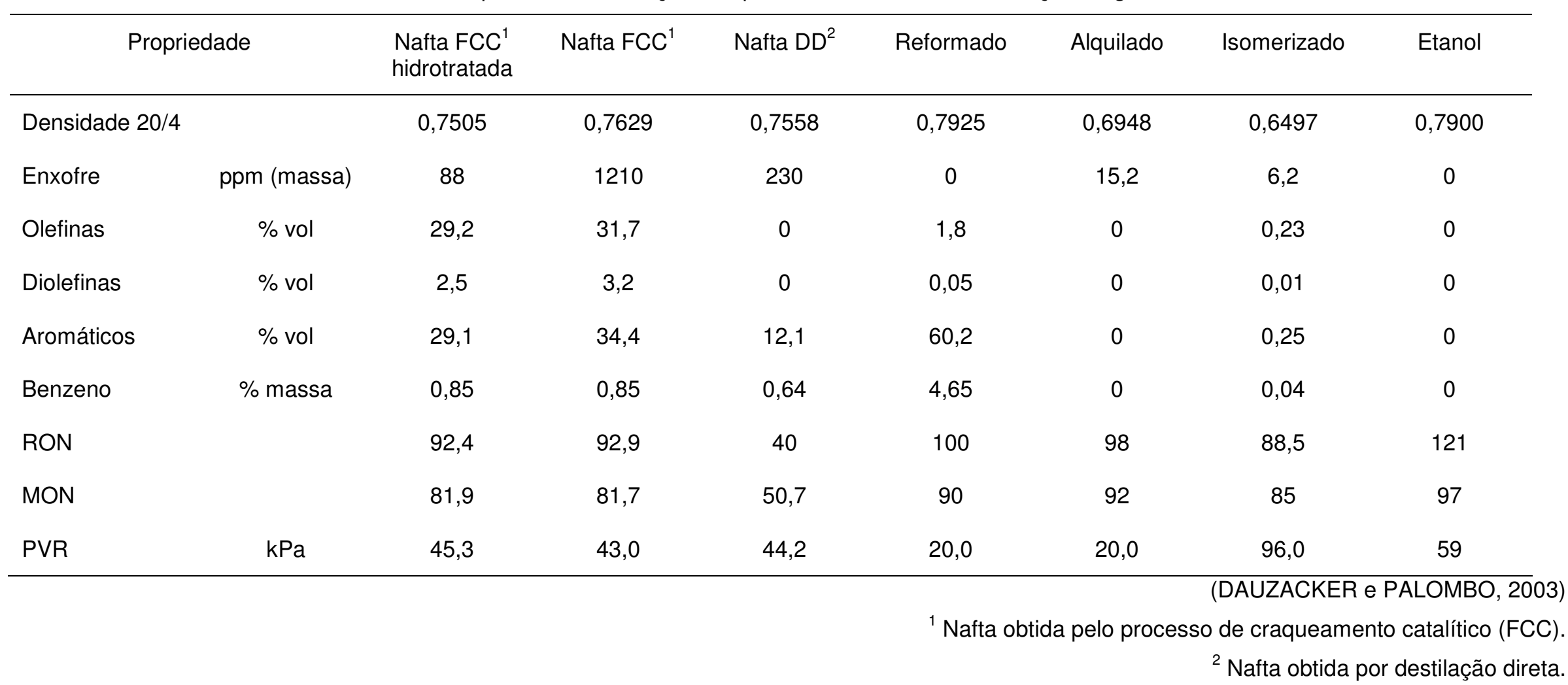


Tanto 0 iso-octano como 0 alquilado não apresentam nenhuma das preocupações acima descritas, por isso são considerados os candidatos naturais a substituição do MTBE. A desvantagem do uso do iso-octano em relação ao alquilado está no custo de produção, além de exigir o dobro de olefinas para produzir o mesmo volume de booster de octanagem. Os EUA optaram pelo uso do alquilado como corrente a substituir MTBE, e este já corresponde a uma proporção de 11 a 13\% (em volume) na gasolina vendida nessa região. (Hydrocarbon Publishing, 2008)

Atualmente a capacidade instalada para a produção de alquilado está praticamente estacionada desde 2004 em aproximadamente 230 milhões de metros cúbicos por dia, sendo que $60 \%$ desta estão nos EUA, como mostrado na Figura 1.1 (a) e (b). A produção de alquilado não acompanha o aumento de sua demanda, pois a matéria prima para sua obtenção (parafinas e olefinas leves) também tem demanda de mercado e valor comercial. Dessa maneira, o aumento de produção do alquilado está diretamente ligado à disponibilidade de matéria prima. O aumento da demanda por alquilado, aliada à falta de perspectiva para aumento de sua oferta, gera uma pressão pelo aumento de preços no mercado internacional.
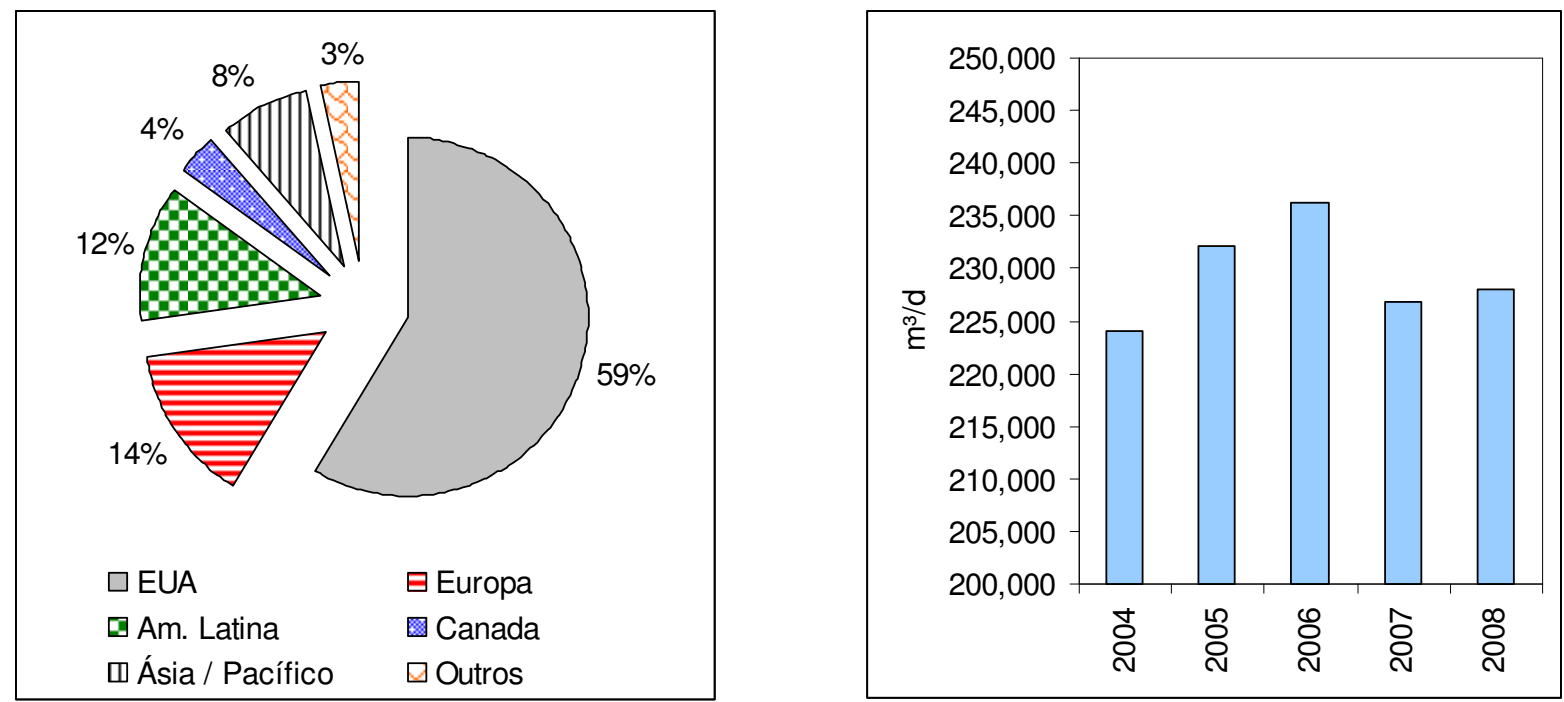

Figura 1.1: (a) Distribuição da produção de alquilado em diversas regiões; (b) Evolução da produção de alquilado (Hydrocarbon Publishing, 2008). 


\section{OBJETIVOS}

A otimização de processos tem se mostrado, ao longo do tempo, uma importante ferramenta para empresas maximizarem os resultados de unidades já existentes, respeitando os limites operacionais e de qualidade do produto impostos a ela. Essa maximização de resultados pode vir (entre outras maneiras) pelo aumento da produção, rendimento e/ou eficiência da unidade; pelo aumento da qualidade do produto e, ainda, pela redução de custos de produção.

A máxima rentabilidade de uma unidade de alquilação ocorre quando esta opera em um ponto onde sua carga é a maior possível, com octanagem do alquilado compatível com as necessidades da refinaria e alto rendimento de alquilado (em relação à olefinas). Além disso, o consumo de catalisador deve ser baixo, assim como a taxa de corrosão na unidade (tempo de campanha). Considerando o mercado atual, onde os preços do alquilado estão bastante elevados, tornou-se atrativo economicamente para muitas empresas investir em modelos e otimizadores em tempo real para suas unidades de alquilação, buscando operar de forma segura e estável no ponto ótimo. A Tabela 2.1 apresenta exemplos de produtos comerciais para a otimização de unidades de alquilação e o ganho estimado quando de sua utilização. Considerando a capacidade mundial instalada, existe um ganho potencial aproximado US\$80 milhões de dólares por ano em ações de otimização no processo de alquilação.

Os produtos abaixo relacionados têm diferentes graus de complexidade e necessitam de diferentes dados para realizar o que se propõem. Porém, eles têm em comum o uso de um modelo matemático para representar a unidade de alquilação, predizendo a evolução da variável dependente (exemplo: qualidade do produto) e indicando como o controlador deve atuar para mantê-la na faixa desejada. 
Tabela 2.1: Otimizadores comerciais e ganhos esperados com sua utilização.

\begin{tabular}{cc}
\hline Licenciador & Ganhos estimados (c\$/bbl carga fresca) \\
\hline Aspen & $10-30$ \\
Emerson & $8-16$ \\
Honeywell & $10-25$ \\
Invensys & $10-20$
\end{tabular}

(Hydrocarbon Publishing, 2008)

O modelo de processo é uma das principais ferramentas da engenharia de processos uma vez que seu uso abrange diversas áreas de aplicação (Tabela 2.2). $\mathrm{Na}$ maioria dos casos, ao se adquirir uma solução comercial para otimização de processos, o uso do modelo matemático fica restrito ao motivo da compra, sendo vetada sua utilização para outras funções.

Os modelos matemáticos para unidade de alquilação comercializados atualmente se utilizam dos dados das plantas industriais para os quais os modelos serão aplicados para estimar seus parâmetros internos e, dessa maneira, representar da melhor forma possível a unidade em questão. Apesar de representarem adequadamente o processo, esses modelos têm limitações, tais como apresentar o alquilado como soma de pseudo componentes, mesmo sendo sua composição amplamente conhecida e discutida (ALBRIGTH e WOOD, 1997; DURRETT et al, 1963; CUPIT et al, 1961) e facilmente medida por cromatografia. A análise cromatográfica do alquilado fornece importantes informações a respeito do mecanismo de reação que está predominando no reator, facilitando a identificação e solução de problemas operacionais. Outra importante limitação desses modelos é a sua incapacidade de mensurar a formação dos fluoretos orgânicos, compostos responsáveis por grande parte dos problemas de obstrução e corrosão observados nas unidades de alquilação.

Além disso, por serem modelos fechados, em nenhum momento o usuário toma conhecimento das equações utilizadas, assim como poucas informações estão disponíveis a respeito de sua construção - como hipóteses adotadas, limites de utilização e, se são estatísticos (empíricos) ou fenomenológicos - o que dificulta a interpretação de dados fornecidos pelo modelo. 
Tabela 2.2: Aplicação de modelos matemáticos na engenharia de processos.

\begin{tabular}{|c|c|}
\hline Área de aplicação & Uso \\
\hline \multirow[t]{5}{*}{ Projeto de processo } & Avaliação técnica, ambiental e econômica de projetos. \\
\hline & $\begin{array}{l}\text { Avaliação do efeito de parâmetros de projeto/processo no } \\
\text { desempenho da unidade. }\end{array}$ \\
\hline & Otimização. \\
\hline & Análise de interação de processos. \\
\hline & Minimização de efluentes na etapa de projeto. \\
\hline \multirow[t]{3}{*}{ Controle de processo } & Avaliar estratégia de controle regulatório. \\
\hline & Análise dinâmica de mudança de set point ou distúrbios. \\
\hline & Otimização de produção e partida de unidades. \\
\hline \multirow[t]{2}{*}{ Solução de problemas } & $\begin{array}{l}\text { Identificação de causas para perda de qualidade do } \\
\text { produto. }\end{array}$ \\
\hline & Identificação de causas para problemas de processo. \\
\hline \multirow[t]{3}{*}{ Segurança de processo } & $\begin{array}{l}\text { Identificação de regimes de operação potencialmente } \\
\text { perigosos. }\end{array}$ \\
\hline & Quantificação de volumes lançados em caso de acidente. \\
\hline & $\begin{array}{l}\text { Estimativa de conseqüências em caso de acidentes } \\
\text { (incêndio, entre outros) }\end{array}$ \\
\hline \multirow[t]{3}{*}{ Treinamento de operador } & Partida e parada de unidades. \\
\hline & Resposta a emergência. \\
\hline & Operações de rotina. \\
\hline
\end{tabular}

(adaptado de CAMERON e HANGOS, 2001)

\subsection{Objetivo Geral}

Este trabalho se propõe a construir e validar um modelo matemático fenomenológico para o reator de uma unidade de alquilação catalítica que utiliza o ácido fluorídrico (HF) como catalisador, que seja capaz de representar adequadamente as principais reações químicas envolvidas no processo em questão, bem como estimar a quantidade de tri-metil-pentanos e di-metil-hexano presentes na composição do alquilado. 


\subsection{Objetivos Específicos}

Para atingir o objetivo deste trabalho, as seguintes etapas foram cumpridas:

- Revisão da literatura visando selecionar um mecanismo cinético, amplamente aceito pela comunidade científica, capaz de explicar todos os fenômenos que ocorrem no reator de alquilação;

- Revisão da literatura em busca de dados experimentais capazes de auxiliar na calibração / validação do modelo matemático proposto;

- Revisão da literatura para obter o comportamento de dissociação do ácido fluorídrico (HF) concentrado;

- Planejar e realizar coleta de dados industriais em uma planta industrial de alquilação para a calibração / validação do modelo proposto;

- Escrever as equações que descrevem o modelo cinético proposto;

- Resolver numericamente o sistema de equações obtido e comparar os resultados com os dados observados na literatura e na unidade industrial.

- Simular condições operacionais comuns a uma unidade de alquilação e descrever os eventos que ocorrem no interior do reator. 


\section{MATERIAIS E MÉTODOS}

Esse trabalho se propõe a construir e validar um modelo matemático fenomenológico para uma unidade de alquilação catalítica que utiliza o ácido fluorídrico (HF) como catalisador, que seja capaz de representar adequadamente as principais reações químicas envolvidas no processo em questão, bem como estimar a composição do alquilado em termos de tri-metil-pentanos (TMP) e di-metil-hexanos (DMH), que são os componentes de maior importância, uma vez que conferem, respectivamente, maior e menor octanagem ao alquilado. Para alcançar o objetivo proposto foi utilizada a metodologia apresentada esquematicamente na Figura 3.1.

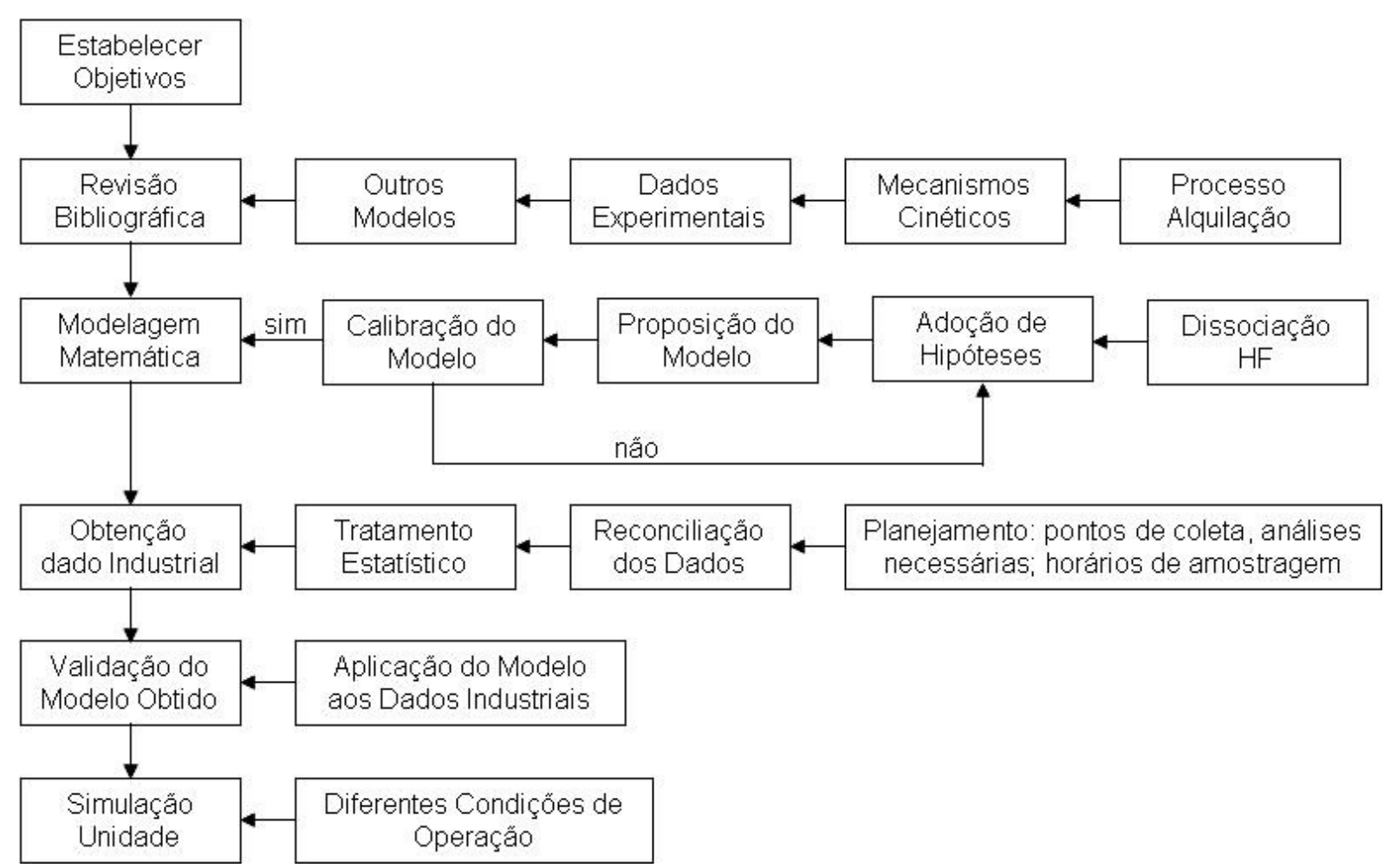

Figura 3.1: Metodologia utilizada para elaboração do trabalho.

A revisão bibliográfica foi realizada para subsidiar a construção do modelo matemático. Nesta etapa o processo de alquilação catalítica foi descrito para contextualizar este trabalho. Em seguida foram explorados diferentes mecanismos cinéticos que descrevem o processo e como eles evoluíram com o passar dos anos, porém, somente o mecanismo atualmente aceito para a alquilação com HF, proposto 
por HUTSON (1977), está apresentado no corpo deste texto. Em seguida foram obtidos da literatura dados experimentais, em escala de laboratório, que permitissem a calibração do modelo matemático proposto nesse trabalho. Por último, foram estudados outros modelos matemáticos de processo de alquilação, independentemente do catalisador utilizado no processo.

Em seguida foram coletados dados de qualidade de carga e produtos, além de outros parâmetros de processo, na unidade de alquilação de propriedade da Petrobras, localizada na Refinaria Presidente Bernardes em Cubatão, Brasil. O planejamento da coleta de dados levou em consideração os pontos disponíveis para amostrar as correntes de interesse, as análises necessárias para caracterizá-las e o tempo de residência na unidade. Os dados obtidos passaram por uma etapa de reconciliação, através de balanços de massa e energia, de maneira a identificar erros de medidas (instrumentos de campo) e, quando possível, corrigir os dados. Nos casos onde a correção não foi possível, desconsiderou-se o ponto para futuras análises.

Para que um modelo matemático represente adequadamente uma unidade industrial é necessário o ajuste de seus parâmetros com dados da planta em questão. A resposta do modelo terá uma qualidade tão boa tanto aquela observada nos dados utilizados no ajuste de parâmetros. Portanto, realizar uma boa coleta de dados industriais é indispensável para a construção do modelo.

Precauções devem ser tomadas para que os pontos de amostragem sejam adequados e para que as amostras retiradas sejam representativas do processo. No trabalho em questão os pontos de amostragem disponíveis na unidade industrial não cobrem todas as correntes necessárias para a montagem do modelo, portanto, foi necessário, por balanços completar algumas informações não disponíveis. Um exemplo onde essa metodologia foi empregada é a composição de saída do decantador, que foi obtida através dos dados de composição e vazão dos diversos produtos na saída da unidade.

A Figura 3.2 apresenta o fluxograma simplificado da unidade da qual os dados foram coletados, bem como a identificação das correntes necessárias para a 
montagem do modelo. A Tabela 3.1 descreve os equipamentos apresentados no fluxograma. A Tabela 3.2 descreve as correntes marcadas no fluxograma, bem como as análises disponíveis para montagem do modelo.

A construção do modelo fenomenológico é baseada em balanços de massa e energia no conjunto reacional, utilizando mecanismos cinéticos disponíveis na literatura (CIAPETTA, 1945; CUPIT et al, 1961; HUTSON e HAYS, 1977) com seus parâmetros estimados por regressão não linear a partir dos dados obtidos na literatura. A construção do modelo completo foi dividida em etapas, obtendo-se em cada uma delas modelos com diferentes graus de complexidade, devido a mudanças nas hipóteses adotadas e reações modeladas. Um modelo mais simples, capaz apenas de prever a polimerização das olefinas, foi utilizado para obter o valor das constantes cinéticas por regressão não linear e avaliar a aderência das hipóteses utilizadas. Utilizando essas constantes, modelos mais complexos, capazes de prever a composição do produto, foram construídos. A regressão não-linear para obtenção dos parâmetros cinéticos, assim como a resolução do sistema de equações diferenciais foi realizada através do software MATLAB 7.0.4 $\circledast$, utilizando-se para tanto as rotinas Isqnonlin e ode15s respectivamente.

A validação do modelo matemático foi realizada através da comparação dos resultados obtidos pelo modelo com os resultados reais da planta de alquilação.

Devido o sigilo dos dados utilizados nesse trabalho, todos os resultados serão apresentados por meio da forma reduzida pela média e valores máximos e mínimos, segundo Equação 3.1, fazendo que todos os dados estejam no intervalo entre 0 e 1.

$$
\tilde{y}_{i}=\frac{y_{i}-y_{\min }}{y_{\max }-y_{\min }}
$$




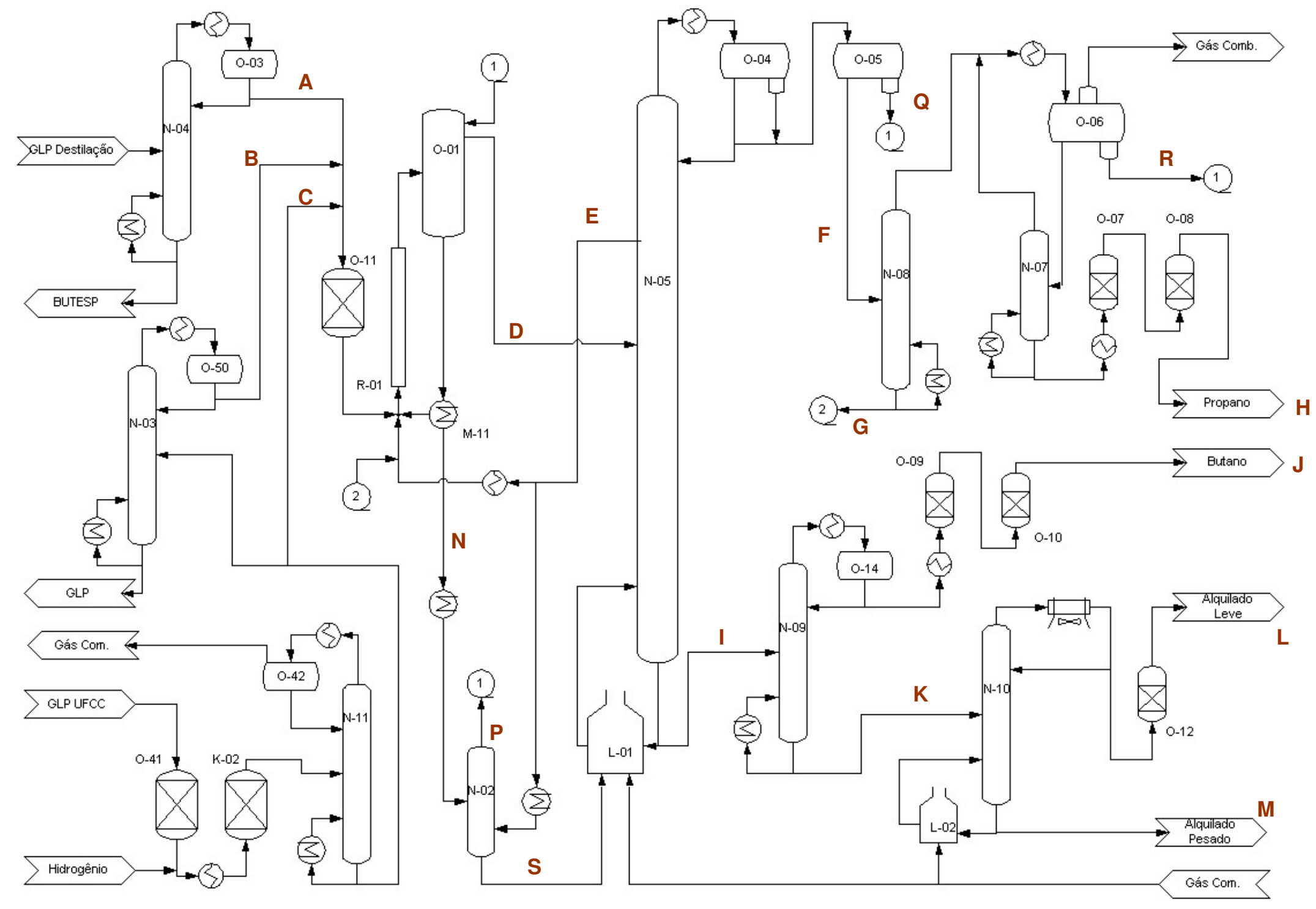

Figura 3.2: Fluxograma simplificado da unidade industrial em estudo. 
Tabela 3.1: Descrição dos equipamentos apresentados na Figura 4.1.

\begin{tabular}{|c|c|}
\hline Equipamento & Função \\
\hline $\mathrm{N}-11$ & $\begin{array}{l}\text { Destilação: separar efluente do reator de hidrogenação seletiva em } \\
\text { butenos carga da alquilação - fundo) e hidrogênio (topo). }\end{array}$ \\
\hline $\mathrm{N}-02$ & $\begin{array}{l}\text { Destilação: manter a pureza do ácido circulante, separando o HF } \\
\text { (topo) do ASO e água que estão solubilizados neste (fundo). }\end{array}$ \\
\hline $\mathrm{N}-03$ & $\begin{array}{l}\text { Destilação: separar o iC4 carga da unidade (topo) dos demais } \\
\text { isômeros do butano (fundo). }\end{array}$ \\
\hline $\mathrm{N}-05$ & $\begin{array}{l}\text { Destilação: separar efluente do decantador em HF (arrastado) e } \\
\text { propano (topo); iC4 não reagido (lateral) e n-butano e alquilado } \\
\text { (fundo). }\end{array}$ \\
\hline $\mathrm{N}-08$ & Destilação: separar HF e propano (topo) do iC4 não reagido (fundo). \\
\hline $\mathrm{N}-07$ & $\begin{array}{l}\text { Destilação: recuperar o HF arrastado pela separação deste (topo) do } \\
\text { propano (fundo). }\end{array}$ \\
\hline $\mathrm{N}-09$ & $\begin{array}{l}\text { Destilação: ajustar a PVR do alquilado pela remoção do n-butano } \\
\text { (topo). }\end{array}$ \\
\hline $\mathrm{N}-10$ & $\begin{array}{l}\text { Destilação: separar o alquilado de menor tamanho de cadeia - } \\
\text { alquilado leve - (topo) do alquilado pesado (fundo). }\end{array}$ \\
\hline $\mathrm{R}-01$ & $\begin{array}{l}\text { Riser da unidade de alquilação, onde as olefinas reagem com o iC4, } \\
\text { na presença de HF, para formar o alquilado e sub-produtos. }\end{array}$ \\
\hline $\mathrm{K}-02$ & $\begin{array}{l}\text { Reator: hidrogenar as diolefinas presentes na corrente de butanos } \\
\text { oriunda da unidade de craqueamento catalítico. }\end{array}$ \\
\hline O-01 & $\begin{array}{l}\text { Decantador: separar efluente do riser em duas fases: hidrocarbonetos } \\
\text { (sobrenadante) e HF com subprodutos (decantado) }\end{array}$ \\
\hline O-04/O-05 & $\begin{array}{l}\text { Reatores: quebrar fluoretos orgânicos formados no riser em HF e } \\
\text { alquilado, de maneira a obter um menor consumo de ácido. }\end{array}$ \\
\hline O-11/O-42 & $\begin{array}{l}\text { Secadores de carga: remover água das correntes de carga da } \\
\text { unidade. }\end{array}$ \\
\hline O-07/O-09 & $\begin{array}{l}\text { Vasos de alumina: reter HF presentes na corrente de propano e } \\
\text { butano. }\end{array}$ \\
\hline O-08/O-10/O-12 & $\begin{array}{l}\text { Vasos de potassa / soda: reter HF presentes na corrente de propano, } \\
\text { butano e alquilado leve. }\end{array}$ \\
\hline
\end{tabular}


Tabela 3.2: Dados industriais disponíveis para construção do modelo.

\begin{tabular}{|c|c|c|c|c|}
\hline Local & Produto & Vazão & Temperatura & Composição \\
\hline \multirow{2}{*}{$A$} & \multirow{2}{*}{ iC4 carga } & \multirow{2}{*}{$x$} & \multirow{2}{*}{$x$} & Enxofre total \\
\hline & & & & Cromatografia \\
\hline \multirow{2}{*}{$\mathrm{B}$} & \multirow{2}{*}{ iC4 carga } & \multirow{2}{*}{$x$} & \multirow{2}{*}{$x$} & Enxofre total \\
\hline & & & & Cromatografia \\
\hline \multirow{2}{*}{ C } & \multirow{2}{*}{$\begin{array}{l}\text { Olefinas } \\
\text { carga }\end{array}$} & \multirow{2}{*}{$x$} & \multirow{2}{*}{$x$} & Enxofre total \\
\hline & & & & Cromatografia \\
\hline $\mathrm{D}$ & $\begin{array}{l}\text { Efluente } \\
\text { Decantador }\end{array}$ & $\mathrm{X}$ & $x$ & ND \\
\hline$E$ & Reciclo iC4 & $x$ & $x$ & Cromatografia \\
\hline $\mathrm{F}$ & $\begin{array}{c}\text { HF, } \\
\text { Propano, } \\
\text { iC4 }\end{array}$ & $x$ & $x$ & ND \\
\hline G & $\begin{array}{l}\text { iC4 para } \\
\text { reciclo }\end{array}$ & $x$ & $x$ & ND \\
\hline $\mathrm{H}$ & Propano & - & $x$ & ND \\
\hline 1 & $\begin{array}{l}\text { n-butano, } \\
\text { alquilado }\end{array}$ & $\mathrm{x}$ & $x$ & ND \\
\hline$J$ & n-Butano & $x$ & $x$ & Cromatografia \\
\hline $\mathrm{K}$ & Alquilado & $x$ & $x$ & Destilação ASTM D86 \\
\hline \multirow{3}{*}{ L } & \multirow{3}{*}{$\begin{array}{l}\text { Alquilado } \\
\text { Leve }\end{array}$} & \multirow{3}{*}{$\mathrm{x}$} & \multirow{3}{*}{$x$} & Octanagem \\
\hline & & & & Cromatografia \\
\hline & & & & Destilação ASTM D86 \\
\hline M & $\begin{array}{l}\text { Alquilado } \\
\text { Pesado }\end{array}$ & $x$ & $x$ & Destilação ASTM D86 \\
\hline $\mathrm{N}$ & $\begin{array}{c}\mathrm{HF} \\
\text { circulante }\end{array}$ & $x$ & $x$ & $\begin{array}{c}\text { Pureza, Teor de água, Teor de } \\
\text { ASO }\end{array}$ \\
\hline $\mathrm{O}$ & HF & ND & ND & ND \\
\hline $\mathrm{P}$ & HF & ND & ND & ND \\
\hline Q & $\mathrm{HF}$ & ND & ND & ND \\
\hline $\mathrm{R}$ & $\mathrm{HF}$ & ND & ND & ND \\
\hline$S$ & ASO & ND & ND & ND \\
\hline
\end{tabular}




\section{REVISÃO BIBLIOGRÁFICA}

O petróleo é uma mistura complexa de hidrocarbonetos que é utilizado na sua forma bruta apenas como óleo combustível, com baixo potencial energético. Porém, com um processamento adequado é possível obter diversos produtos, entre eles combustíveis (gás de refinaria, GLP, gasolina, querosene e diesel e óleo combustível), solventes (exemplos: hexano, benzeno, tolueno, xilenos, aguarrás), lubrificantes e matéria prima para diversos setores industriais (como: petroquímico, farmacêutico, alimentício). A esse processamento dá-se o nome de refino do petróleo.

O conjunto de unidades que farão parte de uma refinaria, bem como a maneira com que elas interagem, depende principalmente da qualidade do petróleo que será processado por ela e do perfil de produtos almejado. A Figura 4.1 apresenta um diagrama de blocos de uma refinaria cujo principal objetivo é a produção de combustíveis com elevada qualidade. 


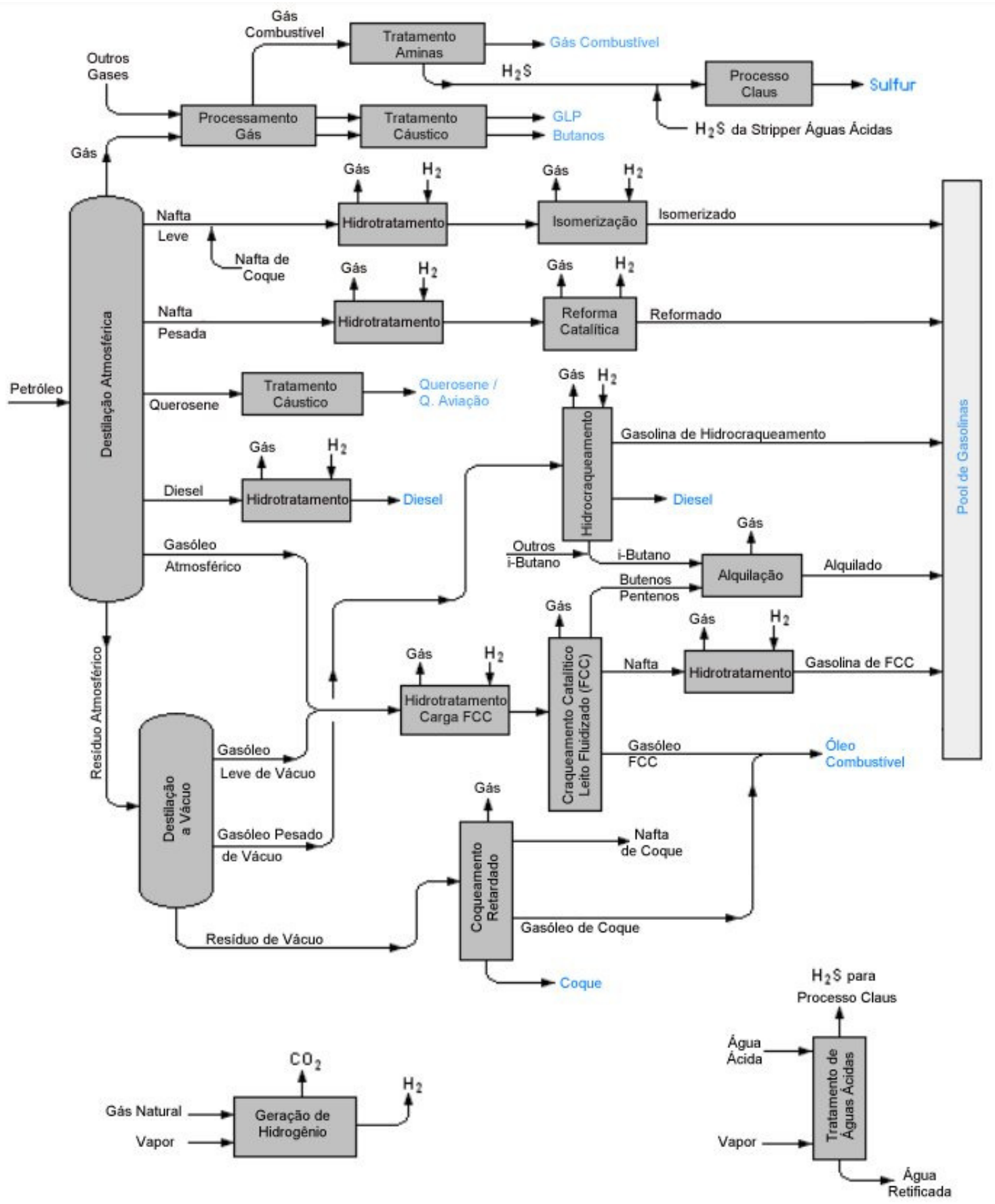

Figura 4.1: Diagrama de blocos simplificado de uma refinaria de petróleo - adaptado de http://en.wikipedia.org/wiki/File:RefineryFlow.png (acessado em 23/10/2010).

A unidade de alquilação catalítica é encontrada principalmente em refinarias com o objetivo de maximixar a produção de gasolina de alta qualidade, com capacidades que variam entre $0,5 \%$ e $7 \%$ da capacidade da unidade de destilação, como mostrado na Tabela 4.1. Sua carga é composta de hidrocarbonetos insaturados com 3, 4 e 5 carbonos, oriundos da unidade de craqueamento catalítico, que irão reagir com o iso-butano (iC4), vindo de diversas unidades da refinaria, para 
formar a corrente na faixa da gasolina, com elevada octanagem e baixo teor de contaminantes, conhecida como alquilado.

Tabela 4.1: Capacidade de unidades de alquilação no mundo.

\begin{tabular}{cc}
\hline Região & Capacidade (\% da capacidade da destilação) \\
\hline EUA & 6,53 \\
Canadá & 3,55 \\
América Latina & 2,92 \\
Europa & 0,58 \\
Ásia / Pacífico & 0,69 \\
Outros & 0,65 \\
Média Mundial & 2,28 \\
\hline
\end{tabular}

(Hydrocarbon Publishing, 2008)

\subsection{Processo de Alquilação}

O processo de alquilação foi descoberto no início da década de $30 \mathrm{com}$ o estudo de Ipatieff e Grosse que reportaram que as parafinas não são inertes, ao contrário do que se pensava na época, e que em certas circunstâncias sofriam reações de alquilação (IPATIEFF e GROSSE, 1935). O alquilado apresentava a maior octanagem entre os compostos conhecidos para a produção de gasolina e suas demais propriedades eram excelentes para o uso na gasolina de aviação (HIMES e MEHLBERG, 2008).

A primeira unidade comercial de alquilação construída entrou em operação no ano de 1938. O processo de alquilação tomou força com a Segunda Grande Guerra, onde diversas unidades foram construídas para fornecer ao exército um combustível que permitisse um melhor rendimento dos aviões (ALBRIGHT, 2009). Desde então dois processos distintos são largamente utilizados para a produção do alquilado: a rota via ácido sulfúrico $\left(\mathrm{H}_{2} \mathrm{SO}_{4}\right)$ e a via ácido fluorídrico $(\mathrm{HF})$. Aproximadamente $51 \%$ 
da produção de alquilado são obtidas via $\mathrm{HF}$, enquanto que $41 \%$ são creditados à via $\mathrm{H}_{2} \mathrm{SO}_{4}$. Os $10 \%$ restantes usam outros processos (Hydrocarbon Publishing, 2008).

A seleção de qual tecnologia utilizar é dependente de um grande número de fatores, como as necessidades da refinaria, viabilidade econômica dos processos (investimento e custos operacionais), composição de carga e qualidade dos produtos (DE KLERK e VAAL, 2008). Na literatura são facilmente encontradas comparações entre os processos, seguem abaixo alguns pontos importantes a serem considerados.

O processo via HF utiliza temperatura da ordem de 30 a $40 \stackrel{\circ}{\circ}$, enquanto 0 processo via $\mathrm{H}_{2} \mathrm{SO}_{4}$ utiliza valores da ordem de 5 a $10 \stackrel{\circ}{\circ}$. Essa diferença faz com que o custo para remoção de calor no primeiro caso seja significantemente menor, pois pode-se aplicar água como fluido de resfriamento. No segundo caso é necessário o uso de um ciclo de refrigeração (ALBRIGHT, 2009).

A cinética da reação no processo com $\mathrm{HF}$ é muito mais rápida que no processo com $\mathrm{H}_{2} \mathrm{SO}_{4}$. Com isso os reatores que utilizam a primeira tecnologia têm tempo de residência da ordem de 10 segundos, enquanto que o outro processo exige tempos da ordem de 20 a 30 minutos. Isso faz com que o tamanho e o custo do reator da alquilação por HF sejam muito menores (ALBRIGHT, 2009).

O consumo de catalisador na alquilação por HF é da ordem de $1 \mathrm{~kg}$ de HF por tonelada de alquilado, enquanto na alquilação por $\mathrm{H}_{2} \mathrm{SO}_{4}$ é da ordem de $100 \mathrm{~kg}$ de ácido por tonelada de alquilado (BUI, 2007). Além disso, a recuperação do catalisador (ácido) no primeiro caso pode ser realizada na própria unidade com um simples processo de destilação, enquanto no segundo caso o ácido normalmente é recuperado por outra empresa, normalmente próxima a refinaria (ALBRIGHT, 2009).

Em compensação, a qualidade do produto obtido pela alquilação com ácido sulfúrico tem uma melhor octanagem devido ao menor teor de di-metil-hexanos formados na reação. Outra vantagem deste processo é o uso de um menor excesso 
de iso-butano, olefina para controlar a reação (7:1 contra 13:1), reduzindo custos com a separação do iC4 não reagido (ALBRIGHT, 2009).

Em 1987, um vazamento em uma unidade de alquilação (HF) de uma refinaria no Texas fez com que aproximadamente 4000 pessoas fossem evacuadas da região ao redor da refinaria (http://www2.fluoridealert.org/Pollution/OilRefineries/Hydrofluoric-Acid-Leak-in-Texas-Leaves-a-Residue-of-Questions, acessado em 24/10/2010). Ambos os processos utilizam ácidos altamente corrosivos e tóxicos e tem a necessidade de manter um grande inventário de ácido que, ao longo dos anos se tornou uma preocupação com a segurança do processo e da região no entorno da refinaria (HOMMELTOFT, 2001). Essa preocupação vem movendo a busca por novos catalisadores para o processo de alquilação.

Processos de alquilação que utilizam catalisadores sólidos têm sido apontados por muitos como a tecnologia que irá substituir o processo atual. Esses catalisadores, de maneira geral, devem apresentar elevada área superficial e poros de tamanhos elevados. Há também diversos estudos no tipo de leito a ser utilizado, sendo os mais comuns: leito fixo, leito fluidizado e leito móvel. Apesar de existirem alguns processos industriais estabelecidos (UOP e Exelus), todos eles enfrentam problemas com a rápida desativação do catalisador (aproximadamente 12 horas para o processo da Exelus), sendo sua regeneração bastante difícil (ALBRIGHT, 2009).

\subsection{Alquilação com Ácido Fluorídrico}

O processo de alquilação consiste basicamente na reação do iC4 com butenos para formar o tri-metil-pentano (TMP), na presença de um catalisador ácido forte, no caso o ácido fluorídrico (HF), conforme Reação 4.1. Quando a olefina utilizada é o propeno, o processo ocorre via Reação 4.2 Essa reação ocorre na fase ácida e é extremamente exotérmica. 
$i C_{4} H_{10}+C_{4} H_{8} \underset{H F}{\longrightarrow} i C_{8} H_{18}$

Reação 4.1

$\mathrm{C}_{3} \mathrm{H}_{6}+2 \quad i \mathrm{C}_{4} \mathrm{H}_{10} \underset{\mathrm{HF}}{\longrightarrow} \mathrm{C}_{3} \mathrm{H}_{8}+i \mathrm{C}_{8} \mathrm{H}_{18}$

Reação 4.2

Uma unidade industrial de alquilação que utiliza o HF como catalisador, como mostrado na Figura 4.2, pode ser representada em quatro processos principais: preparo de carga, seção de reação, fracionamento e tratamento. Cada uma dessas etapas será detalhada a seguir.

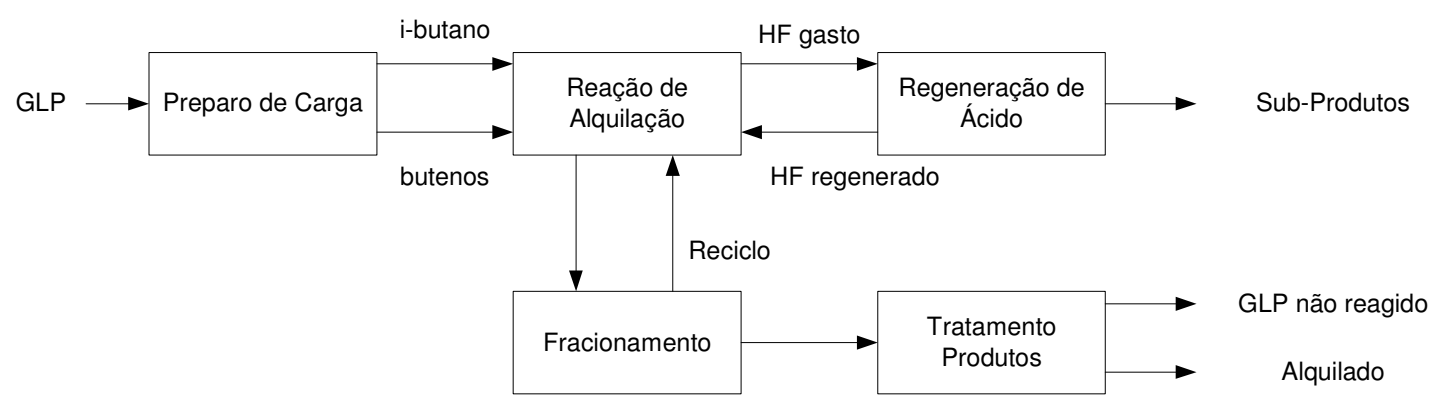

Figura 4.2: Diagrama de blocos de uma unidade de alquilação por HF.

A carga da unidade é composta de uma mistura de butanos (n-butano e ibutano), olefinas leves (propeno, buteno-1, iso-buteno, cis-buteno-2; trans-buteno-2 e butadieno), água e compostos sulfurados (gás sulfídrico e mercaptanas). 0 enxofre e o butadieno são contaminantes para o processo e, se chegarem ao reator de alquilação, podem trazer grandes prejuízos à unidade. A seção de preparo de carga, apresentada na Figura 4.3, tem dois objetivos principais: reduzir a concentração dos contaminantes a níveis aceitáveis e adequar a composição estequiométrica exigida pelo processo.

A primeira etapa do preparo de carga consiste na remoção dos compostos sulfurados, onde os butanos entram em contato com uma solução de soda cáustica (com concentração entre 10\% e 20\%), de maneira a estabelecer um teor máximo de enxofre na carga da alquilação em 20 ppm (wt.). 

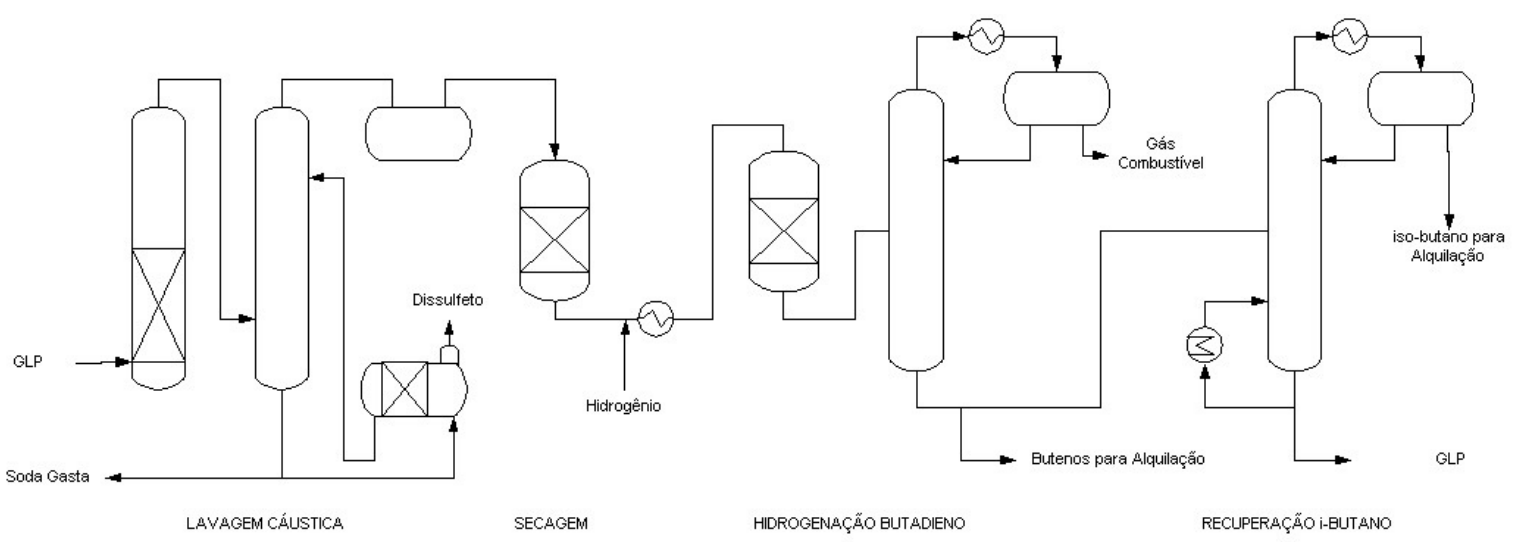

Figura 4.3: Fluxograma simplificado da seção de preparo de carga.

Em seguida a carga é permeada em um leito de alumina com elevada área superficial (peneira molecular) para a remoção de água solúvel que ataca o leito da unidade subseqüente. A corrente já isenta de compostos sulfurados e água é aquecida até aproximadamente $70^{\circ} \mathrm{C}$ e alimentada a um reator, juntamente com hidrogênio em uma relação molar de 5 partes de hidrogênio para 1 de butadieno, onde um catalisador a base de paládio irá promover a hidrogenação seletiva do 1,3butadieno, enquadrando esse em aproximadamente 200 ppm (vol.).

A última etapa do processo de preparo de carga consiste no fracionamento da carga, por destilação, em duas correntes distintas: uma rica em iC4 e outra concentrada em butenos. Essa etapa visa adequar a relação volumétrica entre o iC4 e olefinas que será alimentada ao reator, de maneira a minimizar reações indesejadas no riser, e garantir a qualidade do produto final.

As correntes obtidas na seção de preparo de carga, juntamente com o iC4 proveniente do reciclo são misturadas e alimentadas ao reator com uma relação entre o iC4 e butenos entre 9:1 e 15:1. O reator é do tipo tubular, com fluxo ascendente (reator tipo riser), em sua base a carga é dispersa no ácido fluorídrico circulante e, ao longo do reator os butenos reagem com o iC4 para formar o alquilado e demais subprodutos da reação. Esses subprodutos são hidrocarbonetos de elevados pesos moleculares que ficam solubilizados no $\mathrm{HF}$, por isso são conhecidos como óleo solúvel em ácido (ASO). Há um acréscimo de temperatura ao longo do riser uma vez que as reações de alquilação são bastante exotérmicas. A 
diferença de temperatura entre base e topo do reator fica na ordem de $5^{\circ} \mathrm{C}$. O calor gerado pela reação é removido através do resfriamento do ácido circulante.

O efluente do reator é composto por inertes (propano e butano), iC4 não reagido, alquilado, ASO e HF. Este é enviado para um vaso de decantação, onde por diferença de densidade os hidrocarbonetos são separados do HF e do ASO. Os hidrocarbonetos são enviados para a seção de fracionamento, enquanto parte do HF é enviada para a seção de regeneração de ácido e outra parte é resfriada e circulada para o riser. A Figura 4.4 apresenta de maneira simplificada o fluxograma da seção de reação.

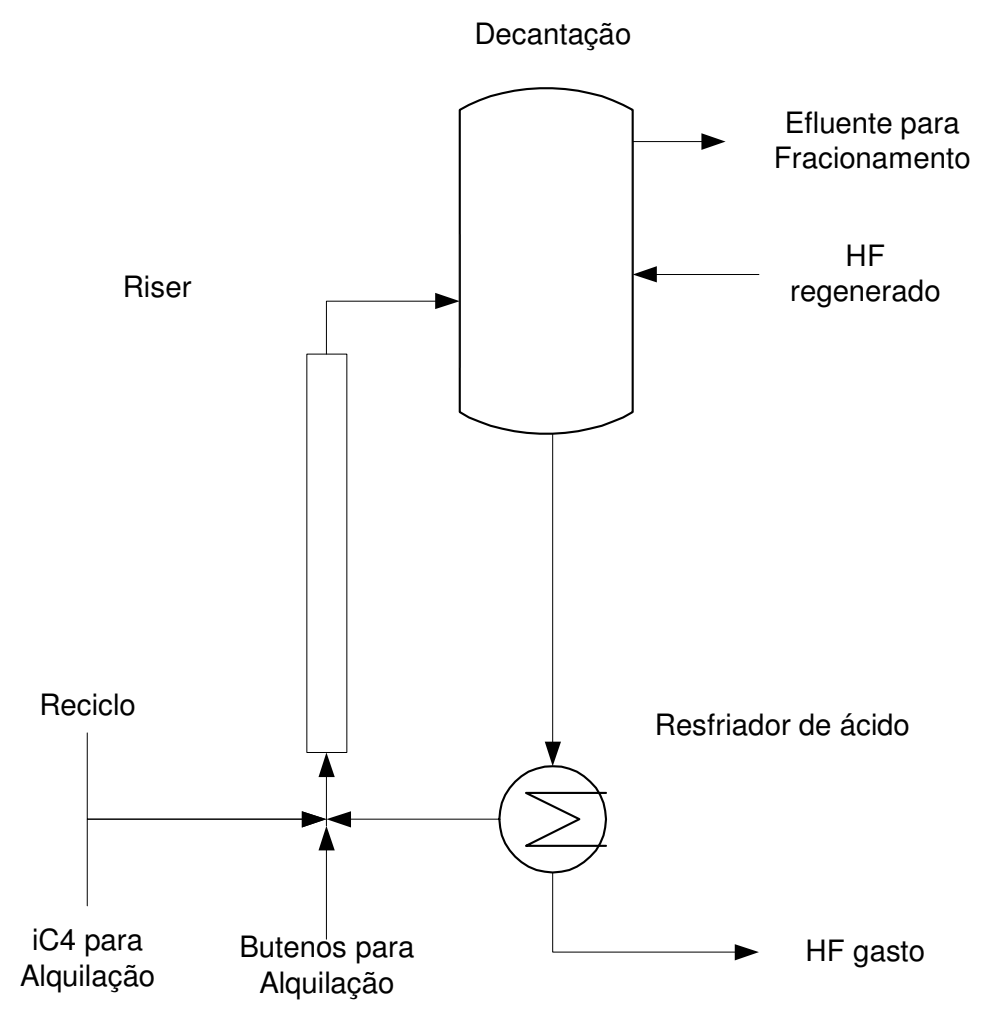

Figura 4.4: Fluxograma simplificado da seção de reação.

O ácido circulante deve ter sua pureza mantida entre $85 \%$ e $90 \%$, com um percentual entre $1 \%$ e $2 \%$ de água para otimizar a formação de tri-metil-pentanos (TMP). Para manter essa composição, uma pequena fração do inventário de ácido circulante é enviada para uma planta de regeneração de ácido (Figura 4.5), que tem como função separar o ASO e a água do HF por diferença de ponto de ebulição. Essa fração varia entre $0,1 \%$ e $1 \%$ (wt.) da vazão de ácido circulante, dependendo 
das condições operacionais da unidade. Nessa planta o HF é vaporizado e enviado para uma coluna de destilação, onde o $\mathrm{HF}$ sai pelo topo e é retornado para o decantador, enquanto o ASO, juntamente com a água, é retirado pelo fundo e enviado para descarte apropriado. Na seção inferior da torre de regeneração há uma alimentação de iC4, cuja função é retificar o produto de fundo, de maneira a minimizar a perda de ácido pelo fundo da torre. O HF forma um azeótropo com a água, com aproximadamente $35 \%$ de ácido, portanto essa é uma grande fonte de perda de ácido da unidade (WESTON et al, 2008).

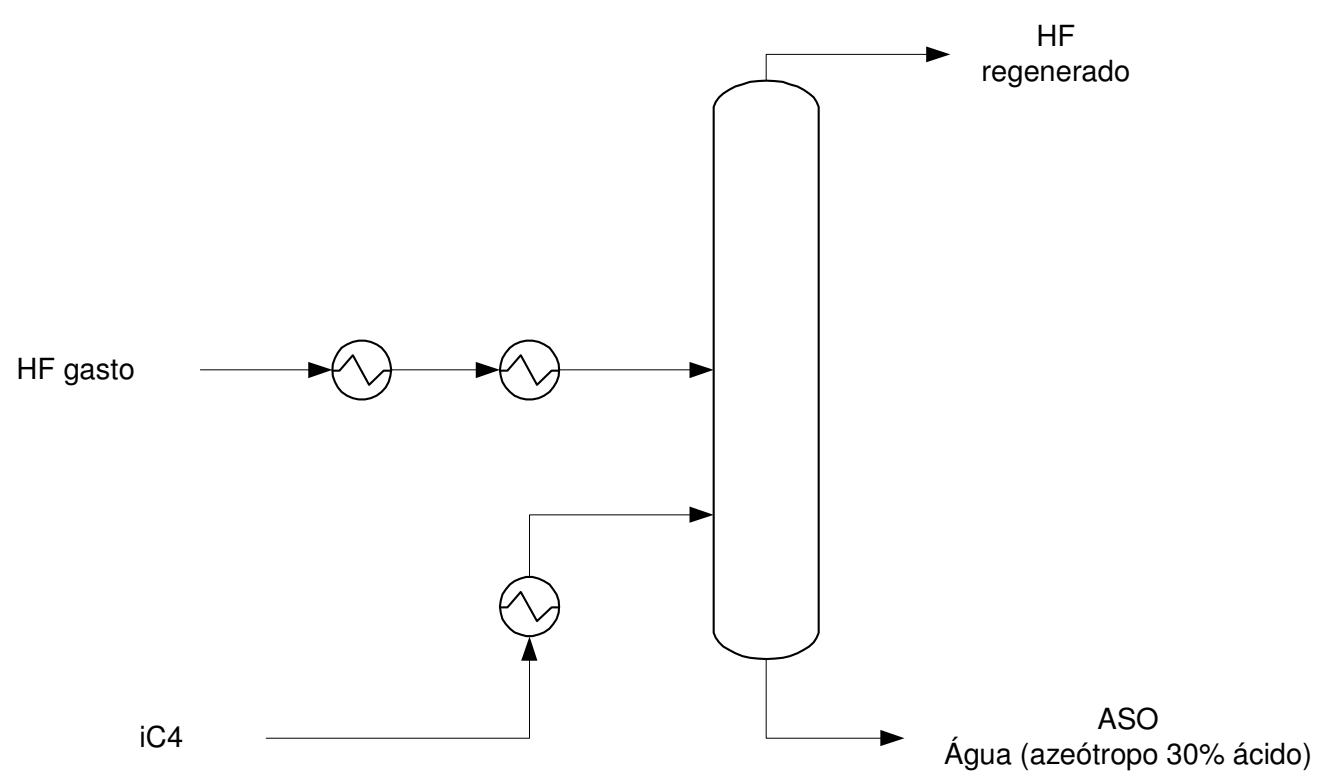

Figura 4.5: Fluxograma simplificado da seção de recuperação de ácido.

Os hidrocarbonetos provenientes do decantador ácido são enviados para a seção de fracionamento, composta por um conjunto de torres de destilação com objetivo de fracionar essa corrente em HF (que foi arrastado do decantador), propano, iC4 (que foi alimentado em excesso ao riser), n-butano e alquilado. No topo da primeira torre é obtida uma corrente que contém HF, propano, iC4 e um composto conhecido como fluoreto orgânico (intermediário da reação de alquilação formado no riser), que é uma grande fonte de perda de ácido da unidade. Com o objetivo de reduzir o consumo de ácido por conta de perdas de fluoreto orgânico, há um sistema chamado de recontactor, onde os fluoretos orgânicos, na presença de 
ácido se decompõem e reagem, segundo a Reação 4.3, para formar HF e alquilado. A Figura 4.6 apresenta um fluxograma simplificado da seção de fracionamento.

$$
\mathrm{C}_{4} \mathrm{H}_{9} \mathrm{~F}+i \mathrm{C}_{4} \mathrm{H}_{10} \longrightarrow \mathrm{TMP}+\mathrm{HF}
$$

Reação 4.3

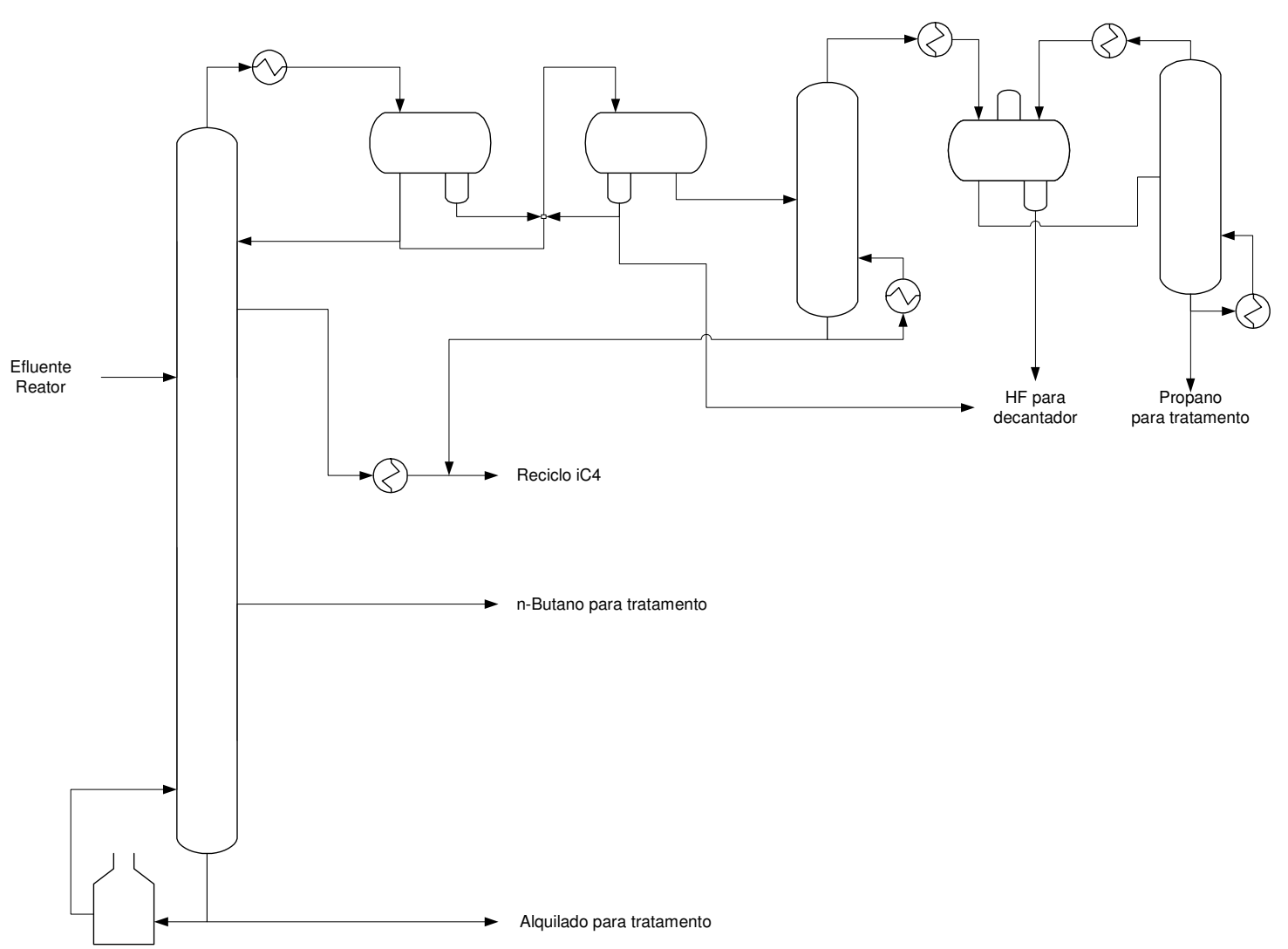

Figura 4.6: Fluxograma simplificado da seção de fracionamento.

O propano, n-butano e alquilado são enviados para a seção de tratamento, enquanto o HF retorna para o decantador e o iC4 retorna para a base do riser na forma de reciclo. Os tratamentos do propano e do butano são bastante semelhantes. Estas correntes são aquecidas acima de $175^{\circ} \mathrm{C}$ para que os fluoretos orgânicos se decomponham em uma olefina e uma molécula de HF, conforme Reação 4.4. Em seguida a corrente passa por um leito de alumina, onde esta irá reagir com o HF (Reação 4.5), e por um leito de hidróxido de potássio que irá transformar HF não reagido no leito anterior em fluoreto de potássio (FIORE e MORGADO, 2011). A Figura 4.7 apresenta de maneira resumida este tratamento. Já o alquilado é tratado 
através de uma solução aquosa de soda cáustica, onde o HF presente na corrente irá ser transformado em fluoreto de sódio, conforme a Figura 4.8.

$$
\mathrm{C}_{4} \mathrm{H}_{9} \mathrm{~F} \longrightarrow \mathrm{C}_{4} \mathrm{H}_{8}+\mathrm{HF}
$$

$$
\mathrm{Al}_{2} \mathrm{O}_{3}+6 \mathrm{HF} \longrightarrow 2 \mathrm{AlF}_{3}+3 \mathrm{H}_{2} \mathrm{O}
$$

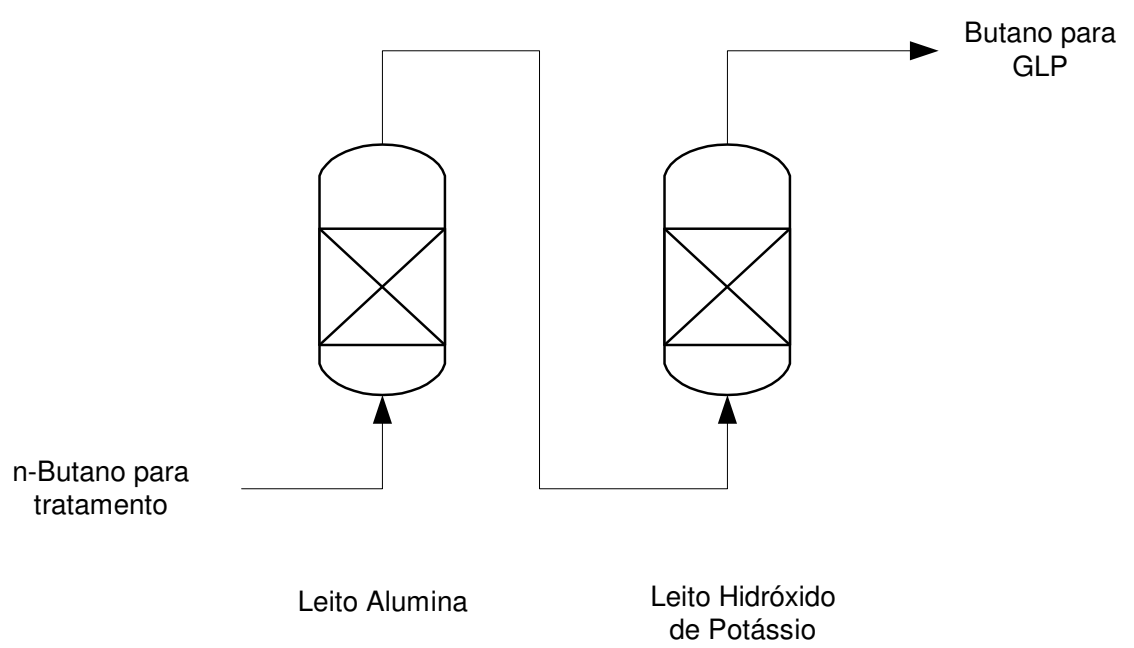

Figura 4.7: Fluxograma simplificado da seção de tratamento de propano e n-butano.

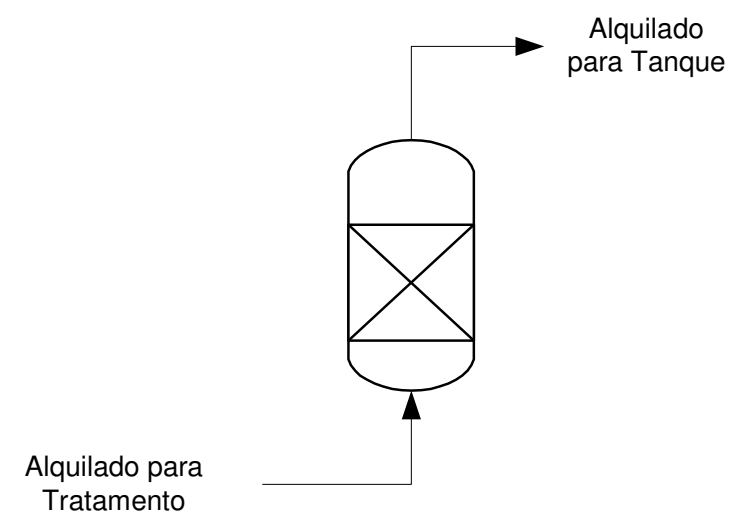

Leito Hidróxido de Sódio

Figura 4.8: Fluxograma simplificado da seção de tratamento de alquilado. 


\subsubsection{Reator por gravidade}

Existem diferentes tipos de processos comerciais para a produção de alquilado pela rota ácido fluorídrico. Estes diferem basicamente na concepção do reator e na maneira com que o ácido flui entre as diferentes regiões do sistema de reação. A Figura 4.9 apresenta o modelo concebido pela Conoco Phillips (CoP), que se utiliza da gravidade para estabelecer a circulação de ácido.

A circulação do ácido é estabelecida pelo fato da mistura entre hidrocarbonetos e ácido apresentarem uma massa específica inferior aquela apresentada pelo presente no decantador. A vazão de circulação pode ser determinada com base no balanço de massa e energia no sistema reacional, enquanto a altura mínima de ácido exigida para que aja circulação é obtida por um balanço de pressão entre a entrada do trocador de calor e a base do riser (FIORE et al, 2010).

O sistema de reação apresentado acima é composto de um riser, um decantador e resfriador de ácido. Os hidrocarbonetos são alimentados, juntamente com o HF oriundo do resfriador, ao sistema pela base do riser, aonde as reações de alquilação irão se desenvolver. O efluente deste é enviado para o decantador, onde por diferença de massa específica e solubilidade, o hidrocarboneto (sobrenadante) é separado dos subprodutos da reação e do ácido (decantado). Os hidrocarbonetos são direcionados para a seção de separação, enquanto o ácido (juntamente com os subprodutos), por gravidade, é enviado a um trocador de calor para remover o calor gerado na reação, e retorna para o riser. 


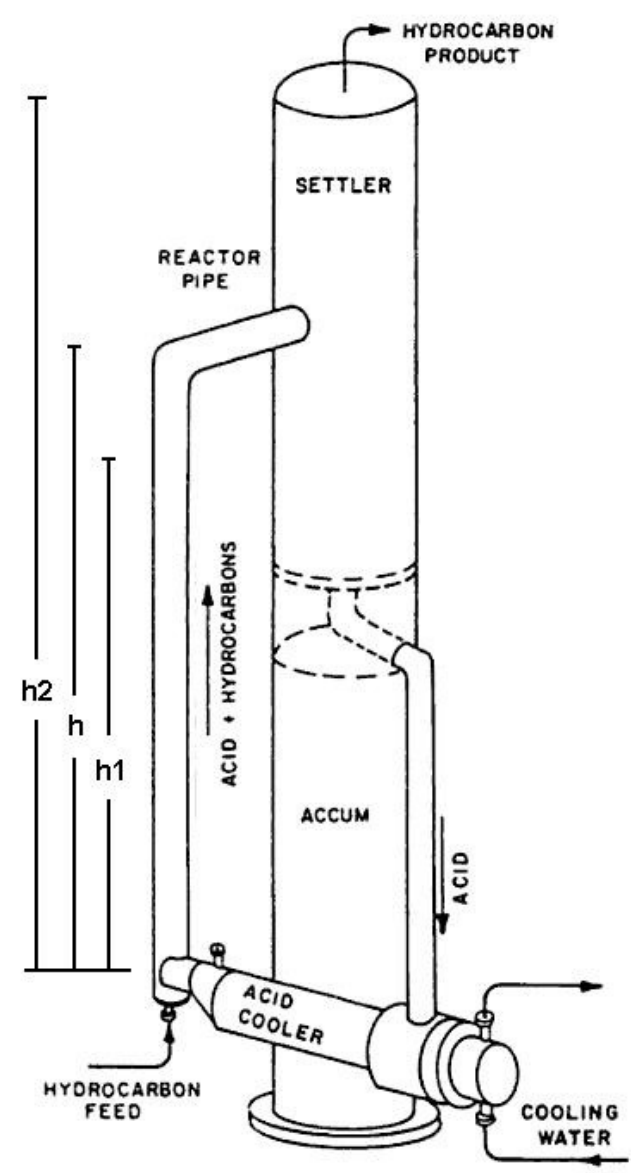

Figura 4.9: Reator de alquilação com circulação de ácido por gravidade, modelo Conoco Phillips (GARY e HANDWERK, 2002)

As reações de alquilação que ocorrem via mecanismo HF ocorrem em sua maioria na fase ácida, como mostrado na Figura 4.10, portanto, na base do riser há um dispersor de hidrocarbonetos cujo intuito é formar uma boa emulsão deste no ácido, que garante uma melhor qualidade do produto final e minimiza as reações de formação de subprodutos (KRAMER, 1977). O tempo de residência no riser é da ordem de 10 segundos, o que determina, juntamente com as dimensões do decantador, suas dimensões. 


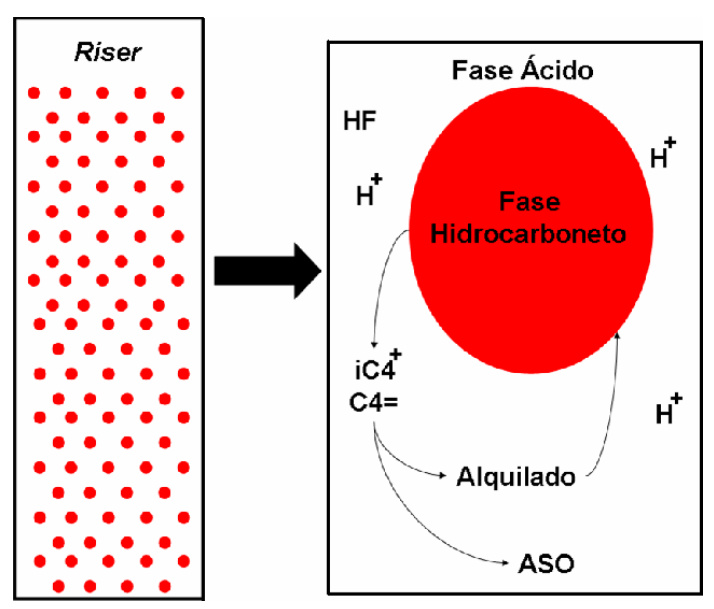

Figura 4.10: Esquema reações de alquilação.

Ao deixar o riser, a mistura de hidrocarbonetos e o ácido são encaminhados para um decantador, onde ocorre a separação entre as fases uma vez que o hidrocarboneto tem massa específica aproximadamente 30\% inferior à do ácido. Para que essa separação ocorra de maneira adequada, sem que ocorra arraste de ácido pelo hidrocarboneto, a velocidade de ascensão do hidrocarboneto não pode ser superior a velocidade de decantação do ácido. Essa variável define o diâmetro do decantador. Já a altura deste equipamento é definida pelo tempo de residência necessário para que ocorra a separação e pela altura de ácido necessária para haver circulação.

A separação dos subprodutos da reação, isto é fluoretos orgânicos (hidrocarboneto com um átomo de flúor em sua estrutura) e ASO (hidrocarboneto de elevado peso molecular), dos demais hidrocarbonetos também é feita no decantador. Estes são solúveis no ácido, portanto permanecem na fase ácida. A Inequação 4.1 apresenta a ordem de solubilidade dos produtos no ácido.

$$
\text { Água }>\text { Fluoreto Orgânico }>\text { ASO }>\text { Butenos }>\text { iButano }>\text { Alquilado } \quad \text { Inequação } 4.1
$$

Como as reações de alquilação ocorrem na fase ácida, a presença desses subprodutos de reação no ácido aumenta sua viscosidade o que contribui para reduzir a quantidade de iC4 solubilizado neste e, portanto, prejudicando a qualidade dos produtos finais e aumentando a formação de subprodutos. Para manter a 
concentração de ácido em valores adequados ao processo, parte do ácido é enviada a uma torre de regeneração, onde o ASO é removido.

As reações de alquilação são altamente exotérmicas, resultando em diferenças de temperatura entre base e topo do riser na faixa de 5 a $8^{\circ} \mathrm{C}$. Para remover este calor, o ácido já decantado é enviado para um trocador de calor. No caso de sistemas reacionais que se utilizam da gravidade para promover a circulação de ácido utilizam trocadores do tipo casco / tubo, enquanto outros sistemas adotam soluções diferentes. Como as reações de alquilação por HF ocorrem em temperaturas acima de $35^{\circ} \mathrm{C}$, água pode ser utilizada como fluido de resfriamento.

\subsubsection{Mecanismo da Reação de Alquilação}

Após a descoberta das reações de alquilação por IPATIEFF e GROSSE, diversos estudos foram realizados no sentido de elucidar a seqüência de eventos que leva à formação do alquilado. Apesar da aparente simplicidade da reação (butenos reagindo com $\mathrm{iC4}$ ) e do pequeno número de reagentes presentes na carga da unidade, o contato dessa carga com um catalisador ácido (como $\mathrm{HF} \mathrm{e} \mathrm{H}_{2} \mathrm{SO}_{4}$ ) resulta em várias reações seqüenciais e paralelas que acabam por gerar um produto com uma estrutura bastante complexa (CUPIT et al, 1961). O mecanismo de reação depende do tipo de ácido utilizado como catalisador (ALBRIGHT e LI, 1970), neste trabalho será apresentado o mecanismo proposto para a alquilação utilizando o HF como catalisador.

Inicialmente foi proposto por IPATIEFF e GROSSE que a reação de alquilação se dá pela simples adição do grupo alquil e de um hidrogênio à dupla reação, porém este mecanismo não explica o perfil de produtos obtido (IPATIEFF, apud SCHMERLING, 1945). Mais tarde comprovou-se que o ácido fluorídrico (e outros ácidos) tem a capacidade de reagir com moléculas de hidrocarbonetos 
olefínicos, com tamanhos de cadeia variados, formando o fluoreto orgânico (GROSSE e LINN, 1938).

O primeiro mecanismo de reação capaz de explicar a composição do alquilado gerado considera que a reação de alquilação é iniciada pela adição de um próton (cátion hidrogênio), oriundo do ácido (Reação 4.6), à dupla ligação da olefina, formando um carbocátion, seguido de reações em cadeia Esse mecanismo está baseada no fato que toda reação de hidrocarbonetos catalisada por ácido pode ser explicada por uma ou mais etapas apresentadas abaixo (SCHMERLING, 1953):

- Formação do carbocátion pela adição de um próton oriundo do ácido;

- Adição do carbocátion a uma molécula insaturada (ligação PI), formando um carbocátion de maior peso molecular;

- Decomposição do carbocátion em outro de menor tamanho ou em uma molécula insaturada e um próton;

- Isomerização do carbocátion pela migração de hidrogênio;

- Neutralização da carga iônica pela extração de um próton do carbocátion ou pela adição de um ânion oriundo de outra molécula.

$$
H F \stackrel{\mathrm{H}_{2} \mathrm{O}}{\longrightarrow} H^{+}+F^{-}
$$

Reação 4.6

Apesar de conseguir representar de maneira adequada a maior parte dos produtos da alquilação, este mecanismo não identifica como ocorrem as reações de decomposição do íon carbônion, bem como não explica as reações de isomerização ocorridas no reator e não prevê a possibilidade de ocorrência de reações de polimerização.

Estudos com carbono 14 mostraram que o carbocátion com 12 átomos de carbono sofre reações de craqueamento, podendo formar qualquer uma das três opções: um carbocátion com 6 carbonos mais uma olefina com 6 átomos de carbono; um carbocátion com 5 átomos de carbono e uma olefina com 7; ou uma olefina com 5 átomos de carbono e um carbocátion com 7 átomos (HOFMANN e SCHIRIESHEM, 1962). 
Mais tarde um estudo mostrou que nas condições de operação de um reator de alquilação as reações de isomerização têm um papel bastante importante na composição do produto final. Estas podem inclusive exercer um papel mais importante que a composição de alimentação do reator (PETERSON et al, 1965; ZIMMERMAN et al, 1962).

As Reações 4.1 e 4.2 apresentadas acima são simplificações de todas as reações que ocorrem no riser. O modelo consolidado para o mecanismo de reação utilizando o HF como catalisador considera que ocorre um processo catiônico, com propagação em cadeia (similar as reações de polimerização), isomerização, dimerização de olefinas e craqueamento de carbocátions $A$ seqüência de eventos proposta pode ser simplificada pelas Reações 4.6 a 4.20 (HUTSON e HAYS, 1977).

Iniciação: A reação de alquilação inicia com o ataque do $\mathrm{H}^{+}$à dupla ligação das olefinas presentes na carga da unidade (Reações 4.7 e 4.9), formando o carbocátion responsável pelo início da reação de polimerização. Quando a olefina atacada é o iso-buteno ou o cis-buteno-2 ou trans-buteno-2, o carbocátion formado é o iC4+. Quando a olefina atacada é o propeno ou o buteno-1, um segundo passo na iniciação é necessário. O iC4 transfere um hidrogênio para o carbocátion, gerando propano, n-butano e iC4 ${ }^{+}$, conforme reações 4.8 e 4.10 .

$$
\begin{array}{lr}
C_{3} H_{6}+H^{+} \longrightarrow C_{3} H_{7}^{+} & \text {Reação } 4.7 \\
C_{3} H_{7}^{+}+i C_{4} H_{10} \longrightarrow C_{3} H_{8}+i C_{4} H_{9}^{+} & \text {Reação } 4.8 \\
C_{4} H_{8}+H^{+} \longrightarrow C_{4} H_{9}^{+} & \text {Reação } 4.9 \\
C_{4} H_{9}^{+}+i C_{4} H_{10} \longrightarrow C_{4} H_{10}+i C_{4} H_{9}^{+} & \text {Reação } 4.10
\end{array}
$$

Propagação: Nessa etapa, o $\mathrm{iC}^{+}$ataca a dupla ligação do propeno e butenos, formando um carbocátion de maior tamanho molecular (Reações $4.11 \mathrm{e}$ 4.12). Esse pode passar por reações de isomerização, polimerização ou extrair um hidrogênio do iC4, formando uma parafina e uma nova molécula de iC4 $4^{+}$(Reações 4.13 e 4.14 - reações de transferência de cadeia). 


$$
\begin{array}{ll}
i C_{4} H_{9}^{+}+C_{3} H_{6} \longrightarrow C_{7} H_{15}^{+} & \text {Reação } 4.11 \\
i C_{4} H_{9}^{+}+C_{4} H_{8} \longrightarrow i C_{8} H_{17}^{+} & \text {Reação } 4.12 \\
C_{7} H_{15}^{+}+i C_{4} H_{10} \longrightarrow i C_{4} H_{9}^{+}+C_{7} H_{16} & \text { Reação } 4.13 \\
i C_{8} H_{17}^{+}+i C_{4} H_{10} \longrightarrow i C_{4} H_{9}^{+}+i C_{8} H_{18} & \text { Reação } 4.14
\end{array}
$$

Terminação: Consiste na reação inversa da iniciação. Um íon iC4 ${ }^{+}$quebra formando uma olefina e um próton, conforme reação 4.15 .

$$
i C_{4} H_{9}^{+} \longrightarrow i C_{4} H_{8}+H^{+} \quad \text { Reação } 4.15
$$

Dimerização: Importante reação que ocorre no riser é a dimerização do buteno-1, buteno-2 e do i-buteno, gerando di-metil-hexanos, conforme reações 4.16 , 4.17 e 4.18.

$$
\begin{array}{ll}
2 \mathrm{C}_{4} \mathrm{H}_{8}-1+H^{+}+i \mathrm{C}_{4} H_{10} \longrightarrow 3,4-\mathrm{DMH}+i \mathrm{C}_{4} H_{9}^{+} & \text {Reação 4.16 } \\
2 \mathrm{C}_{4} \mathrm{H}_{8}-2+H^{+}+i \mathrm{C}_{4} H_{10} \longrightarrow 3,4-\mathrm{DMH}+i \mathrm{C}_{4} H_{9}^{+} & \text {Reação 4.17 } \\
2 i \mathrm{C}_{4} \mathrm{H}_{8}+\mathrm{H}^{+}+i \mathrm{C}_{4} \mathrm{H}_{10} \longrightarrow 2,5-\mathrm{DMH}+i \mathrm{C}_{4} \mathrm{H}_{9}^{+} & \text {Reação 4.18 }
\end{array}
$$

Isomerização: As reações de isomerização dos carbocátions presentes no meio reacional respondem pela grande variedade de isômeros do di-metil-pentano (DMP), di-metil-hexano (DMH) e tri-metil-pentanos (TMP) presentes no alquilado.

As Reações 4.7 a 4.18 são responsáveis por 80 a $90 \%$ da composição do produto da unidade de alquilação, os restante é gerado por reações secundárias e outras indesejadas, apresentadas nas Reações 4.19 a 4.28 .

Excesso de Polimerização (ASO): Quando não há transferência de hidrogênio do i-butano para o carbocátion, este continua reagindo com olefinas, formando uma molécula de elevado peso molecular (Reação 4.19). Estas reações são quimicamente similares às reações de propagação porém no processo de alquilação são reações indesejáveis, e conhecidas no jargão da área, como reações de polimerização. 
$i C_{8} H_{17}^{+} \stackrel{C_{4} H_{8}}{\longrightarrow} C_{16} H_{33}^{+} \stackrel{C_{4} H_{8}}{\longrightarrow} C_{20} H_{41}^{+} \stackrel{C_{4} H_{8}}{\longrightarrow} C_{24} H_{49}^{+}$

Disproporcionamento: Reações responsáveis pelas pequenas concentrações de i-pentano, i-hexano e i-heptano encontradas no alquilado. Um exemplo desta está representado na Reação 4.20.

$i C_{4} H_{10}+2,2,4-T M P \longrightarrow 2-$ metilbutano $+2,2$ - dimetilpentano $\quad$ Reação 4.20

Craqueamento: Reação que também ocorre no riser, onde um carbocátion de cadeia longa é quebrado, formando duas moléculas de tamanho menor, uma olefina mais um carbocátion. Essa reação pode ocorrer de duas maneiras diferentes, como apresentado nas Reações 4.21 e 4.22

$$
\begin{aligned}
& C_{12} H_{25}^{+} \longrightarrow i C_{5} H_{11}^{+}+C_{7} H_{14} \\
& C_{12} H_{25}^{+} \longrightarrow i C_{7} H_{15}^{+}+i C_{5} H_{10}
\end{aligned}
$$$$
\text { Reação } 4.21
$$

Foi demonstrado que o propeno, i-buteno e o buteno-2, quando passam pelo processo de alquilação reagem de maneiras diferentes (sob o mesmo mecanismo), gerando isômeros diferentes, conforme as Reações 4.23 a 4.28. (CIAPETTA, 1945; CUPIT et al, 1961).

$$
\begin{aligned}
& \mathrm{C}_{3} \mathrm{H}_{7}^{+}+\mathrm{C}_{3} \mathrm{H}_{6} \longrightarrow \mathrm{C}_{6} \mathrm{H}_{13}^{+} \\
& \text {Reação } 4.23 \\
& \mathrm{C}_{3} \mathrm{H}_{7}^{+}+\mathrm{C}_{4} \mathrm{H}_{8} \longrightarrow \text { di-metil- } \text { pentano }^{+} \\
& \text {Reação } 4.24 \\
& \mathrm{C}_{4} \mathrm{H}_{9}^{+}+\mathrm{C}_{4} \mathrm{H}_{8}-1 \longrightarrow 2,4-\text { di-metil - hexano }{ }^{+} \\
& \text {Reação } 4.25 \\
& \mathrm{C}_{4} \mathrm{H}_{9}^{+}+\mathrm{iC}_{4} \mathrm{H}_{8} \longrightarrow 2,2,4-\text { tri-metil- } \text { pentano }^{+} \\
& \text {Reação } 4.26 \\
& \mathrm{C}_{4} \mathrm{H}_{9}^{+}+\text {cis }-\mathrm{C}_{4} \mathrm{H}_{8}-2 \longrightarrow 2,2,3-\text { tri-metil- } \text { pentano }^{+} \\
& \text {Reação } 4.27 \\
& \mathrm{C}_{4} \mathrm{H}_{9}^{+}+\text {trans }-\mathrm{C}_{4} \mathrm{H}_{8}-2 \longrightarrow 2,2,3-\text { tri-metil- } \text { pentano }^{+} \\
& \text {Reação } 4.28
\end{aligned}
$$




\subsubsection{Qualidade do Produto}

O alquilado é tipicamente uma mistura de hidrocarbonetos com tamanhos de cadeia entre 5 e 12 carbonos, onde predominam os isômeros do octano. O derivado de petróleo que apresenta essa faixa de hidrocarbonetos é a gasolina, conforme mostrado na Figura 4.11. Dessa maneira, a qualidade do alquilado produzido em uma unidade industrial é dada por sua PVR (pressão de vapor Reid), composição e faixa de destilação.

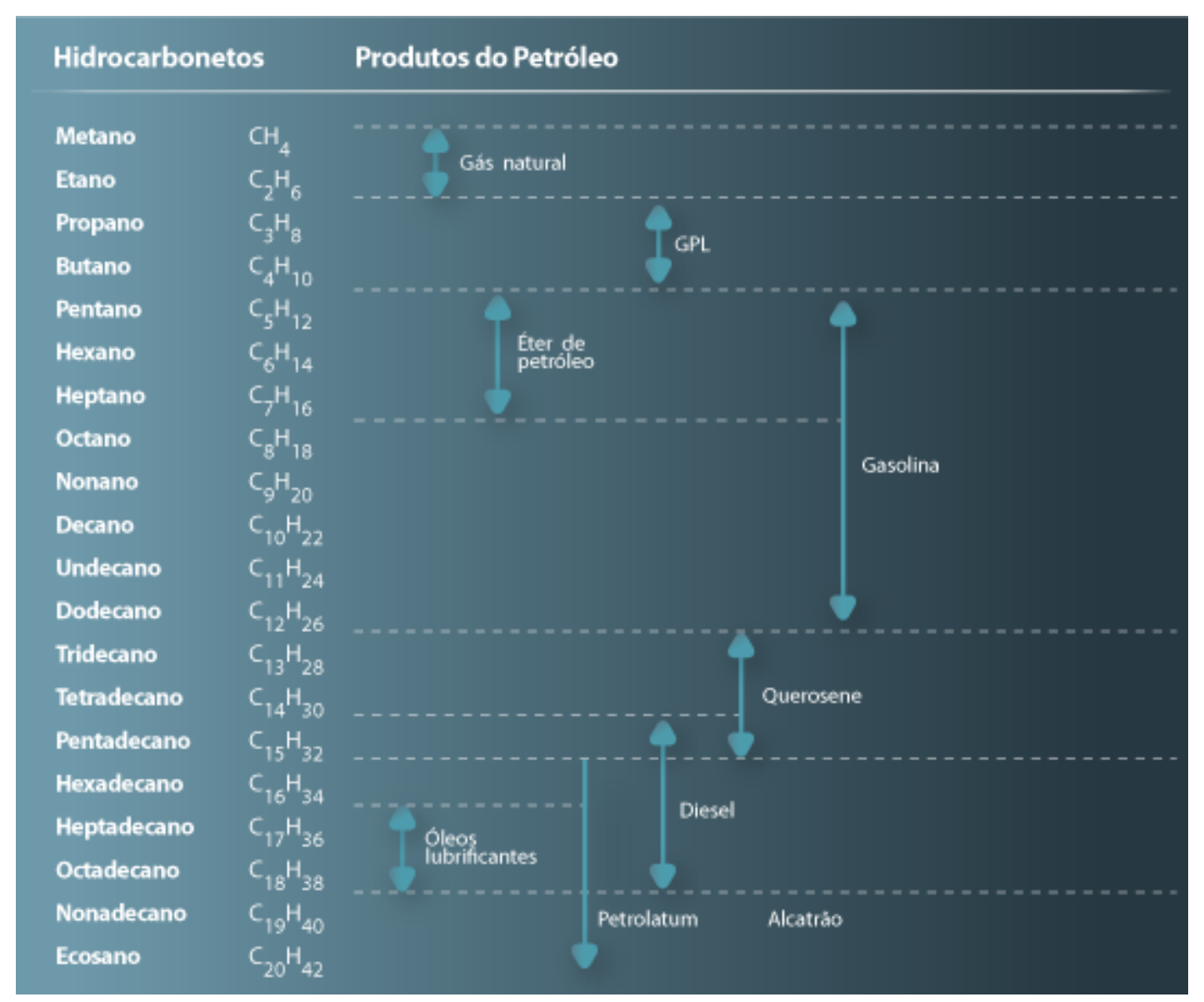

Figura 4.11: Distribuição dos hidrocarbonetos nos derivados do petróleo (http://labvirtual.eq.uc.pt acessado em 06/11/2010).

A primeira característica é facilmente especificada na seção de fracionamento através da remoção dos butanos por destilação. Já a composição e a faixa de destilação do alquilado são função da maneira como a reação ocorre no riser. 
Portanto um bom controle das variáveis operacionais é indispensável para obter o produto dentro da especificação desejada.

O produto de maior interesse industrial é o 2,2,4 tri-metil-pentanos (224 TMP) e seus isômeros devido à sua elevada octanagem. Outros como os isômeros do dimetil-hexano são indesejáveis devido à sua baixa octanagem. Hidrocarbonetos com mais de 12 carbonos são indesejados devido ao seu elevado ponto de ebulição para o uso em gasolinas especiais. A Tabela 4.2 apresenta os principais componentes do alquilado com suas propriedades.

Tabela 4.2: Propriedades dos principais componentes do alquilado.

\begin{tabular}{|c|c|c|c|}
\hline Componente & Abreviação & Ponto de Ebulição $\left({ }^{\circ} \mathrm{C}\right)$ & Octanagem (MON) \\
\hline i-Pentano & iC5 & 27,8 & 89,7 \\
\hline n-Pentano & nC5 & 36,1 & 63,2 \\
\hline 2,2 di metil butano & 2,2 DMB & 49,7 & 93,4 \\
\hline 2,3 di metil butano & 2,3 DMB & 58,0 & 84,2 \\
\hline 2 metil pentano & $2 \mathrm{MP}$ & 60,3 & 73,5 \\
\hline 3 metil pentano & $3 \mathrm{MP}$ & 63,3 & 73,3 \\
\hline n-hexano & nC6 & 67,9 & 26,0 \\
\hline 2,2 di metil pentano & 2,2 DMP & 79,3 & 95,6 \\
\hline 2,4 di metil pentano & 2,4 DMP & 80,5 & 83,8 \\
\hline $2,2,3$ tri metil butano & 2,2,3 TMB & 80,9 & 101,3 \\
\hline 3,3 di metil pentano & 3,3 DMP & 86,8 & 86,6 \\
\hline 2 metil hexano & $2 \mathrm{MH}$ & 90,0 & 46,4 \\
\hline 2,3 di metil pentano & 2,3 DMP & 89,8 & 88,5 \\
\hline 3 metil hexano & $3 \mathrm{MH}$ & 91,9 & 55,0 \\
\hline $2,2,4$ tri metil pentano & 2,2,4 TMP & 99,2 & 100,0 \\
\hline 2,5 di metil hexano & $2,5 \mathrm{DMH}$ & 109,1 & 55,7 \\
\hline 2,4 di metil hexano & 2,4 DMH & 109,4 & 69,9 \\
\hline $2,2,3$ tri metil pentano & 2,2,3 TMP & 109,8 & 99,9 \\
\hline $2,3,4$ tri metil pentano & 2,3,4 TMP & 113,5 & 95,9 \\
\hline $2,3,3$ tri metil pentano & 2,3,3 TMP & 114,8 & 99,4 \\
\hline 2,3 di metil hexano & 2,3 DMH & 115,6 & 78,9 \\
\hline 2 metil heptano & $2 \mathrm{MC7}$ & 117,7 & 23,8 \\
\hline 3,4 di metil hexano & $3,4 \mathrm{DMH}$ & 117,7 & 81,7 \\
\hline 3 metil heptano & $3 \mathrm{MC7}$ & 118,9 & 35,0 \\
\hline $2,2,5$ tri metil hexano & $2,2,5 \mathrm{TMH}$ & 124,1 & 88,0 \\
\hline
\end{tabular}




\subsubsection{Dados experimentais e variáveis operacionais}

As variáveis operacionais de uma unidade de alquilação têm como função controlar cada uma das etapas da reação, de maneira a permitir um bom controle da qualidade do produto obtido. As principais variáveis, bem como seu efeito, estão citadas a seguir.

Manter as variáveis operacionais dentro da faixa recomendada é importante para que não ocorra formação excessiva de polímero (ASO) e fluoretos orgânicos, que levam ao problema operacional conhecido como "fuga ácida". A "fuga ácida" se caracteriza pela formação acentuada de subprodutos da reação de alquilação (ASO) e pela perda do nível de ácido no decantador.

\subsubsection{Razão HF / Hidrocarboneto}

Uma vez que as reações de alquilação ocorrem na interface entre o $\mathrm{HF}$ e os hidrocarbonetos, a relação entre estes exerce um importante papel na qualidade do produto final. Uma baixa razão faz com que pouco iC4 seja solubilizado no ácido, dificultando a etapa de transferência de hidrogênio, e, portanto aumentando a formação de ASO.

Além disso, uma elevada vazão de ácido circulante faz com que o processo seja mais tolerante a contaminantes presentes na carga, uma vez que será necessária uma maior quantidade destes para alterar a pureza do HF.

Em reatores de alquilação cuja circulação do ácido é realizada por diferença de pressão (gravidade), o ácido fluorídrico tem como função resfriar o reator, uma vez que as reações de alquilação são bastante exotérmicas.

Por esses motivos a razão HF/HC deve ficar na ordem de 4:1. 


\subsubsection{Temperatura de Reação}

A composição do alquilado produzido é fortemente afetada pela temperatura de reação. Em geral, a octanagem do alquilado aumenta em um ponto quando a temperatura é reduzida em $10^{\circ} \mathrm{C}$. Isso ocorre devido ao aumento da concentração de TMP e redução de DMH no efluente do reator. Além disso, o aumento da temperatura leva ao aumento nas reações de craqueamento, evidenciado pelo aumento do iC5 no produto. A Figura 4.12 resume a influência da temperatura na qualidade do alquilado.
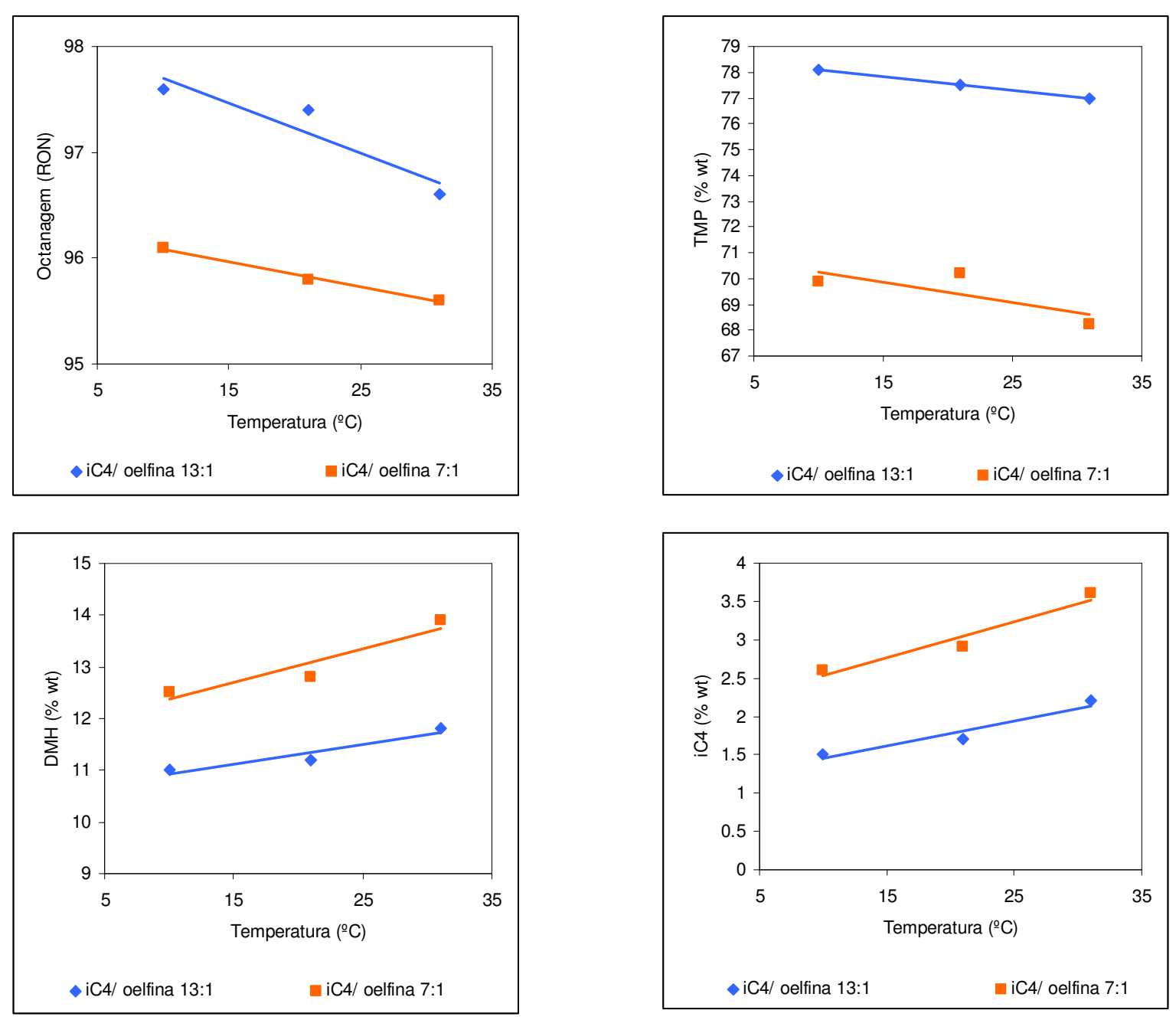

Figura 4.12: Influência da temperatura de reação na qualidade do alquilado (MAKOVEK e HASKELL, 1977). 
Em compensação, temperaturas muito baixas reduzem a solubilidade do iC4 no ácido e reduzem a velocidade de reação (Arrhenius). Unidades que operam com $\mathrm{HF}$ como catalisador operam normalmente com temperaturas entre $20^{\circ} \mathrm{C}$ e $40^{\circ} \mathrm{C}$.

\subsubsection{Concentração de HF}

A concentração do HF tem influência basicamente sobre as etapas de reação de iniciação (Reações 4.6 e 4.8). Portanto, a atividade do catalisador é dependente basicamente de dois fatores: sua capacidade de gerar carbocátions através da transferência de um próton para uma olefina (determinada pela acidez de HAMMETT) e pela solubilidade do iC4 no ácido. Juntos esses dois fatores determinam a concentração de carbocátions no meio reacional, assim como seu tempo de vida. As reações primárias (desejadas) são favorecidas por uma elevada solubilidade do iC4 no ácido e por uma baixa acidez de HAMMETT, ao passo que as reações de formação de DMH e polimerização ocorrem preferencialmente com baixa solubilidade do iC4 e elevada acidez. (CUPIT et al, 1961).

Uma maneira de reduzir a acidez de HAMMETT do HF é aumentar o teor de água no ácido, como mostrado na Figura 4.13. Porém ao fazer isso, a solubilidade do iC4 no HF cai, e a corrosividade do HF aumenta (CUPIT et al, 1961).

Do ponto de vista de qualidade do produto, a máxima concentração de TMP, e mínima de $\mathrm{DMH}$ e C9+ é obtida quando 1.5\% (wt.) de água está presente no ácido. Porém quanto maior a quantidade de água, maior será a influência das reações de craqueamento no riser, gerando uma maior quantidade de C7. A Tabela 4.3 e a Figura 4.14 apresentam esses valores (HUTSON e HAYS, 1977). 


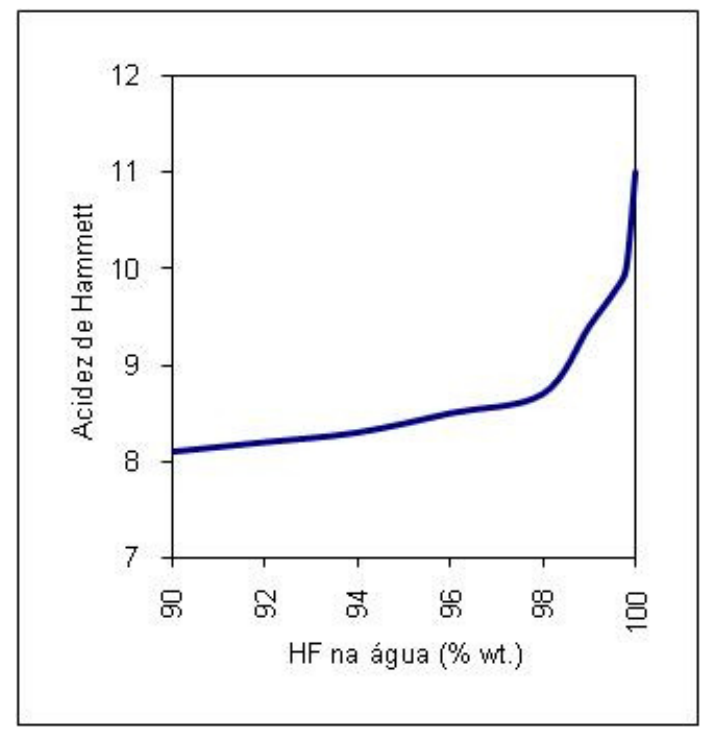

Figura 4.13: Acidez de HAMMETT para o HF (CUPIT et al, 1961).

A octanagem do alquilado, apresentada na Figura 4.14, foi calculada utilizando os dados de composição do alquilado em diferentes concentrações de água e considerando que essa propriedade é aditiva em volume. Novamente é possível comprovar que a qualidade ótima do produto é alcançada quando $1.5 \%$ de água estão presentes no meio reacional.

Tabela 4.3: Influência do teor de água no HF na composição do alquilado (\% wt).

\begin{tabular}{ccccccccc}
\hline $\begin{array}{c}\text { Teor de } \\
\text { água no } \\
\text { HF (\%wt) }\end{array}$ & 0,25 & 0,43 & 0,6 & 0,9 & 1,4 & 2 & 2,8 & 4,4 \\
Produto & & & & & & & & \\
\hline C5 & 10,39 & 5,57 & 4,57 & 3,62 & 2,89 & 3,51 & 3,72 & 4,28 \\
C6 & 4,94 & 3,83 & 2,89 & 2,63 & 2,35 & 2,54 & 2,88 & 3,44 \\
C7 & 17,76 & 19,43 & 19,16 & 24,29 & 23,29 & 26,35 & 25,48 & 28,40 \\
TMP & 37,58 & 47,49 & 50,88 & 52,57 & 55,79 & 53,59 & 54,24 & 50,24 \\
DMH & 10,69 & 10,83 & 8,66 & 7,68 & 6,93 & 6,39 & 7,13 & 6,25 \\
C9+ & 18,16 & 12,87 & 12,79 & 9,07 & 8,63 & 7,50 & 6,49 & 7,32 \\
\hline
\end{tabular}


Uma concentração muito baixa do HF afeta a reação de transferência de hidrogênio para o carbocátion com 8 carbonos, devido à baixa solubilidade do iC4 no ácido, e, portanto esse irá continuar a reagir com olefinas presentes no meio reacional, levando à formação de polímero (ASO).
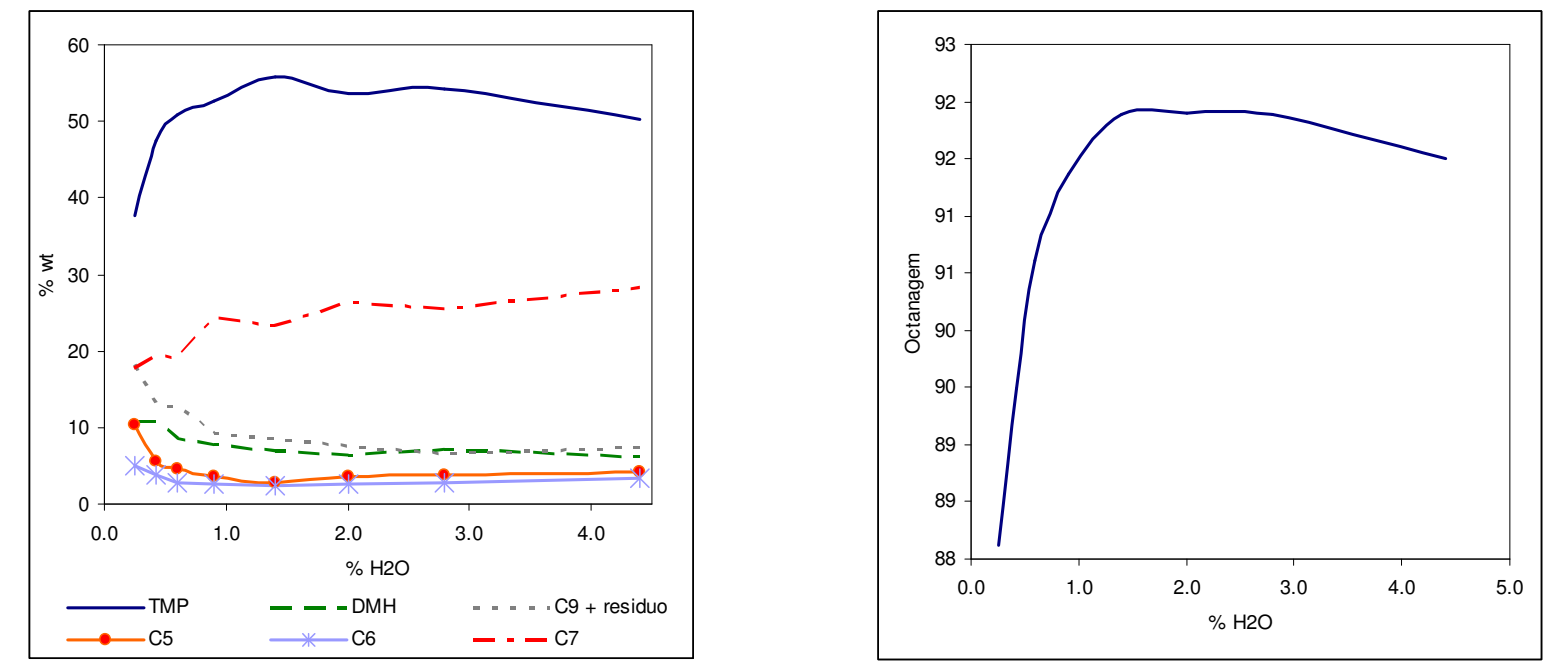

Figura 4.14: Influência da quantidade de água no ácido na composição (HUTSON e HAYS, 1977) e octanagem do alquilado.

\subsubsection{Qualidade da Carga}

Em uma unidade de alquilação convencional seis são os tipos de olefinas presentes no reator: propeno, i-buteno, buteno-1, c-buteno-2, t-buteno-2, 1,3 butadieno. Comparando as relações estequiométricas, apresentadas na Tabela 4.4, nota-se que o propeno consome uma maior quantidade de iC4, devido à reação de transferência de hidrogênio do iC4 para o carbocátion com 3 carbonos (Reação 4.8). Já entre os butenos, o buteno-1 consome uma menor quantidade de iC4, porém gera um menor volume de alquilado. O buteno-2 e o i-buteno consomem a mesma quantidade de $\mathrm{iC4}$, porém o primeiro tem um maior rendimento volumétrico de alquilado. 
Tabela 4.4: Consumo de olefinas e rendimento de alquilado para diferentes olefinas.

\begin{tabular}{lcccc}
\hline & Buteno-1 & i-buteno & Buteno-2 & Propeno \\
\hline $\mathrm{m} 3$ iC4 / m3 olefina & 1,10 & 1,15 & 1,15 & 1,33 \\
m3 alquilado / m3 olefina & 1,73 & 1,78 & 1,80 & ND \\
\hline
\end{tabular}

Além dos diferentes rendimentos e consumo de iC4, o mecanismo da reação de alquilação mostra que diferentes tipos de olefina reagem formando produtos diferentes (CUPIT et al, 1961), portanto, a composição da carga alimentada ao riser tem grande influência sobre a qualidade do alquilado produzido. $O$ butadieno quando presente no meio reacional, por apresentar duas insaturações, favorece as reações de polimerização e, portanto, a formação de ASO.

O uso do propeno como carga de alquilação implica na formação de um alquilado rico em isômeros do heptano (7 carbonos) com maior percentual de $\mathrm{C} 9+\mathrm{e}$, por conseqüência, em uma menor octanagem do produto final. Já o uso de butenos gera um alquilado rico em isômeros com 8 carbonos e um baixo percentual de C9+, portanto sua octanagem é elevada. A Figura 4.15 apresenta uma comparação do perfil de produtos gerado pelas diferentes olefinas, bem como sua respectiva octanagem.

Para entender a diferença de octanagem observada para os diferentes butenos é necessário estudar a composição completa do alquilado formado por estas. Segundo o mecanismo de reação, quando o 1-buteno reage com o iC4 $4^{+}$uma grande quantidade de $\mathrm{DMH}^{+}$é formada, e este, após a transferência de hidrogênio será transformado em DMH, que tem baixa octanagem (CUPIT et al, 1961). 

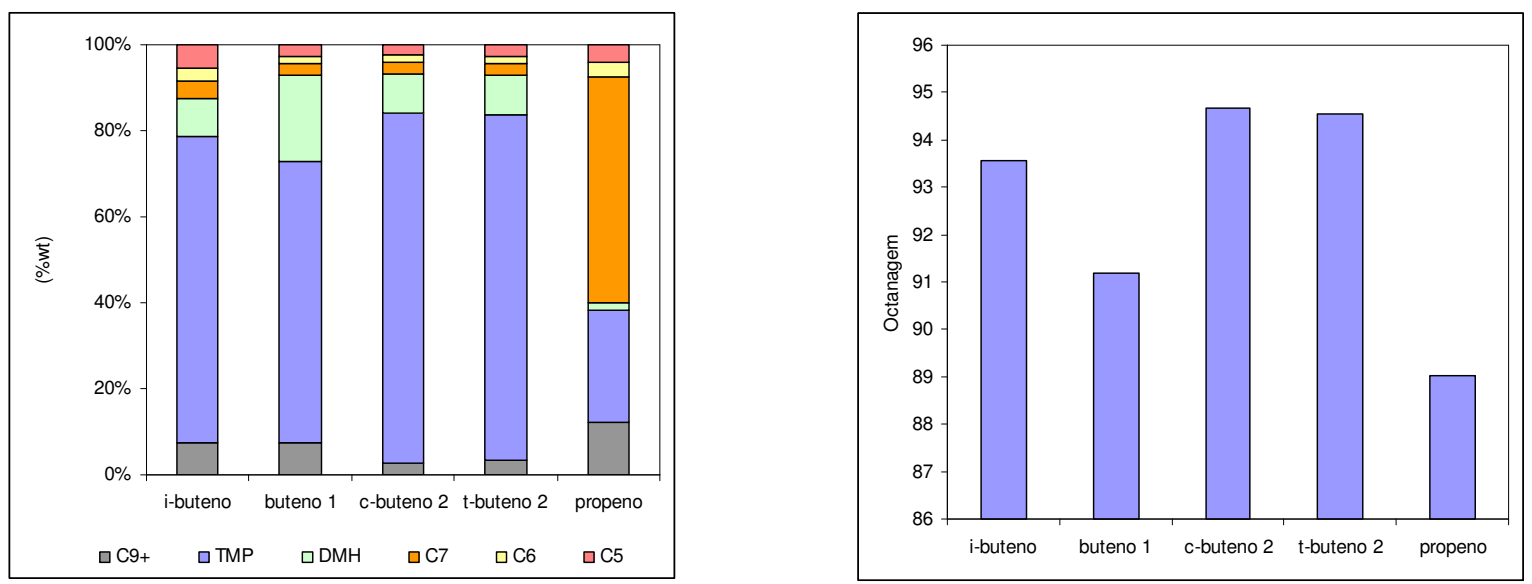

Figura 4.15: Influência do tipo de olefina na composição (HUTSON e HAYS, 1977) e octanagem do alquilado.

Já a diferença de octanagem observada quando o i-buteno e o buteno-2 estão presentes no meio reacional não pode ser explicada pela formação de $\mathrm{DMH}$, uma vez que estas olefinas levam à formação de quantidades semelhantes do dimetil-hexano. O principal fator que influencia essa diferença de octanagem é o total de TMP formado em cada um dos casos. O i-buteno leva a um percentual aproximado de $70 \%$ de TMP no alquilado, enquanto que o buteno-2 leva a aproximadamente $80 \%$ de TMP no alquilado. A distribuição dos isômeros do DMH e TMP também difere quando diferentes olefinas são utilizadas (CUPIT et al, 1961), como mostrado na Figura 4.16.
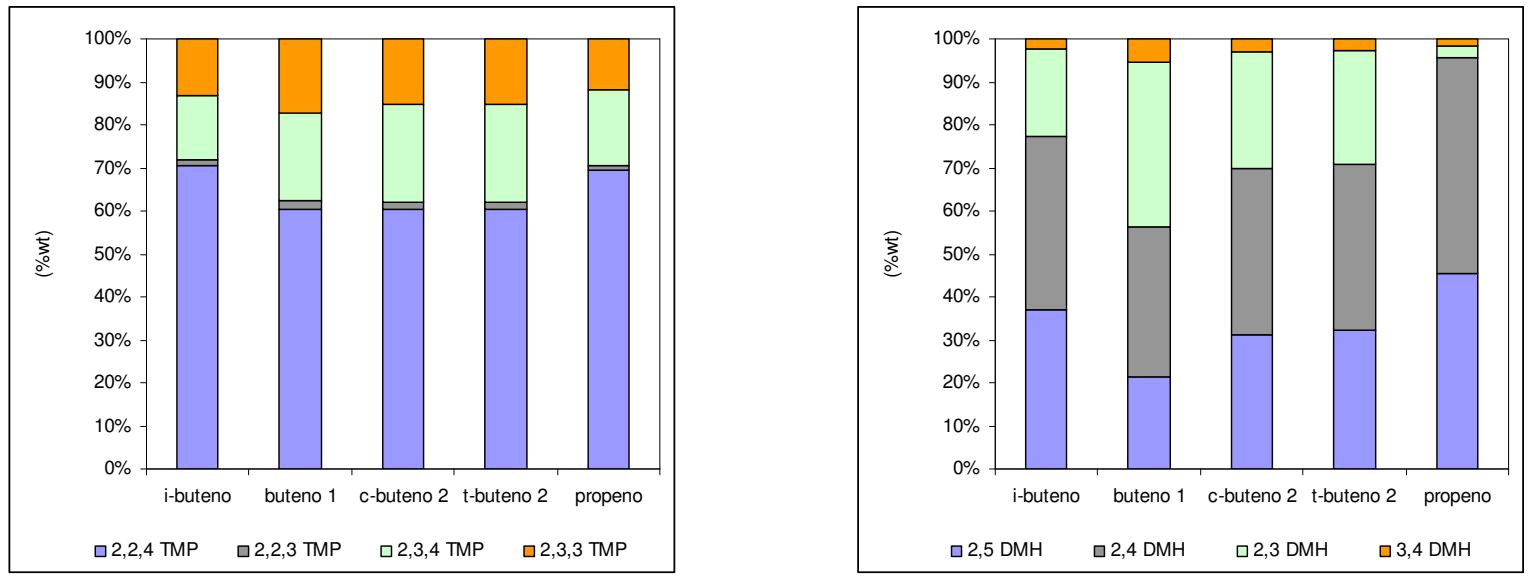

Figura 4.16: Isômeros do DMH e TMP com diferentes olefinas (HUTSON e HAYS, 1977) 
A Tabela 4.5 apresenta a composição do alquilado quando diferentes olefinas são utilizadas como carga de uma unidade de alquilação.

Tabela 4.5: Composição do alquilado para diferentes olefinas @ iC4/olefina =13:1.

\begin{tabular}{cccccc}
\hline & i-buteno & buteno 1 & c-buteno 2 & t-buteno 2 & Propeno \\
\hline C5 & 5,48 & 2,69 & 2,25 & 2,63 & 4,10 \\
C6 & 3,11 & 1,70 & 1,82 & 1,81 & 3,51 \\
C7 & 3,83 & 2,74 & 2,76 & 2,82 & 52,36 \\
TMP & 71,21 & 65,63 & 81,16 & 80,33 & 26,03 \\
DMH & 8,81 & 19,77 & 9,17 & 9,08 & 1,76 \\
C9+ & 7,56 & 7,28 & 2,83 & 3,33 & 12,23 \\
\hline & & & \multicolumn{3}{c}{ (HUTSON e HAYS, 1977) }
\end{tabular}

\subsubsection{Razão iC4/olefina}

No mecanismo de reação, a etapa responsável por eliminar a carga positiva do íon carbônion é a transferência de hidrogênio do iC4 para o carbocátion. Para controlar adequadamente essa etapa e, portanto, obter hidrocarbonetos com o tamanho de cadeia desejado (8 átomos de carbono), os reatores de alquilação por $\mathrm{HF}$ trabalham com excesso de iC4. Esse excesso é expresso pela relação entre as vazões de iC4 e olefinas (totais) alimentadas ao riser.

Quando o propeno é utilizado como carga de unidades de alquilação, além de controlar o encerramento da propagação da cadeia, o iC4 também transfere um hidrogênio para o íon $\mathrm{C}^{+}$, gerando uma molécula de propano e um íon $\mathrm{C}^{+}$. Isso reduz a formação de isômeros com 7 átomos de carbono, ao passo que aumenta a formação dos isômeros com 8 átomos de carbono. Isso faz com que a octanagem do produto final aumente. A Tabela 4.6 apresenta a influência da relação iC4/olefina no alquilado formado a partir de propeno. 
Tabela 4.6: Influência da relação iC4/olefina sobre o alquilado produzido a partir de propeno.

\begin{tabular}{cccccccc}
\hline iC4/olefina & 4,6 & 13 & 16 & 22 & 52 & 109 & 126 \\
\hline C5 & 5,09 & 4,10 & 4,82 & 3,69 & 3,33 & 2,24 & 1,36 \\
C6 & 4,55 & 3,51 & 3,90 & 2,63 & 2,08 & 2,02 & 1,72 \\
C7 & 55,11 & 52,36 & 45,79 & 48,84 & 45,50 & 42,58 & 40,49 \\
TMP & 16,88 & 26,03 & 30,55 & 33,49 & 43,05 & 47,33 & 51,94 \\
DMH & 2,57 & 1,76 & 3,36 & 2,73 & 2,02 & 2,14 & 2,18 \\
C9+ & 15,73 & 12,23 & 11,48 & 8,62 & 3,96 & 3,62 & 2,24 \\
Octanagem & 87,63 & 89,01 & 89,05 & 89,87 & 91,56 & 91,97 & 92,52 \\
\hline
\end{tabular}

Assim como na alquilação do propeno, uma relação iC4/olefina adequada também aumenta a octanagem e a relação TMP/DMH do alquilado obtido por butenos. A Figura 4.17 mostra esse o efeito.
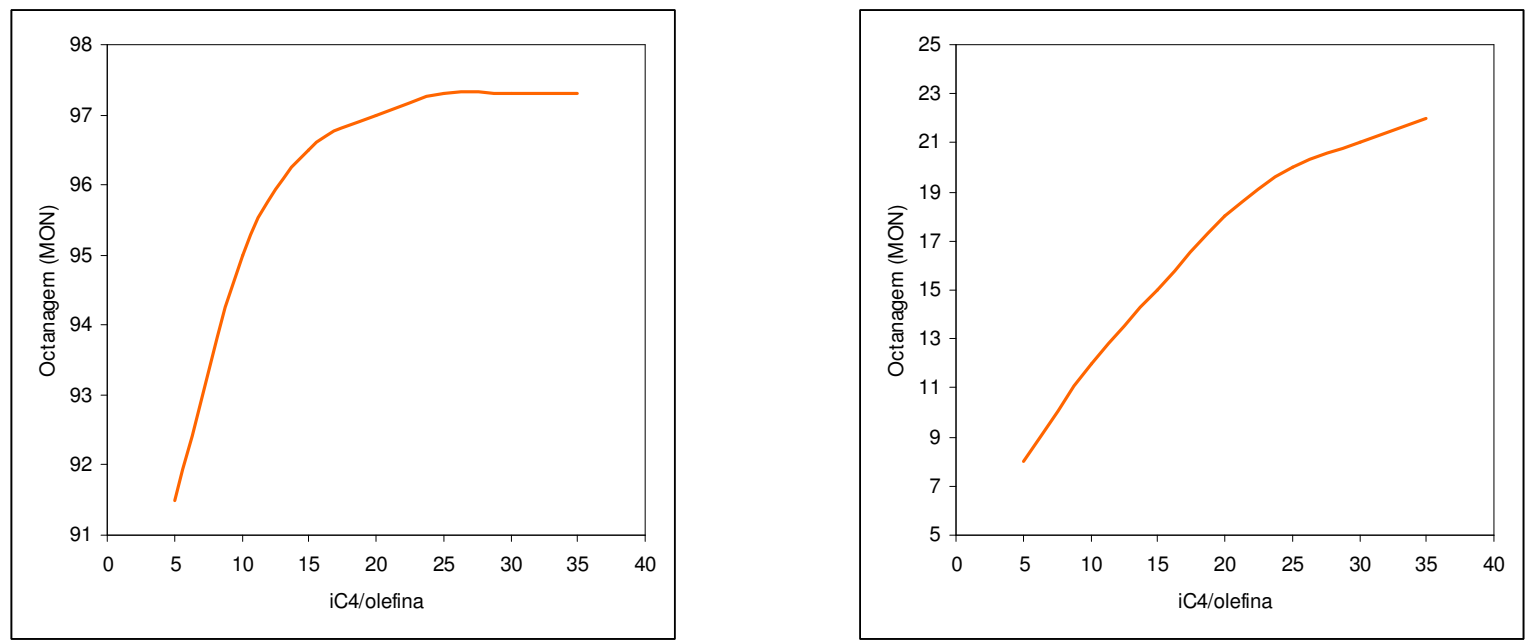

Figura 4.17: Efeito da relação iC4/olefina sobre a qualidade do alquilado obtido a partir de buteno-2 (HUTSON, 1978) 
Outra importante propriedade do alquilado que é controlada pela reação de transferência de hidrogênio é seu ponto final de ebulição (PFE). Quanto maior for o PFE, maior a cadeia de átomos de carbono que integra o alquilado, e pior serão suas propriedades na mistura do pool de gasolina. O PFE aumenta com a redução da relação iC4/olefina e, quanto menor esta for, maior será a formação de polímero (ASO). A Figura 4.18 mostra estas relações.
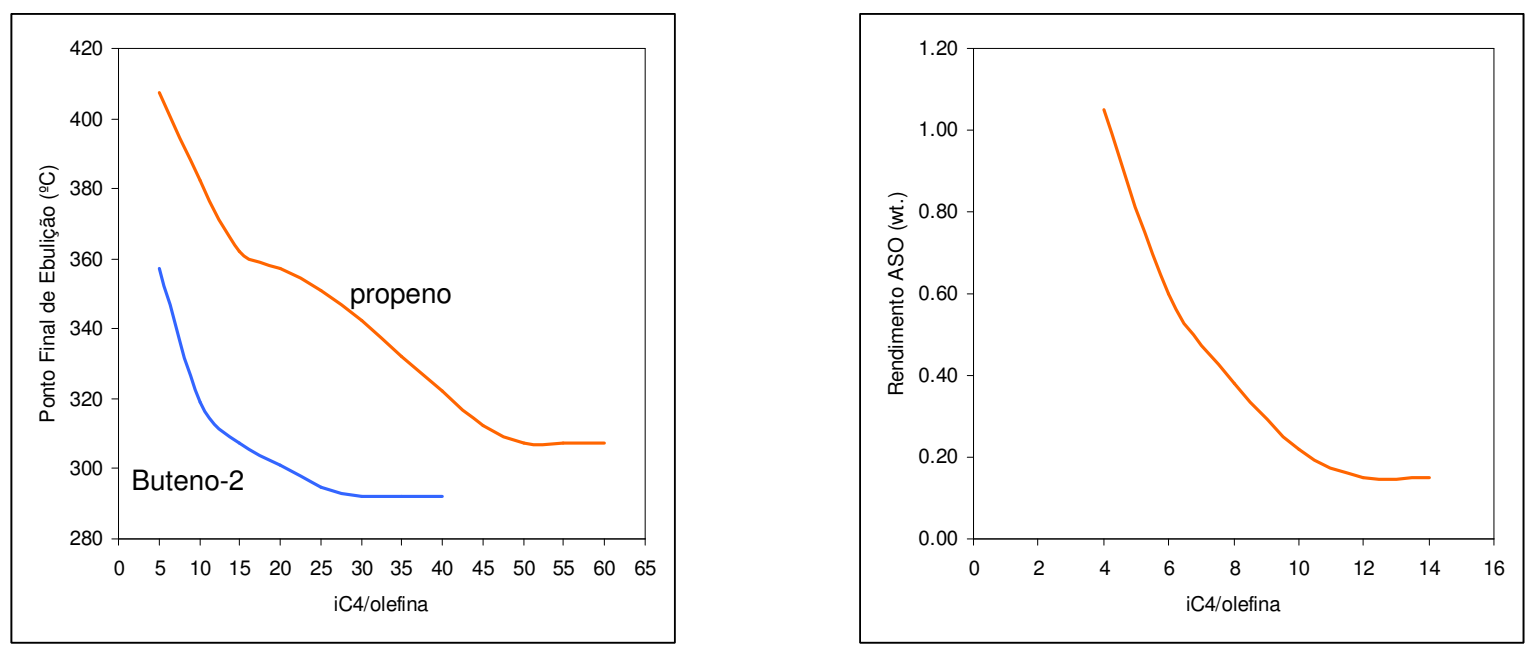

Figura 4.18: Efeito da relação iC4/olefina sobre o PFE do alquilado e sobre a produção de ASO (HUTSON, 1978) 


\section{RESULTADOS E DISCUSSÃo}

Nessa seção serão apresentados os resultados da modelagem de uma unidade de alquilação que utiliza o ácido fluorídrico como catalisador, a calibração desse modelo com dados experimentais disponíveis em literatura, e validação com dados industriais.

O modelo fenomenológico apresentado no presente documento é uma representação simplificada da cinética de reação proposta por HUTSON e HAYS (1977). O alquilado foi representado como uma mistura de tri-metil-pentanos, dimetil-hexanos e frações pesadas. Para estimar a quantidade de ácido dissociado presente no meio de reação foi utilizada a equação de HAMMETT.

Os dados experimentais de literatura utilizados na etapa de calibração foram obtidos de dois artigos publicados por HUTSON e HAYS (1977) e HUTSON (1978).

Os dados industriais foram obtidos em uma unidade de propriedade da Petrobras, cituada no município de Cubatão, estado de São Paulo, Brasil. Como a composição e vazão de saída do reator são variáveis desconhecidas (por não haver medições e análises de laboratório dessa corrente), ela foi obtida através de outros dados medidos, utilizando-se para tanto balanços de massa e energia. Os dados obtidos foram reconciliados, sendo descartados os conjuntos de dados com erro superior a $1 \%$ no balanço de massa. 


\subsection{Modelagem Matemática}

Historicamente, sistemas reacionais complexos são modelados a partir de propriedades intensivas das correntes (comumente chamadas de bulk properties), como o caso da temperatura de ebulição. No caso do processo de alquilação, diversos autores obtiveram resultados satisfatórios usando essa abordagem, como o caso do trabalho publicado por HUTSON e LOGAN (1975). Contudo, esses modelos são limitados, uma vez que descrevem o comportamento de poucas variáveis e, portanto, pouco contribuem para a análise do comportamento de uma unidade industrial.

Com o aumento da capacidade de processamento de dados, modelos matemáticos mais complexos têm sido desenvolvidos para diversos processos industriais. No caso da alquilação, os esforços se concentraram na modelagem e simulação de sistemas que utilizam catalisadores sólidos, como o caso dos trabalhos publicados por NAYAK et al (2010); SIMPSON et al (1996); DE JONG et al (1996). Porém pouco foi desenvolvido para os processos catalisados pelos ácidos sulfúrico e fluorídrico. PRICKETT e MAVROVOUNIOTS (1997) desenvolveu uma linguagem computacional (Reaction Description Language) capaz de descrever um sistema genérico de reações complexas e a transformação dos reagentes em produtos. Essa linguagem foi aplicada ao processo de alquilação com ácido sulfúrico, obtendo-se como resultado a distribuição de tamanho de cadeia do alquilado formado, assim como o grau de ramificação para cada fração.

O presente trabalho tem como objetivo obter um modelo matemático fenomenológico capaz de descrever o comportamento de um reator industrial alquilação, que utiliza do HF como catalisador, quando as principais variáveis do processo são alteradas. A Figura 5.1 apresenta o diagrama esquemático utilizado para a construção do modelo. A carga da unidade (1), composta basicamente por butenos e i-butano, é alimentada na base do reator, onde entrará em contato com o HF circulante (2), cuja composição é basicamente ácido fluorídrico (80\% - 95\%), água $(0,05 \%$ - 5\%) e ASO $(0,05-15 \%)$. Ao longo do reator, as reações de alquilação ocorrem, formando os produtos e subprodutos e liberando calor. A 
corrente de saída do reator (3) é alimentada ao decantador, onde o ácido é separado dos hidrocarbonetos por diferença de densidade, gerando a corrente de produtos (5), que é enviada para fracionamento, e ácido fluorídrico circulante (4). No decantador também é alimentada uma corrente de HF (6) oriunda da planta de regeneração de ácido e da recuperação de ácido arrastado pela corrente 5. O ácido que deixa o decantador (4) passa por um resfriador, onde o calor gerado pelas reações será removido, e fechando a circulação de ácido. Nesse equipamento é retirada uma pequena fração do ácido circulante (7), que é enviada à regeneração para remover os subprodutos.

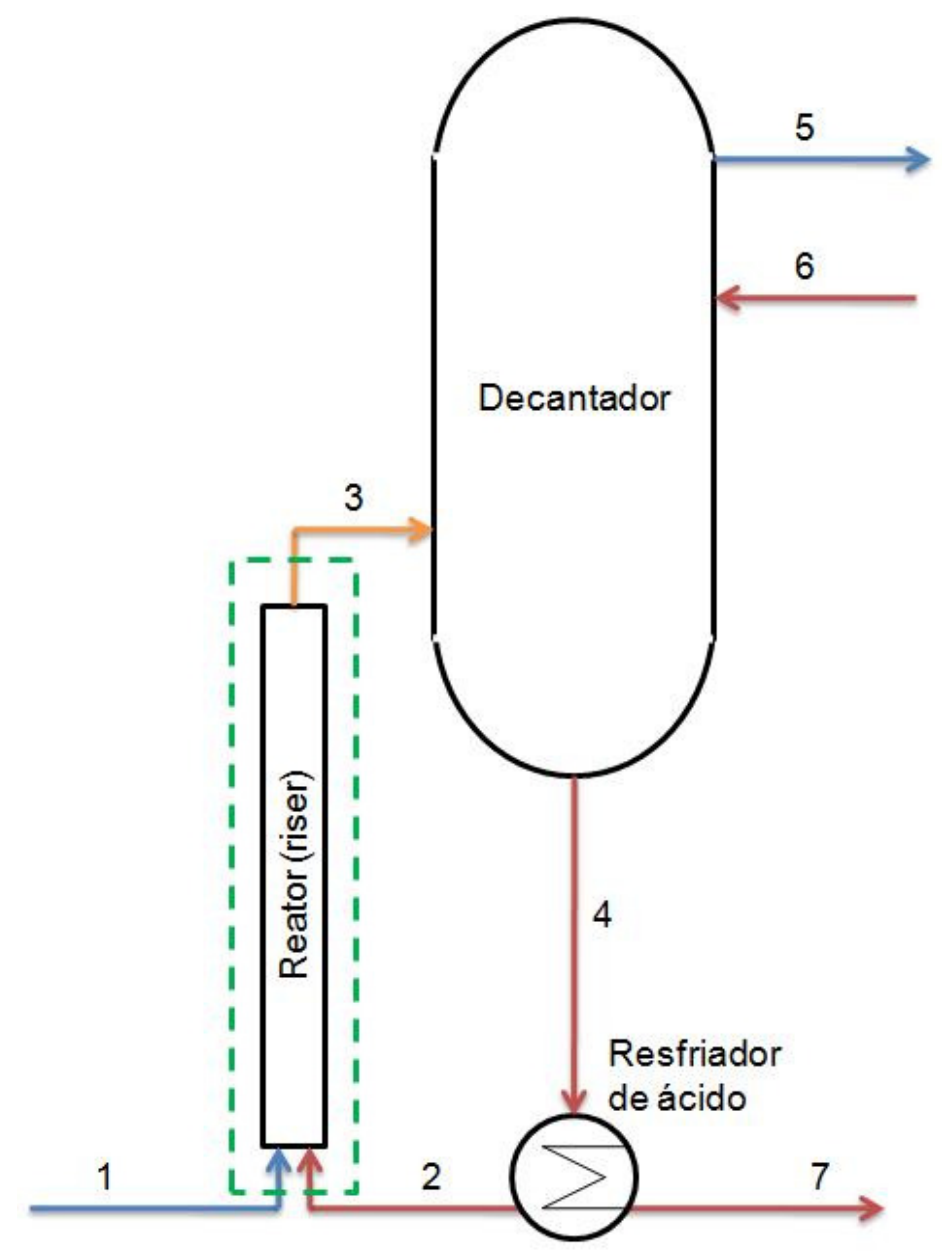

Figura 5.1: Volume de controle utilizado para a obtenção do modelo fenomenológico. 
A construção do modelo preocupou-se apenas em descrever os fenômenos que ocorrem no reator da unidade (destacado pela linha pontilhada na Figura 5.1). O volume de controle utilizado para equacionar os balanços de massa e energia foi um elemento infinitesimal do reator, uma vez que esse foi modelado como um reator ideal tipo PFR.

O mecanismo cinético utilizado para a construção do modelo foi o apresentado por HUTSON e HAYS, 1977. Nesse, a reação de alquilação se inicia pelo ataque das insaturações presentes nos reagentes pelo próton liberado pela dissociação do ácido fluorídrico. Portanto, a primeira etapa do processo de construção do modelo consistiu em avaliar como ocorre a dissociação do ácido fluorídrico e quantificar a concentração dos produtos desta dissociação.

O equacionamento matemático das demais etapas do mecanismo cinético adotado foi composto pelos seguintes passos: adoção de hipóteses, equacionamento, calibração do modelo com dados de literatura, aplicação do modelo calibrado aos dados coletados na unidade e análise dos resultados obtidos. Esse processo é interativo, isto é, cada conjunto de hipóteses estabelecidas gera um resultado que é analisado. Caso os resultados obtidos pelo modelo não consigam representar o comportamento da unidade, mudanças nas hipóteses eram propostas, e o novo modelo posto à prova. Esse processo se repetiu até que um conjunto de equações e parâmetros cinéticos capazes de descrever em grande parte 0 comportamento da unidade de alquilação fosse obtido. A Figura 5.2 apresenta de forma gráfica esses passos.

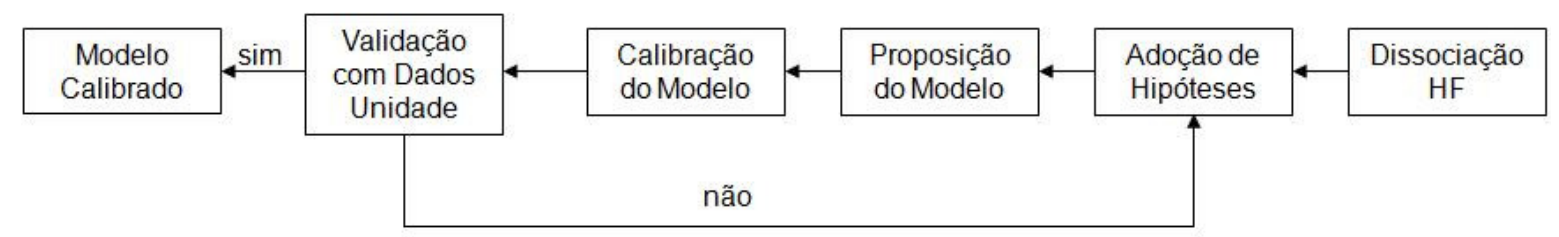

Figura 5.2: Metodologia utilizada para a construção do modelo fenomenológico. 


\subsubsection{Dissociação do Ácido Fluorídrico}

O ácido fluorídrico anidro (AHF) é considerado um ácido de Brønsted, isso é, tem a tendência a doar um próton (MOLNAR, 2003). Ele é considerado um ácido forte, apesar de em soluções diluídas se comportar como um ácido fraco.

Em soluções aquosas diluídas, a espécie ácida presente no meio é o $\mathrm{H}_{3} \mathrm{O}^{+}$, conforme apresentado na Reação 5.1. Nessa região, quando comparadas soluções de igual concentração, o HF é significantemente menos ácido que qualquer ácido forte (HYMAN et al, 1957).

$$
\mathrm{HF}+\mathrm{H}_{2} \mathrm{O} \longleftrightarrow \mathrm{H}_{3} \mathrm{O}^{+}+\mathrm{F}^{-}
$$

Reação 5.1

A acidez do HF aumenta rapidamente quando a concentração molar de HF na água se aproxima de $50 \%$. Nesse ponto em diante ele passa a ser um ácido mais forte que a maior parte dos ácidos fortes, quando comparadas soluções de mesma concentração. Diversos autores atribuem esse comportamento ao aparecimento de íons poliméricos, tais como $\mathrm{HF}_{2}^{-}, \mathrm{H}_{2} \mathrm{~F}_{3}^{-}$, e cadeias ainda mais longas conforme a concentração do ácido aumenta. Com isso também aumenta a concentração da espécie ácida $\mathrm{H}_{2} \mathrm{~F}^{+}$, aumentando a acidez. $\mathrm{O}$ equilíbrio pode ser descrito pelas Reações 5.2 e 5.3 (HYMAN et al, 1957).

$$
\begin{aligned}
& n H F+H_{2} O \longleftrightarrow H_{3} O^{+}+F^{-}(H F)_{(n-1)} \\
& H F+n H F \longleftrightarrow H_{2} F^{+}+F^{-}(H F)_{(n-1)}
\end{aligned}
$$

O conceito de $\mathrm{pH}$ de uma solução não é aplicável a sistemas não aquosos ou em soluções ácidas concentradas, como o caso do processo de alquilação catalisado por ácido fluorídrico. HAMMETT e DEYRUP definiram a variável $h_{0}$ conforme a Equação 5.1, usualmente escrita na forma logarítmica, Equação 5.2. 


$$
\begin{array}{lr}
h_{0}=K_{H B}+\frac{\left[H B^{+}\right]}{[B]} & \text { Equação } 5.1 \\
H_{0}=-\log \left(h_{0}\right)=p K_{H B}-\log \left(\frac{\left[H B^{+}\right]}{[B]}\right) & \text { Equação } 5.2 \\
\text { Onde: } & \mathrm{K}_{\mathrm{HB}} \text { é a constante de equilíbrio termodinâmico para } \mathrm{BH}^{+} .
\end{array}
$$

A função de acidez de HAMMETT, $\left(\mathrm{H}_{0}\right)$ para soluções de ácido fluorídrico é bastante conhecida. A Figura 5.3 apresenta esses resultados para soluções de HF em água em concentrações que variam desde $0 \%$ molar até 100\%.

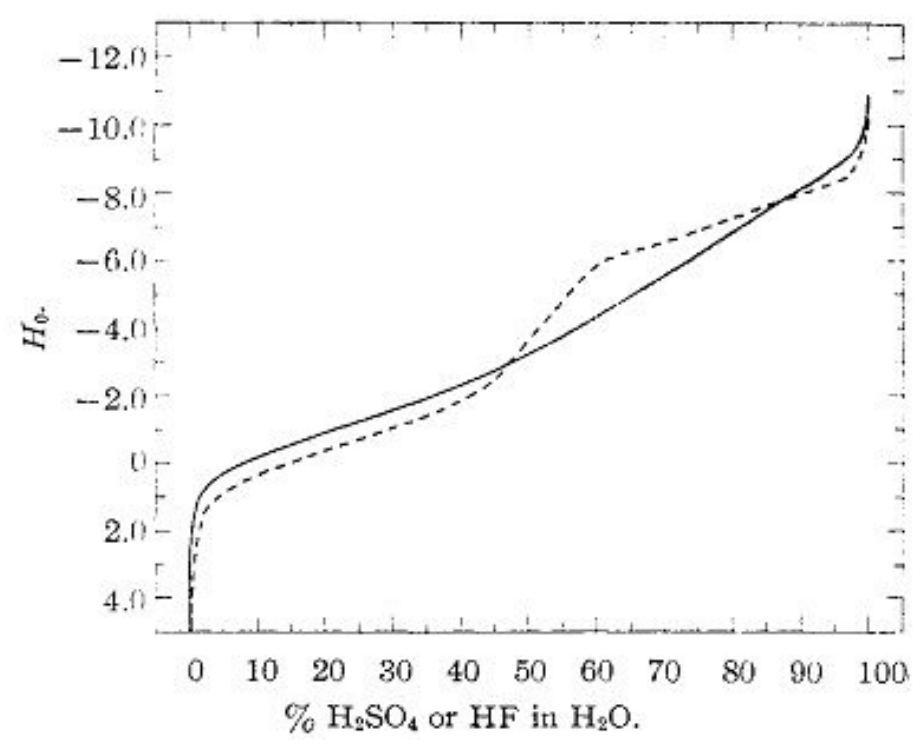

Figura 5.3: Função acidez de HAMMETT para o HF em função da quantidade de água na solução. Comparação com os dados para o ácido sulfúrico (linha contínua: ácido sulfúrico; linha tracejada: ácido fluorídrico). (HYMAN et al, 1957).

\subsubsection{Cinética de Reação}

O mecanismo cinético da reação de alquilação pode ser comparado ao mecanismo de polimerização, sendo a principal diferença envolvida o momento em que se obtem o polímero morto. Enquanto no processo de polimerização desejam-se cadeias de elevado peso molecular, a alquilação deseja obter cadeias de baixo peso molecular (oligômeros), tipicamente formados por apenas duas moléculas de 
monômeros. No processo de alquilação ainda ocorrem reações de dimerização e formação de fluoreto orgânico. Na modelagem matemática foram adotadas as seguintes etapas (SCHMERLING, 1953; HUTSON e HAYS, 1977):

- Dissociação do ácido fluorídrico;

- Iniciação da cadeia;

- Propagação da cadeia;

- Transferência de cadeia;

- Terminação;

- Isomerização;

- Dimerização;

- Formação de fluoreto orgânico.

A carga da unidade de alquilação consiste tipicamente dos reagentes (monoolefinas leves e i-butano); de inertes (propano, n-butano); contaminantes (butadieno e enxofre).

As primeiras unidades de alquilação que entraram em operação utilizavam como fonte de olefinas uma corrente rica em propeno e butenos. Porém, como o passar dos anos, o propeno adquiriu elevado valor comercial, por ser utilizado na produção do polipropileno, deixando de ser carga de unidades de alquilação. $\mathrm{Na}$ unidade de alquilação objeto de estudo, a corrente de olefinas que alimentam o reator é composta basicamente de buteno-1, c-buteno-2, t-buteno-2 e i-buteno.

O uso de diferentes isômeros do buteno como carga de uma unidade de alquilação leva a diferentes composições do produto final. Quando o buteno-1 é utilizado, observa-se uma grande produção de di-metil-hexanos (DMH) em detrimento a tri-metil-pentanos (TMP), além de aumentar o rendimento em frações pesadas (alquilado pesado). Caso o i-buteno seja utilizado, há uma produção preferencial de TMP e uma redução no rendimento de alquilado pesado. Ao utilizar o buteno-2 como carga de alquilação obtém-se o melhor rendimento e qualidade do produto obtido. Não há grande distinção no comportamento do c-buteno-2 e tbuteno-2 (HUTSON e HAYS, 1977). Portanto no modelo matemático apresentado 
neste trabalho foi considerada apenas a presença do buteno-1, buteno-2 e i-buteno como mono-olefinas.

Os contaminantes são substâncias que, uma vez presentes no meio reacional irão levar à queda no rendimento, ao maior consumo de ácido e à formação de subprodutos da reação (ASO). O butadieno, por apresentar duas insaturações, faz com que a reação de polimerização não seja interrompida no momento certo, levando à formação excessiva ASO. Como não existem dados de literatura disponíveis para calibrar o modelo matemático com a presença de butadieno, assim como a unidade de alquilação modelada possui um tratamento destinado à remoção do butadieno, sua presença no modelo não foi considerada.

O enxofre, outro contaminante, leva à formação de ASO, porém o mecanismo pelo qual isso ocorre não está bem esclarecido na literatura. Dessa maneira não foi possível modelar fenomenologicamente sua presença no meio reacional.

Considerou-se que as constantes cinéticas para cada grupo de reações (iniciação, propagação, transferência de cadeia, terminação, isomerização, dimerização e formação de fluoreto orgânico) independem das espécies que estão reagindo, admitindo um único valor constante para todo o grupo.

Pelo apresentado acima, as etapas de dissociação do HF e iniciação podem ser descritas pelas Reações 5.4 a 5.7. A etapa de dissociação está apenas representada simplificadamente, sendo a forma correta apresentada nas Reações 5.2 e 5.3. $\mathrm{O} \mathrm{H}^{+}$não representa o íon hidrogênio, mas o próton liberado pelo HF.

Dissociação do Ácido Fluorídrico

$H F \stackrel{k_{d} ; k_{i}}{\longleftrightarrow} H^{+}+F^{-}$

Reação 5.4

Iniciação

$\mathrm{C}_{4} \mathrm{H}_{8}-1+\mathrm{H}^{+} \stackrel{k_{1}}{\longrightarrow} \mathrm{C}_{4} H_{9}^{+}-1$

Reação 5.5

$\mathrm{C}_{4} \mathrm{H}_{8}-2+\mathrm{H}^{+} \stackrel{k_{1}}{\longrightarrow} \mathrm{C}_{4} \mathrm{H}_{9}^{+}-2$

Reação 5.6

$i C_{4} H_{8}+H^{+} \stackrel{k_{1}}{\longrightarrow} i C_{4} H_{9}^{+}$

Reação 5.7 
Para a etapa de propagação, representada pelas Reações 5.8 a 5.28, considerou-se que o DMH é formado pelas reações do buteno- 1 com os demais carbocátions com 4 átomos de carbono e do carbocátion gerado a partir do buteno-1 com os butenos. Já o TMP é gerado pelas demais reações.

$$
\begin{aligned}
& \text { Propagação } \\
& C_{4} H_{9}^{+}-1+C_{4} H_{8}-1 \stackrel{k_{2}}{\longrightarrow} D M H^{+} \\
& C_{4} H_{9}^{+}-1+C_{4} H_{8}-2 \stackrel{k_{2}}{\longrightarrow} D M H^{+} \\
& C_{4} H_{9}^{+}-1+i C_{4} H_{8} \stackrel{k_{2}}{\longrightarrow} D M H^{+} \\
& C_{4} H_{9}^{+}-2+C_{4} H_{8}-1 \stackrel{k_{2}}{\longrightarrow} D M H^{+} \\
& C_{4} H_{9}^{+}-2+C_{4} H_{8}-2 \stackrel{k_{2}}{\longrightarrow} T M P^{+} \\
& C_{4} H_{9}^{+}-2+i C_{4} H_{8} \stackrel{k_{2}}{\longrightarrow} T M P^{+} \\
& i C_{4} H_{9}^{+}+C_{4} H_{8}-1 \stackrel{k_{2}}{\longrightarrow} D M H^{+} \\
& i C_{4} H_{9}^{+}+C_{4} H_{8}-2 \stackrel{k_{2}}{\longrightarrow} T M P^{+} \\
& i C_{4} H_{9}^{+}+i C_{4} H_{8} \stackrel{k_{2}}{\longrightarrow} T M P^{+} \\
& D M H^{+}+C_{4} H_{8}-1 \stackrel{k_{3}}{\longrightarrow} A P^{+} \\
& D M H^{+}+C_{4} H_{8}-2 \stackrel{k_{3}}{\longrightarrow} A P^{+} \\
& D M H^{+}+i C_{4} H_{8} \stackrel{k_{3}}{\longrightarrow} A P^{+} \\
& T M P^{+}+C_{4} H_{8}-1 \stackrel{k_{3}}{\longrightarrow} A P^{+} \\
& T M P^{+}+C_{4} H_{8}-2 \stackrel{k_{3}}{\longrightarrow} A P^{+} \\
& T M P^{+}+i C_{4} H_{8} \stackrel{k_{3}}{\longrightarrow} A P^{+} \\
& A P^{+}+C_{4} H_{8}-1 \stackrel{k_{4}}{\longrightarrow} A S O^{+} \\
& A P^{+}+C_{4} H_{8}-2 \stackrel{k_{4}}{\longrightarrow} A S O^{+} \\
& A P^{+}+i C_{4} H_{8} \stackrel{k_{4}}{\longrightarrow} A S O^{+} \\
& A S O^{+}+C_{4} H_{8}-1 \stackrel{k_{4}}{\longrightarrow} A S O^{+} \\
& A S O^{+}+C_{4} H_{8}-2 \stackrel{k_{4}}{\longrightarrow} A S O^{+} \\
& A C_{4} H_{8} \stackrel{k_{4}}{\longrightarrow} A S O^{+} \\
& D S^{2}
\end{aligned}
$$

Reação 5.8

Reação 5.9

Reação 5.10

Reação 5.11

Reação 5.12

Reação 5.13

Reação 5.14

Reação 5.15

Reação 5.16

Reação 5.17

Reação 5.18

Reação 5.19

Reação 5.20

Reação 5.21

Reação 5.22

Reação 5.23

Reação 5.24

Reação 5.25

Reação 5.26

Reação 5.27

Reação 5.28 
As frações pesadas do alquilado, isso é, com mais de 9 átomos de carbono na composição da molécula foram agrupados em um único componente, o alquilado pesado (representado por AP). Os dados de literatura mostram que o maior tamanho de cadeia presente no alquilado pesado tem 14 carbonos (ALBRIGHT e WOOD, 1997), portanto esse valor foi adotado como tamanho de cadeia a partir do qual as os hidrocarbonetos obtidos no reator foram agrupados como ASO. Este último tem diferentes tamanhos de cadeia, podendo apresentar entre 19 e 22 átomos de carbono, dispostos em estruturas cíclicas (MIRON e LEE, 1963).

Em uma primeira tentativa de modelo, adotou-se como aproximação a hipótese da cadeia longa, isto é, a constante cinética de propagação independe do tamanho da cadeia do carbocátion, representada pela Equação 5.3. Esta hipótese é bastante utilizada em reações de polimerização, onde os produtos rapidamente alcançam elevados pesos moleculares (HAMIELEC e TOBITA, 1992).

$$
k_{2}=k_{3}=k_{4}
$$

Equação 5.3

Entretanto, os resultados obtidos quando tal hipótese foi utilizada mostraram que o modelo matemático não foi capaz de representar adequadamente o rendimento dos produtos (alquilado leve e pesado) e subprodutos (ASO) da reação. Diversos estudos mostram que no início da etapa de propagação, a constante cinética decresce conforme o tamanho a massa molar do polímero formado aumenta, até alcançar um valor constante (FLORY, 1953).

Portanto a adoção da Equação 5.3 não é válida para o modelo de alquilação por se tratar de reações de oligomerização, e sua adoção traz prejuízos aos resultados do modelo. Dessa forma a Equação 5.3 não pôde ser adotada, devendo ser substituída pela Equação 5.4.

$$
k_{2} \neq k_{3} \neq k_{4}
$$

Equação 5.4

O i-butano utilizado no processo de alquilação é um agente de transferência de cadeia. $O$ excesso deste no meio reacional tem como objetivo cessar o 
crescimento da cadeia viva quando apenas uma unidade monomérica foi adicionada a ela. No mecanismo cinético estudado, essa etapa pode ser descrita pelas Reações 5.29 a 5.35 .

$$
\begin{aligned}
& \text { Transferência de Cadeia } \\
& C_{4} H_{9}^{+}-1+i C_{4} H_{10} \stackrel{k_{5}}{\longrightarrow} n C_{4} H_{10}+i C_{4} H_{9}^{+} \\
& C_{4} H_{9}^{+}-2+i C_{4} H_{10} \stackrel{k_{5}}{\longrightarrow} n C_{4} H_{10}+i C_{4} H_{9}^{+} \\
& i C_{4} H_{9}^{+}+i C_{4} H_{10} \stackrel{k_{5}}{\longrightarrow} i C_{4} H_{10}+i C_{4} H_{9}^{+} \\
& D M H^{+}+i C_{4} H_{10} \stackrel{k_{5}}{\longrightarrow} D M H+i C_{4} H_{9}^{+} \\
& \mathrm{TMP}^{+}+i C_{4} H_{10} \stackrel{k_{5}}{\longrightarrow} \mathrm{TMP}+i C_{4} H_{9}^{+} \\
& A P^{+}+i C_{4} H_{10} \stackrel{k_{5}}{\longrightarrow} A P+i C_{4} H_{9}^{+} \\
& A S O^{+}+i C_{4} H_{10} \stackrel{k_{5}}{\longrightarrow} A S O+i C_{4} H_{9}^{+}
\end{aligned}
$$

Reação 5.29

Reação 5.30

Reação 5.31

Reação 5.32

Reação 5.33

Reação 5.34

Reação 5.35

A terminação é qualquer conjunto de reações que levam à eliminação do carbocátion de quatro carbonos (HUTSON e HAYS, 1977). Nesse conjunto de reações é obrigatório que uma das etapas contemple a obtenção de um próton e de uma olefina a partir do carbocátion, como apresentado nas Reações 5.36 a 5.38 .

$$
\begin{aligned}
& \text { Terminação } \\
& C_{4} H_{9}^{+}-1 \stackrel{k_{6}}{\longrightarrow} C_{4} H_{8}-1+H^{+} \\
& C_{4} H_{9}^{+}-2 \stackrel{k_{6}}{\longrightarrow} C_{4} H_{8}-2+H^{+} \\
& i C_{4} H_{9}^{+} \stackrel{k_{6}}{\longrightarrow} i C_{4} H_{8}+H^{+}
\end{aligned}
$$

Reação 5.36

Reação 5.37

Reação 5.38

O ânion fluoreto tem a capacidade de reagir com moléculas de hidrocarbonetos olefínicos, com tamanhos de cadeia variados, formando o fluoreto orgânico (GROSSE e LINN, 1938). No sistema em questão foi considerada apenas a formação de fluoreto orgânico com quatro átomos de carbono, uma vez que na unidade industrial em questão não há relatos de formação desses componentes com cadeias maiores. 
Formação de Fluoreto Orgânico

$$
\begin{array}{lr}
C_{4} H_{9}^{+}-1+F^{-} \stackrel{k_{1}}{\longrightarrow} C_{4} H_{9} F & \text { Reação } 5.39 \\
C_{4} H_{9}^{+}-2+F^{-} \stackrel{k_{11}}{\longrightarrow} C_{4} H_{9} F & \text { Reação } 5.40 \\
i C_{4} H_{9}^{+}+F^{-} \stackrel{k_{11}}{\longrightarrow} C_{4} H_{9} F & \text { Reação } 5.41
\end{array}
$$

Dados experimentais mostram que o alquilado formado por diferentes isômeros do buteno apresenta quantidades diferentes de DMH e TMP. Duas explicações são aplicadas para explicar esse fenômeno:

- Elevada isomerização do carbocátion formado por n-butenos aos formados pelo i-buteno (HUTSON e HAYS, 1977);

- Isomerização do $\mathrm{DMH}^{+}$e $\mathrm{TMP}^{+}$a $\mathrm{TMP}^{+}$e $\mathrm{DMH}^{+}$respectivamente (CIAPETTA, 1945);

- Dimerização do buteno-2 e i-buteno levando a DMH (CIAPETTA, 1945).

Utilizando o modelo matemático somente com as Reações 5.4 a 5.41, quando a carga da unidade for composta apenas por buteno-1, o alquilado formado seria composto somente por $\mathrm{DMH}$; enquanto que quando a carga for somente buteno-2 ou i-buteno, o respectivo alquilado seria composto somente por TMP.

Para tentar representar adequadamente o perfil de rendimento em $\mathrm{DMH}$ e TMP obtido através de diferentes olefinas, foram inseridas as reações de isomerização do $\mathrm{DMH}^{+}$e $\mathrm{TMP}^{+}$, conforme Reações 5.42 e 5.43; além de prever a dimerização do buteno-2 e i-buteno, apresentada nas Reações 5.44 e 5.45.

Isomerização

$\mathrm{DMH}^{+} \stackrel{k_{7}}{\longrightarrow} \mathrm{TMP}^{+}$
$\mathrm{TMP}^{+} \stackrel{k_{8}}{\longrightarrow} \mathrm{DMH} H^{+}$ Reação 5.42 Reação 5.43

Dimerização

$2 \mathrm{C}_{4} \mathrm{H}_{8}-2+H^{+}+i \mathrm{C}_{4} \mathrm{H}_{10} \stackrel{k_{9}}{\longrightarrow} \mathrm{DMH}+i \mathrm{C}_{4} \mathrm{H}_{9}^{+}$

Reação 5.44

$2 i C_{4} H_{8}+H^{+}+i C_{4} H_{10} \stackrel{k_{10}}{\longrightarrow} D M H+i C_{4} H_{9}^{+}$

Reação 5.45 
No mecanismo adotado não foram consideradas as reações de craqueamento de moléculas (com mais de 10 átomos de carbono em sua estrutura), pois essas foram agrupadas sob o nome de alquilado pesado. Com isso não foi possível verificar no modelo a formação de compostos como pentanos e heptanos, que contribuem para a redução da octanagem do alquilado.

A cinética de reação apresentada é bastante semelhante com reações de polimerização catiônica. Porém o tipo de tratamento dado às reações de polimerização não é aplicável ao processo em questão, uma vez que o objetivo deste modelo é obter o tamanho médio de cadeia em termos de número de carbonos na molécula ao invés do número de unidades monoméricas. Portanto não foi aplicado o método dos momentos na modelagem do sistema.

$\mathrm{Na}$ base do riser, o ácido circulante oriundo do trocador de calor, encontra com as olefinas e o i-butano (fresco e de reciclo), iniciando as reações de alquilação, encerrando-se no topo deste. Na modelagem matemática foi considerado regime estacionário, e o escoamento no riser altamente turbulento, podendo considerar esse equipamento um reator tubular ideal (PFR), isto é, há homogeneidade de propriedades na direção radial. Dessa forma, a Equação 5.5 pode ser adotada.

$$
v_{z} \frac{d[A]}{d z}=\sum_{1}^{\text {reaçéses }} v_{A i} r_{i}
$$

Onde: $\mathrm{v}_{\mathrm{z}}$ : velocidade na direção do fluxo; [A]: concentração do componente $A$; $r_{i}$ : cinética da reação "i" onde o componente A participa; $v_{\mathrm{Ai}}$ : coeficiente estequiométrico.

Rigorosamente, o hidrocarboneto e o ácido estão em fases diferentes, e para que as reações de alquilação ocorram, o hidrocarboneto deve migrar para a fase ácida, onde reage, e então retornar para a fase hidrocarboneto. Esse mecanismo também é dependente da solubilidade dos hidrocarbonetos no HF. Ao adotar a hiótese de reator como pseudo-homogêneo implica em dizer que todo o hidrocarboneto que entra no reator está imediatamente disponível para reagir. Do ponto de vista de resposta do modelo, essa simplificação não trouxe grande impacto, uma vez que os parâmetros cinéticos obtidos na etapa de calibração do modelo 
passaram a representar não só a velocidade da reação, mas também a disponibilidade de hidrocarboneto para reagir.

Modelos matemáticos criados para descrever o processo de alquilação que utiliza catalisador sólido consideram que todas as reações envolvidas são elementares (NAYAK et al, 2010). Existem diferenças significativas entre as cinéticas de reação quando se utiliza o ácido fluorídrico e um catalisador sólido, porém ambos os mecanismos são muito parecidos. Portanto, para equacionar a cinética do processo, considerou-se que todas as reações envolvidas no mecanismo são elementares. Ao se aplicar a hipótese de cinética elementar para as reações de dimerização, notou-se que o modelo não apresentou bons resultados, portanto para estas reações foi necessária outra abordagem.

A seguir serão apresentadas as equações que representam o comportamento de cada um dos componentes ao longo do reator, obtidas através do balanço de massa em um elemento infinitesimal deste. Para o ácido fluorídrico, seu consumo é descrito pela Equação 5.6.

$$
v_{z} \frac{d[H F]}{d z}=-k_{d}[H F]+k_{i}\left[H^{+}\right]\left[F^{-}\right]
$$

Equação 5.6

O próton $\left(\mathrm{H}^{+}\right)$que inicia a reação de alquilação é formado pela reação direta de dissociação do ácido fluorídrico e de terminação da cadeia viva. Já seu consumo se dá pela reação inversa, de protonação e dimerização de olefinas. Dessa maneira, o balanço de próton pode ser representado pela Equação 5.7.

$$
\begin{aligned}
v_{z} \frac{d\left[H^{+}\right]}{d z}= & +k_{d}[H F]-k_{i}\left[H^{+}\right]\left[F^{-}\right]+ \\
& -k_{1}\left[H^{+}\right]\left\{\left[C_{4} H_{8}-1\right]+\left[C_{4} H_{8}-2\right]+\left[i C_{4} H_{8}\right]\right\}+ \\
& +k_{6}\left\{\left[C_{4} H_{9}^{+}-1\right]+\left[C_{4} H_{9}^{+}-2\right]+\left[i C_{4} H_{9}^{+}\right]\right\}+ \\
& -k_{9}\left[C_{4} H_{8}-2\right]\left[H^{+}\right]-k_{10}\left[i C_{4} H_{8}\right]\left[H^{+}\right]
\end{aligned}
$$


O ânion fluoreto também é gerado pela reação em equilíbrio de dissociação do HF. Seu consumo se dá pela reação de formação de fluoretos orgânicos. Dessa maneira, o balanço dessa substância é dado pela equação 5.8 .

$$
\begin{aligned}
v_{z} \frac{d\left[F^{-}\right]}{d z}= & +k_{d}[H F]-k_{i}\left[H^{+}\right]\left[F^{-}\right]+ \\
& -k_{11}\left[F^{-}\right]\left\{\left[C_{4} H_{9}^{+}-1\right]+\left[C_{4} H_{9}^{+}-2\right]+\left[i C_{4} H_{9}^{+}\right]\right\}
\end{aligned}
$$

Como o ácido fluorídrico está em excesso no meio, é possível afirmar que todo $\circ \mathrm{H}^{+}$e $\mathrm{F}^{-}$consumidos pelas reações são repostos por ele, de maneira a manter o equilíbrio da reação de dissociação (Reação 5.4). Dessa forma é possível escrever as Equações 5.9 e 5.10.

$$
\begin{array}{rlr}
-k_{d}[H F]+k_{i}\left[H^{+}\right]\left[F^{-}\right]= & -k_{1}\left[H^{+}\right]\left\{\left[C_{4} H_{8}-1\right]+\left[C_{4} H_{8}-2\right]+\left[i C_{4} H_{8}\right]\right\}+ \\
& +k_{6}\left\{\left[C_{4} H_{9}^{+}-1\right]+\left[C_{4} H_{9}^{+}-2\right]+\left[i C_{4} H_{9}^{+}\right]\right\}+ \\
& -k_{9}\left[C_{4} H_{8}-2\right]\left[H^{+}\right]-k_{10}\left[i C_{4} H_{8}\right]\left[H^{+}\right] \\
-k_{d}[H F]=k_{i}\left[H^{+}\right]\left[F^{-}\right]= & \left.-k_{11}\left[F^{-}\right]\left\{C_{4} H_{9}^{+}-1\right]+\left[C_{4} H_{9}^{+}-2\right]+\left[i C_{4} H_{9}^{+}\right\}\right\}
\end{array}
$$

A adoção dessa hipótese permite escrever as Equações 5.11 e 5.12 As concentrações de $\mathrm{H}^{+}$e $\mathrm{F}^{-}$são calculadas pela equação de HAMMETT (Equação $5.2)$.

$$
\begin{aligned}
& v_{z} \frac{d\left[H^{+}\right]}{d z}=0 \\
& v_{z} \frac{d\left[F^{-}\right]}{d z}=0
\end{aligned}
$$

Substituindo a Equação 5.9 na Equação 5.6, obtém-se a Equação 5.13, que descreve o consumo de ácido fluorídrico pela reação de alquilação.

$$
v_{z} \frac{d[H F]}{d z}=-k_{11}\left[F^{-}\right]\left\{\left[C_{4} H_{9}^{+}-1\right]+\left[C_{4} H_{9}^{+}-2\right]+\left[i C_{4} H_{9}^{+}\right]\right\}
$$


As olefinas presentes no meio reacional são alimentadas pela base do reator, e consumidas pelas reações de iniciação e propagação. No caso do buteno-2 e ibuteno, também há consumo pelas reações de dimerização. Há uma pequena formação de olefinas dada pela reação de terminação. Tendo isso em vista, o balanço de monômeros é dado pelas Equações 5.14 a 5.16.

Balanço de Olefinas:

$$
\begin{aligned}
& v_{z} \frac{d\left[C_{4} H_{8}-1\right]}{d z}=-k_{1}\left[H^{+}\right]\left[C_{4} H_{8}-1\right]+ \\
& -k_{2}\left[C_{4} H_{8}-1\right]\left\{\left[C_{4} H_{9}^{+}-1\right]+\left[C_{4} H_{9}^{+}-2\right]+\left[i C_{4} H_{9}^{+}\right]\right\}+ \\
& -k_{3}\left[C_{4} H_{8}-1\right]\left\{\left[D M H^{+}\right]+\left[T M P^{+}\right]\right\}+ \\
& -k_{4}\left[C_{4} H_{8}-1\right]\left\{\left[A P^{+}\right]+\left[A S O^{+}\right]\right\}+ \\
& +k_{6}\left[C_{4} H_{9}^{+}-1\right] \\
& v_{z} \frac{d\left[C_{4} H_{8}-2\right]}{d z}=-k_{1}\left[H^{+}\right]\left[C_{4} H_{8}-2\right]+ \\
& -k_{2}\left[C_{4} H_{8}-2\right]\left\{\left[C_{4} H_{9}^{+}-1\right]+\left[C_{4} H_{9}^{+}-2\right]+\left[i C_{4} H_{9}^{+}\right]\right\}+ \\
& -k_{3}\left[C_{4} H_{8}-2\right]\left\{\left[D M H^{+}\right]+\left[T M P^{+}\right]\right\}+ \\
& -k_{4}\left[C_{4} H_{8}-2\right]\left\{A P^{+}\right]+\left[A S O^{+}\right]+ \\
& +k_{6}\left[C_{4} H_{9}^{+}-2\right]+ \\
& -k_{9}\left[H^{+}\right]\left[C_{4} H_{8}-2\right] \\
& v_{z} \frac{d\left[i C_{4} H_{8}\right]}{d z}=-k_{1}\left[H^{+}\right]\left[i C_{4} H_{8}\right]+ \\
& -k_{2}\left[i C_{4} H_{8}\right]\left\{\left[C_{4} H_{9}^{+}-1\right]+\left[C_{4} H_{9}^{+}-2\right]+\left[i C_{4} H_{9}^{+}\right]\right\}_{+} \\
& -k_{3}\left[i C_{4} H_{8}\right]\left\{\left[D M H^{+}\right]+\left[T M P^{+}\right]+\right. \\
& \left.-k_{4}\left[i C_{4} H_{8}\right]\left\{A P^{+}\right]+\left[A S O^{+}\right]\right\}+ \\
& +k_{6}\left[i C_{4} H_{9}^{+}\right]+ \\
& -k_{10}\left[H^{+}\right]\left[i C_{4} H_{8}\right]
\end{aligned}
$$


Outro reagente presente no meio reacional é o i-butano. Este é consumido nas reações de transferência de cadeia, que pode ocorrer com qualquer cadeia viva. $\mathrm{Na}$ Reação 5.31, o i-butano é reagente e produto, sendo gerado e consumido na mesma razão molar. Dessa maneira, no balanço, representado pela Equação 5.17, não há nenhuma contribuição dessa reação.

Balanço de i-butano

$$
v_{z} \frac{d\left[i C_{4} H_{10}\right]}{d z}=-k_{5}\left[i C_{4} H_{10}\right]\left\{\begin{array}{l}
{\left[\begin{array}{l}
{\left[C_{4} H_{9}^{+}-1\right]+\left[C_{4} H_{9}^{+}-2\right]+} \\
{\left[D M H^{+}\right]+\left[T M P^{+}\right]+\left[A P^{+}\right]+\left[A S O^{+}\right.}
\end{array}\right\}}
\end{array}\right\}
$$

A protonação da ligação $\mathrm{PI}$ das olefinas gera uma cadeia viva de baixo peso molecular. Estas, por sua vez são consumidas nas reações de propagação, que produz cadeias vivas de maior peso molecular, e transferência de cadeia. As Equações 5.18 e 5.19 apresentam o balanço de $C_{4} H_{9}^{+}-1$ e $C_{4} H_{9}^{+}-2$.

Balanço de Intermediários

$$
\begin{aligned}
v_{z} \frac{d\left[C_{4} H_{9}^{+}-1\right]}{d z}= & +k_{1}\left[C_{4} H_{8}-1\right]\left[H^{+}\right]+ \\
& -k_{2}\left[C_{4} H_{9}^{+}-1\right]\left\{\left[C_{4} H_{8}-1\right]+\left[C_{4} H_{8}-2\right]+\left[i C_{4} H_{8}\right]\right\}+ \\
& -k_{5}\left[C_{4} H_{9}^{+}-1\right]\left[i C_{4} H_{10}\right]+ \\
& -k_{6}\left[C_{4} H_{9}^{+}-1\right]+ \\
& -k_{11}\left[C_{4} H_{9}^{+}-1\right]\left[F^{-}\right] \\
v_{z} \frac{d\left[C_{4} H_{9}^{+}-2\right]}{d z}= & +k_{1}\left[C_{4} H_{8}-2\right]\left[H^{+}\right]+ \\
& -k_{2}\left[C_{4} H_{9}^{+}-2\right]\left[\left[C_{4} H_{8}-1\right]+\left[C_{4} H_{8}-2\right]+\left[i C_{4} H_{8}\right]\right\}+ \\
& -k_{5}\left[C_{4} H_{9}^{+}-2\right]\left[i C_{4} H_{10}\right]+ \\
& -k_{6}\left[C_{4} H_{9}^{+}-2\right]+ \\
& -k_{11}\left[C_{4} H_{9}^{+}-2\right]\left[F^{-}\right]
\end{aligned}
$$


No caso do $i C_{4} H_{9}^{+}$, além da formação por protonação e consumo por propagação e transferência de cadeia, essa última reação também é responsável por sua formação. Dessa maneira, seu balanço no reator pode ser escrito pela Equação 5.20.

Balanço de Intermediários

$$
\begin{array}{rlr}
v_{z} \frac{d\left[i C_{4} H_{9}^{+}\right]}{d z}= & +k_{1}\left[i C_{4} H_{8}\right]\left[H^{+}\right]+ \\
& -k_{2}\left[i C_{4} H_{9}^{+}\right]\left\{\left[C_{4} H_{8}-1\right]+\left[C_{4} H_{8}-2\right]+\left[i C_{4} H_{8}\right]\right\}+ & \\
& -k_{6}\left[i C_{4} H_{9}^{+}\right]+ \\
& -k_{11}\left[i C_{4} H_{9}^{+}\right]\left[F^{-}\right] \\
& +k_{5}\left[i C_{4} H_{10}\right]\left\{\left[C_{4} H_{9}^{+}-1\right]+\left[C_{4} H_{9}^{+}-2\right]+\right. \\
\left.\left[D M H^{+}\right]+\left[T M P^{+}\right]+\left[A P^{+}\right]+\left[A S O^{+}\right]\right\} & 5.20
\end{array}
$$

As cadeias vivas precursoras do alquilado $\left(\mathrm{DMH}^{+}, \mathrm{TMP}^{+}\right)$são formadas e consumidas pelas reações de propagação. Além disso, elas podem ser formadas ou consumidas pelas reações de isomerização. Esses fenômenos ocorrem até que a cadeia viva encontre uma molécula de i-butano, e então, através da reação de transferência de cadeia, se torne uma cadeia morta. $O$ balanço para essas duas moléculas pode ser escrito pelas Equações 5.21 e 5.22 .

$\mathrm{O}$ balanço de cadeias vivas de maior peso molecular $\left(\mathrm{AP}^{+}\right.$e $\left.\mathrm{ASO}^{+}\right)$é mais simples, uma vez que estão envolvidas somente as reações de propagação (formação e consumo) e transferência de cadeia (consumo). Portanto os balanços dessas espécies são dados pelas Equações 5.23 e 5.24. 
Balanço de Intermediários

$$
\begin{aligned}
v_{z} \frac{d\left[D M H^{+}\right]}{d z}= & +k_{2}\left[C_{4} H_{9}^{+}-1\right]\left\{\left[C_{4} H_{8}-1\right]+\left[C_{4} H_{8}-2\right]+\left[i C_{4} H_{8}\right]\right\}+ \\
& +k_{2}\left[C_{4} H_{8}-1\right]\left\{\left[C_{4} H_{9}^{+}-1\right]+\left[C_{4} H_{9}^{+}-2\right]+\left[i C_{4} H_{9}^{+}\right]\right\}+ \\
& -k_{3}\left[D M H^{+}\right]\left\{\left[C_{4} H_{8}-1\right]+\left[C_{4} H_{8}-2\right]+\left[i C_{4} H_{8}\right]\right\}+ \\
& -k_{5}\left[D M H^{+}\right]\left[i C_{4} H_{10}\right]+ \\
& -k_{7}\left[D M H^{+}\right]+ \\
& +k_{8}\left[T M P^{+}\right] \\
v_{z} \frac{d\left[T M P^{+}\right]}{d z}= & k_{2}\left[C_{4} H_{9}^{+}-2\right]\left\{\left[C_{4} H_{8}-2\right]+\left[i C_{4} H_{8}\right]\right\}+ \\
& +k_{2}\left[i C_{4} H_{9}^{+}\right]\left\{\left[C_{4} H_{8}-2\right]+\left[i C_{4} H_{8}\right]\right\}+ \\
& -k_{3}\left[T M P^{+}\right]\left\{\left[C_{4} H_{8}-1\right]+\left[C_{4} H_{8}-2\right]+\left[i C_{4} H_{8}\right]\right\}+ \\
& -k_{5}\left[T M P^{+}\right]\left[i C_{4} H_{10}\right]+ \\
& +k_{7}\left[D M H^{+}\right]+ \\
& -k_{8}\left[T M P^{+}\right]
\end{aligned}
$$

$v_{z} \frac{d\left[A P^{+}\right]}{d z}=+k_{3}\left[D M H^{+}\right]\left[\left[C_{4} H_{8}-1\right]+\left[C_{4} H_{8}-2\right]+\left[i C_{4} H_{8}\right]\right\}+$

$+k_{3}\left[T M P^{+}\right]\left\{\left[C_{4} H_{8}-1\right]+\left[C_{4} H_{8}-2\right]+\left[i C_{4} H_{8}\right]\right\}+$

$-k_{4}\left[A P^{+}\right]\left\{\left[C_{4} H_{8}-1\right]+\left[C_{4} H_{8}-2\right]+\left[i C_{4} H_{8}\right]\right\}+$

$$
-k_{5}\left[A P^{+}\right]\left[i C_{4} H_{10}\right]
$$

$$
\begin{aligned}
v_{z} \frac{d\left[A S O^{+}\right]}{d z}= & +k_{4}\left[A P^{+}\right]\left\{\left[C_{4} H_{8}-1\right]+\left[C_{4} H_{8}-2\right]+\left[i C_{4} H_{8}\right]\right\}+ \\
& -k_{5}\left[A S O^{+}\right]\left[i C_{4} H_{10}\right]
\end{aligned}
$$


Os produtos (cadeias mortas) obtidos ao final do reator são formados pelas reações de transferência de cadeia. A exceção é o di-metil-hexano (DMH), que também é formado pelas reações de dimerização do buteno-2 e i-buteno. A formação desses produtos é representada pelas Equações 5.25 a 5.29 .

Balanço de Produtos Formados

$$
\begin{array}{lr}
v_{z} \frac{d\left[n C_{4} H_{10}\right]}{d z}=+k_{5}\left[i C_{4} H_{10}\right]\left\{\left[C_{4} H_{9}^{+}-1\right]+\left[C_{4} H_{9}^{+}-2\right]\right\} & \text { Equação } \\
v_{z} \frac{d[D M H]}{d z}= & +k_{5}\left[D M H^{+}\right]\left[i C_{4} H_{10}\right]+\frac{1}{2} k_{9}\left[C_{4} H_{8}-2\right]\left[H^{+}\right]+ \\
& +\frac{1}{2} k_{10}\left[i C_{4} H_{8}\right]\left[H^{+}\right]
\end{array}
$$

O fluoreto orgânico é formado pela reação do ânion $\mathrm{F}^{-}$com os isômeros do $\mathrm{C}_{4} \mathrm{H}_{9}^{+}$. Seu balanço é dado pela Equação 5.30 .

\section{Balanço de Fluoreto Orgânico}

$$
v_{z} \frac{d\left[C_{4} H_{9} F\right]}{d z}=+k_{11}\left[F^{-}\right]\left\{\left[C_{4} H_{9}^{+}-1\right]+\left[C_{4} H_{9}^{+}-2\right]+\left[i C_{4} H_{9}^{+}\right]\right\}
$$

O balanço de energia ao longo do reator considerou a hipótese de reator tubular adiabático, isto é, sem troca de calor entre o reator e o meio ao seu redor. Além disso, considerou-se que o calor de reação da etapa de propagação é muito superior aos demais, portanto todo o calor liberado pela reação de alquilação se deve a esta etapa. Como o excesso de i-butano e ácido no reator são bastante elevados, considerou-se que as propriedades físicas do meio (calor específico e densidade) são constantes ao longo do reator. Desta maneira, o balanço de energia pode ser representado pela Equação 5.31. 


$$
\rho v_{z} c_{p} \frac{d T}{d z}=\sum_{i=1}^{11}\left(-\Delta H_{i}\right) r_{i}
$$

Equação 5.31

Onde: ri: cinética da reação das etapas de propagação; $\Delta H_{i}$ : entalpia das reações de propagação; $\rho$ : densidade do meio reacional; $c_{p}$ : calor específico do meio reacional.

Dados experimentais mostram que um aumento de $20^{\circ} \mathrm{C}$ na temperatura de reação (de $10^{\circ} \mathrm{C}$ para $30^{\circ} \mathrm{C}$ ) implica na perda de apenas 0.5 pontos de octanagem, na redução de $1 \%$ na produção de TMP, com o respectivo aumento de $1 \%$ no rendimento de DMH (HUTSON e HAYS, 1977). O incremento de temperatura no reator de alquilação é da ordem de $5^{\circ} \mathrm{C}$, saindo de aproximadamente $30^{\circ} \mathrm{C}$ para $35^{\circ} \mathrm{C}$. Portanto, considerou-se que as constantes cinéticas apresentadas no modelo não variam com a temperatura na faixa de operação do reator.

\subsection{Calibração do Modelo Fenomenológico}

O modelo obtido anteriormente foi calibrado utilizando os dados experimentais disponíveis em literatura (HUTSON e HAYS, 1977 e HUTSON, 1978). Este processo constituiu-se em encontrar um conjunto de constantes cinéticas $\left(k_{1} \quad \begin{array}{lll}k_{11}\end{array}\right)$ que minimiza o somatório dos erros quadráticos entre o resultado real e o predito pelo modelo, como apresentado na Equação 5.32.

$$
\min _{k_{1}, \ldots, k_{11}} F_{o b j}=\sum_{i}^{\text {componentes }}\left(y_{i}-\hat{y}_{i}\right)^{2}
$$

Equação 5.32

Onde: $F_{o b j}$ : função objetivo a ser minimizada $\mathrm{y}_{\mathrm{i}}$ : valor real da propriedade $\mathrm{i}$

$\hat{y}_{i}$ : valor predito pelo modelo para propriedade $\mathrm{i}$

$\mathrm{Na}$ Equação 5.32, a propriedade avaliada é a vazão volumétrica de cada componente na corrente de saída do reator, sendo eles: buteno-1, buteno-2, ibuteno, i-butano, DMH, TMP, AP e ASO. Foram utilizados 4 pontos apresentados no trabalho de HUTSON, 1978, gerando um total de 32 dados disponíveis para o ajuste dos parâmetros do modelo (12 no total). 
Os resultados para as constantes cinéticas do modelo estão apresentados na forma logarítmica, e em relação ao valor obtido para a constante cinética da reação de transferência de cadeia $\left(k_{5}\right)$, conforme a Equação 5.33 .

$$
\tilde{k}_{i}=\frac{\log k_{i}}{\log k_{5}}
$$

Equação 5.33

A Tabela 5.1 apresenta os valores obtidos para as constantes cinéticas durante a etapa de calibração do modelo. Os resultados mostram que a reação de protonação da ligação $\mathrm{PI}$ das olefinas é extremamente rápida, podendo ser considerada instantânea. Para se obter o perfil de rendimentos e qualidade de produto, as reações de inserção da primeira unidade monomérica (propagação), transferência de cadeia e isomerização também são bastante rápidas, porém, em menor grau que a protonação.

Tabela 5.1: Constantes cinéticas para o modelo proposto.

\begin{tabular}{lc}
\hline \multicolumn{1}{c}{ Reação } & $\tilde{k}_{i}$ \\
\hline Iniciação $\left(\mathrm{k}_{1}\right)$ & $8,75 \mathrm{E}+00$ \\
Propagação $\left(\mathrm{k}_{2}\right)$ & $1,90 \mathrm{E}+00$ \\
Propagação $\left(\mathrm{k}_{3}\right)$ & $8,46 \mathrm{E}-01$ \\
Propagação $\left(\mathrm{k}_{4}\right)$ & $7,69 \mathrm{E}-02$ \\
Transferência de Cadeia $\left(\mathrm{k}_{5}\right)$ & $1,00 \mathrm{E}+00$ \\
Terminação $\left(\mathrm{k}_{6}\right)$ & $1,15 \mathrm{E}-03$ \\
Dimerização buteno-2 $\left(\mathrm{k}_{7}\right)$ & $1,92 \mathrm{E}+00$ \\
Dimerização i-buteno $\left(\mathrm{k}_{8}\right)$ & $2,66 \mathrm{E}-02$ \\
Isomerização DMH ${ }^{+}\left(\mathrm{k}_{9}\right)$ & $1,92 \mathrm{E}+00$ \\
Isomerização TMP $\left(\mathrm{k}_{10}\right)$ & $1,92 \mathrm{E}+00$ \\
Formação Fluoreto Orgânico $\left(\mathrm{k}_{11}\right)$ & $5,58 \mathrm{E}-01$ \\
\hline
\end{tabular}

Como esperado, a cinética da reação de propagação depende do tamanho da cadeia polimérica. As reações que levam a formação de subprodutos, isso é, ASO e fluoreto orgânico são mais lentas que as primeiras etapas da oligomerização. Esse comportamento é compatível com o observado na unidade industrial. As reações de terminação também são bastante lentas quando comparadas às demais. 
A adesão dos dados experimentais aos obtidos pelo modelo foi averiguada através de gráficos de comparação direta e de paridade. Também foi realizada a análise dos resíduos. Os resíduos são obtidos através da Equação 5.34.

$$
\text { Resíduo }_{i}=y_{i}-\hat{y}_{i}
$$

A primeira propriedade avaliada foi $\mathrm{o}$ rendimento em alquilado, cuja comparação direta é apresentada na Figura 5.4. Nota-se que os dados experimentais e os resultados obtidos pelo modelo divergem em comportamento: enquanto o primeiro apresenta uma queda de rendimento conforme a relação entre o i-butano e a olefina aumenta, o segundo apresenta um aumento.

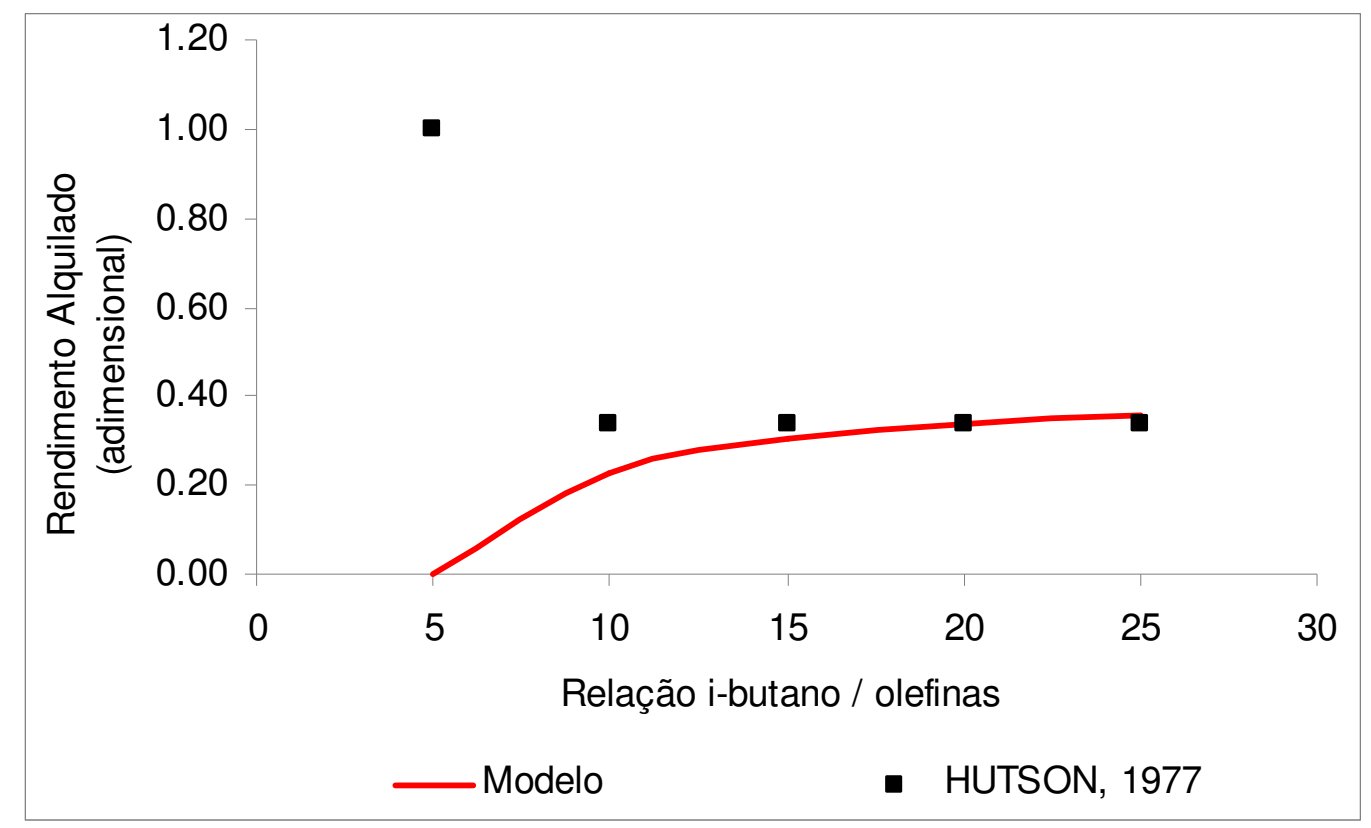

Figura 5.4: Comparação do rendimento em alquilado obtido experimentalmente e através do modelo proposto.

Os dados experimentais utilizados (HUTSON e HAYS, 1977) mostram que conforme a relação entre $\mathrm{o}$ i-butano e as olefinas presente na carga da unidade aumenta, há uma redução no rendimento em frações pesadas do alquilado, assim como uma redução no rendimento ASO (subproduto). Também é apresentado um aumento no consumo de i-butano no reator. Esse comportamento é incompatível com a redução de rendimento apresentada pelos dados experimentais. 
Em uma unidade industrial, quando a relação entre o i-butano e a olefina é reduzida a valores abaixo de 9, o rendimento em alquilado é bastante reduzido, enquanto que o rendimento em ASO aumenta exponencialmente. Nessas condições a unidade deve ser parada. Esses dados corroboram com a hipótese que o ponto experimental para relação 5:1 (primeiro ponto à esquerda no gráfico da Figura 5.4) não representa a realidade. Dessa forma, não é possível afirmar que os resultados do modelo não representam os fenômenos que ocorrem no reator da unidade.

Devido ao resultado explicado acima, a análise do gráfico de paridade (Figura 5.5 A) e a dos resíduos (Figura 5.5 B) ficou prejudicada. Como os dados reportados na literatura mostram que o rendimento de alquilado fica constante após determinada relação entre o i-butano e a olefina, observa-se uma concentração de pontos ao redor dessa concentração.

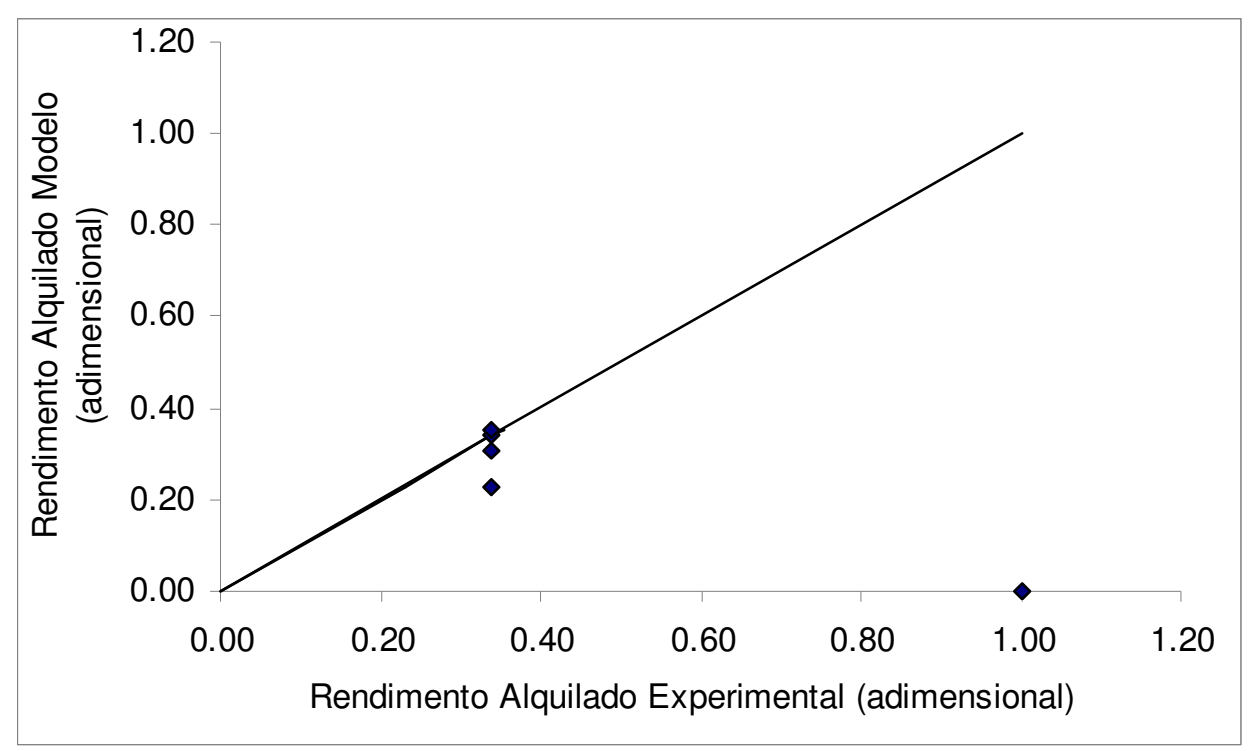

Figura 5.5A: Gráfico de paridade para o rendimento em alquilado. 


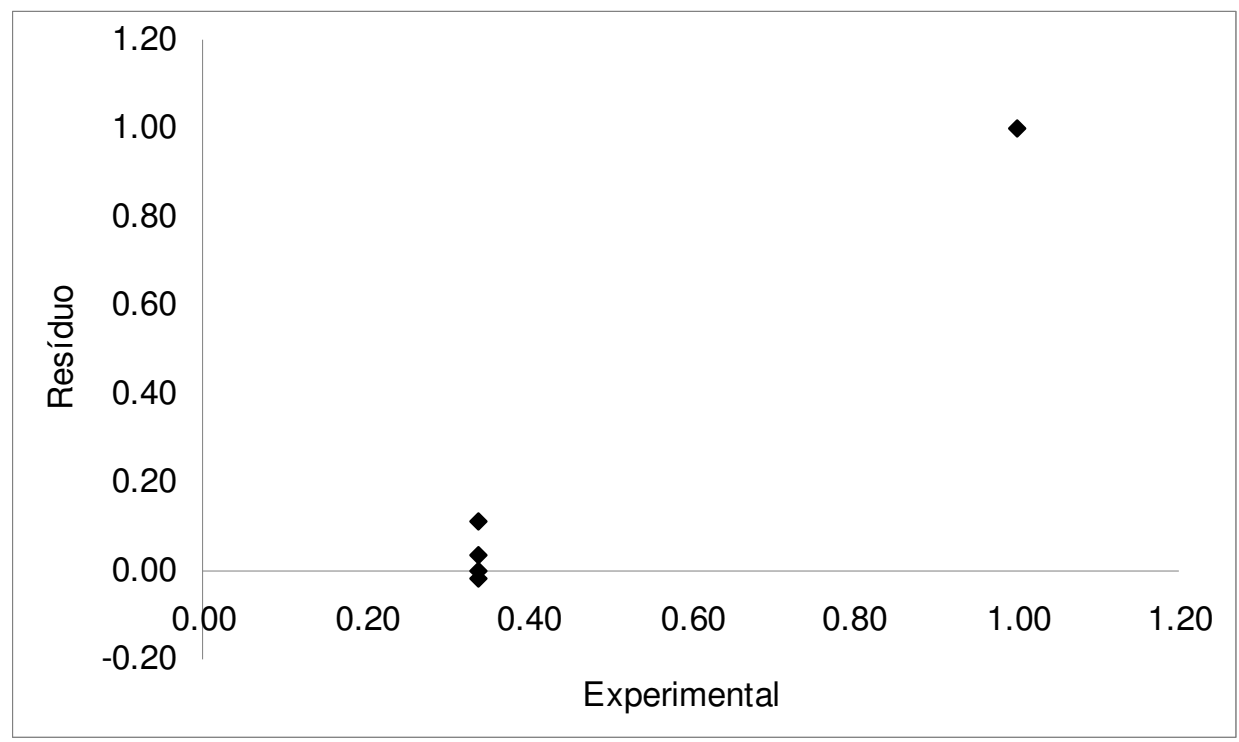

Figura 5.5B: Análise de resíduos para o rendimento em alquilado.

Outra grandeza avaliada foi o rendimento em frações pesadas do alquilado, conhecida como alquilado pesado. A Figura 5.6 apresenta a comparação direta entre os dados experimentais e os obtidos através do modelo. A análise da figura permite afirmar que o modelo conseguiu representar a queda do rendimento em frações pesadas conforme a relação entre o i-butano e a olefina aumenta na entrada do reator.

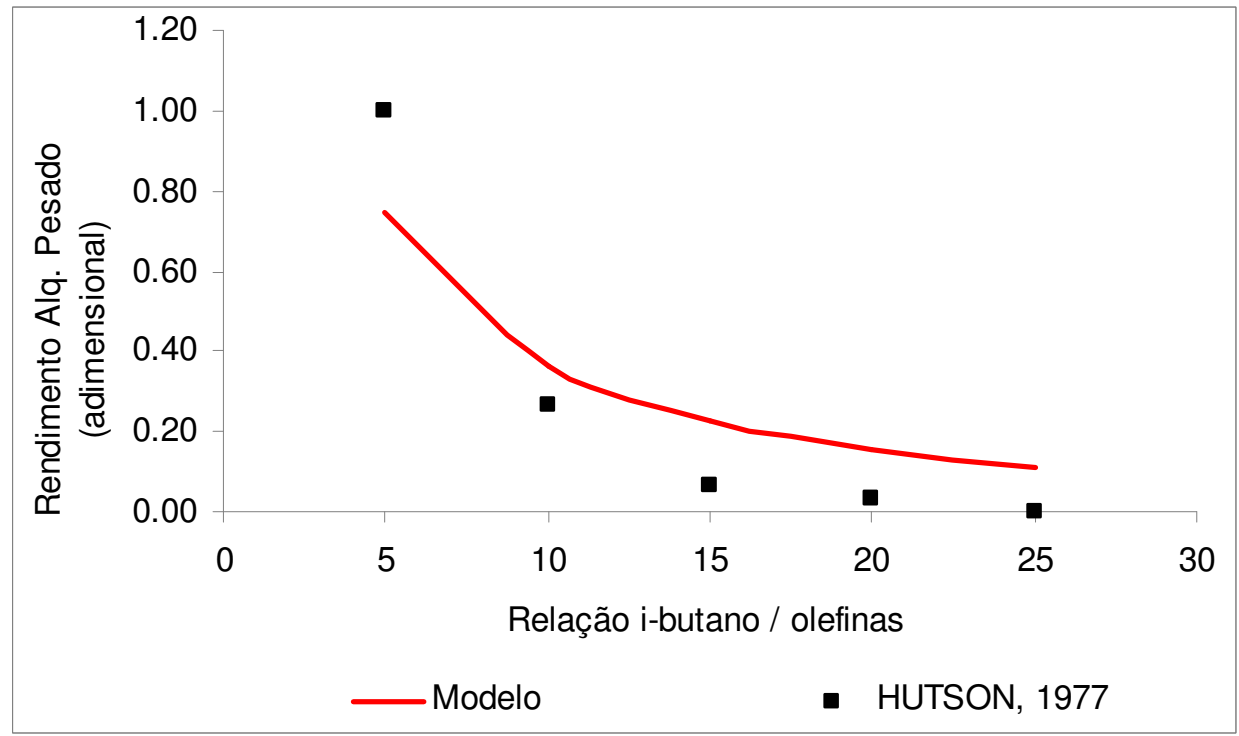

Figura 5.6: Comparação do rendimento em alquilado pesado obtido experimentalmente e pelo modelo proposto. 
O gráfico de paridade para o rendimento de alquilado pesado, apresentado na Figura 5.7, mostra que o modelo tende a estimar um rendimento pouco superior ao observado experimentalmente. Tais dados são corroborados pela análise dos resíduos, Figura 5.8.

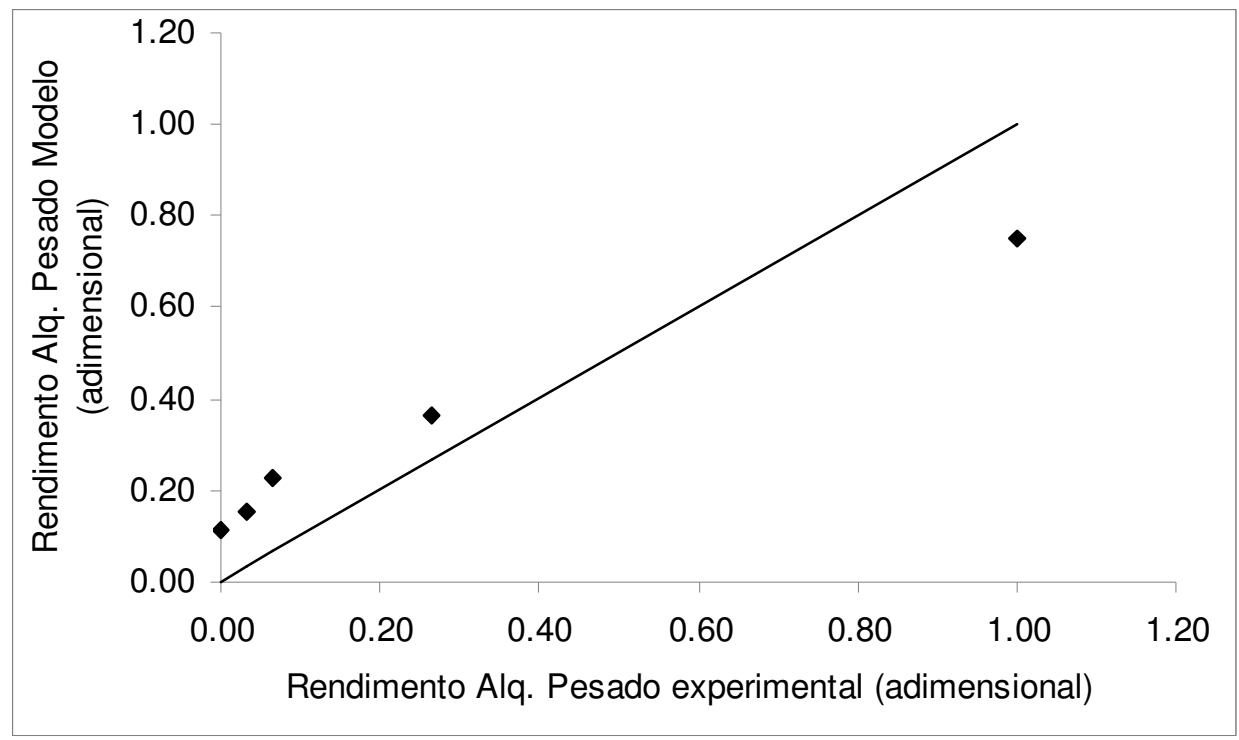

Figura 5.7: Gráfico de paridade para o rendimento em alquilado pesado.

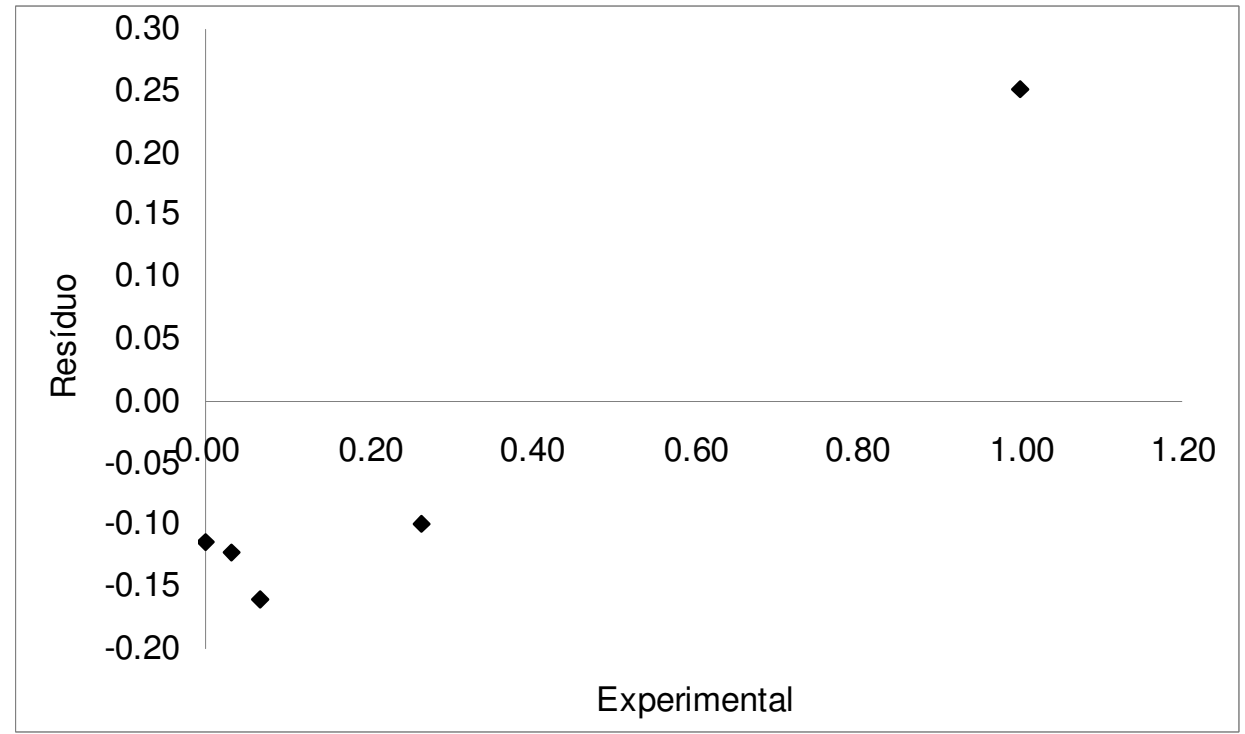

Figura 5.8: Análise de resíduos para o rendimento em alquilado pesado.

O rendimento em subproduto (ASO) é apresentado na Figura 5.9. Assim como o rendimento em frações pesadas do alquilado, o rendimento em ASO tende a reduzir conforme a relação i-butano/olefina aumenta. 


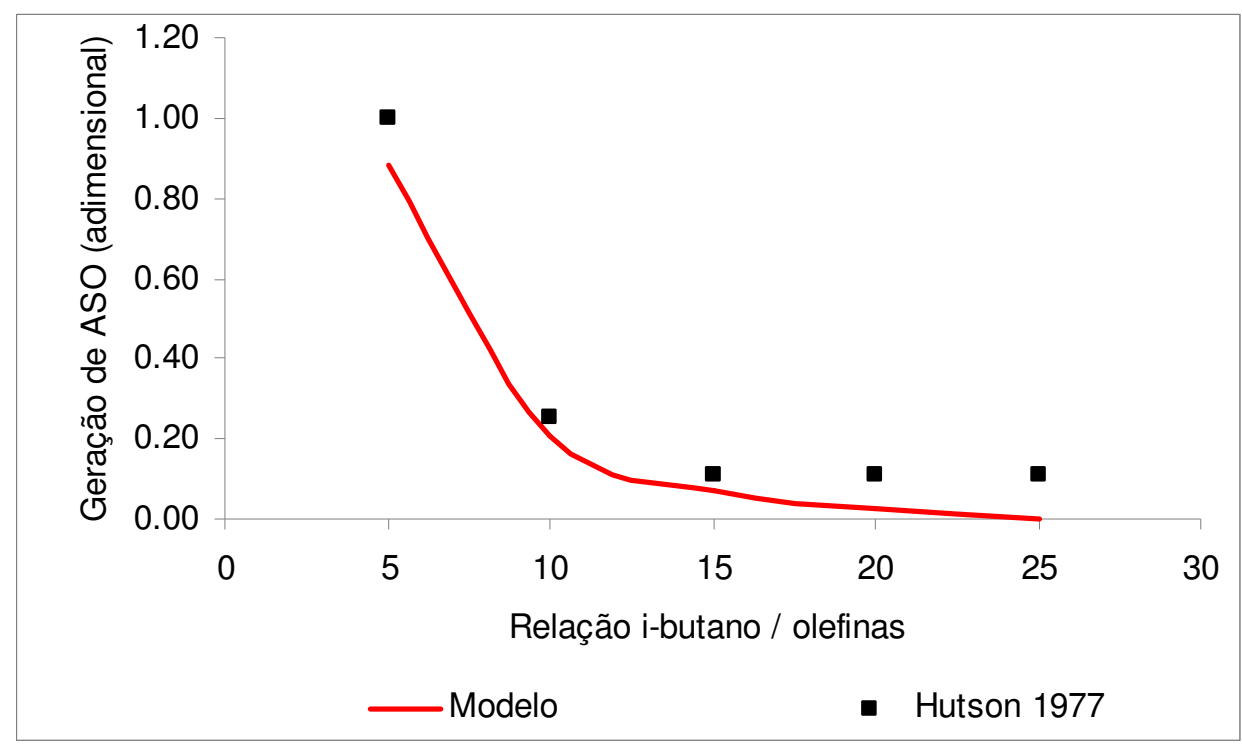

Figura 5.9: Comparação do rendimento em subproduto obtido experimentalmente e pelo modelo proposto.

Os dados experimentais mostram que quando o excesso de i-butano é muito grande o rendimento em ASO tende a um valor baixo e constante, enquanto o modelo ainda prevê uma pequena redução. Apesar dessa diferença, o gráfico de paridade, Figura 5.10, mostra que o modelo consegue estimar de maneira eficiente $o$ rendimento em ASO.

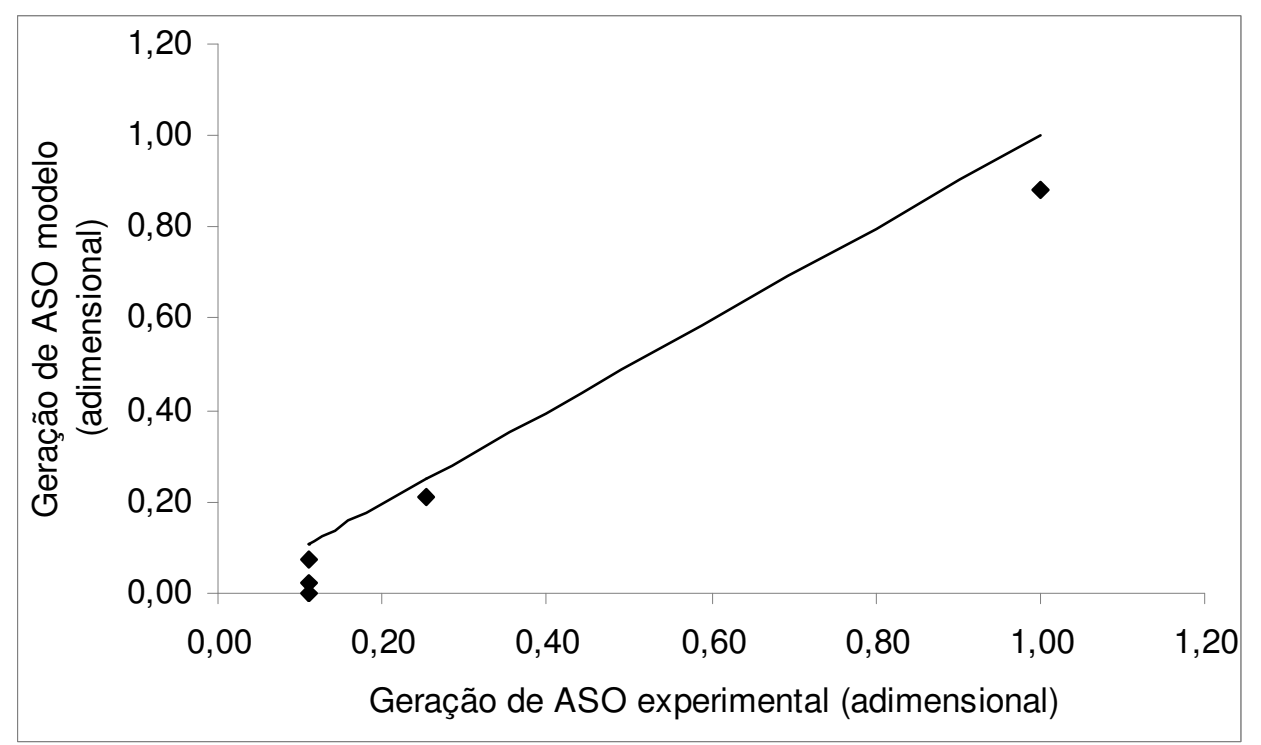

Figura 5.10: Gráfico de paridade para o rendimento em subproduto (ASO). 
A análise de resíduos, apresentada na Figura 5.11, mostra que o resíduo não é função do valor do dado experimental.

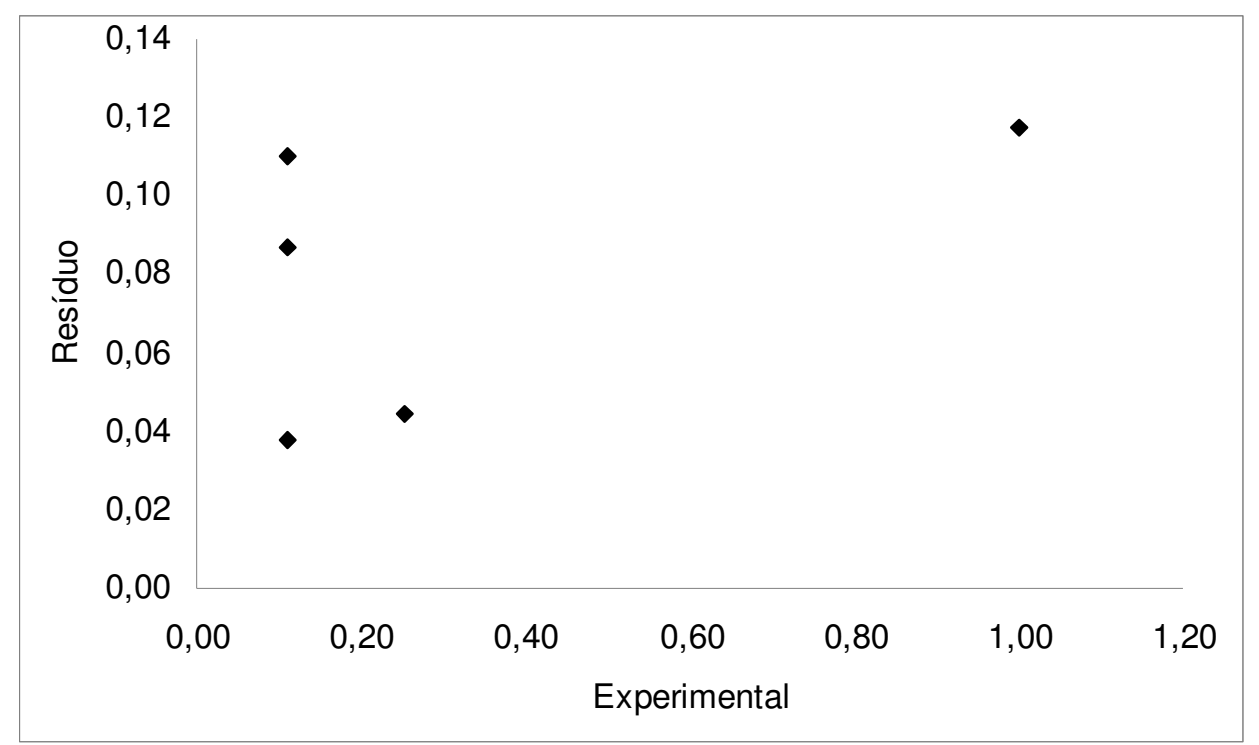

Figura 5.11: Análise de resíduos para o rendimento em subproduto (ASO).

Como foram adotadas as hipóteses de não haver reações de craqueamento e existirem apenas olefinas com 4 átomos de carbono no meio reacional, o modelo matemático obtido considera que o alquilado é composto apenas TMP, DMH e frações pesadas (AP). Os dados experimentais mostram que esses compostos respondem por algo entre $85 \%$ e $95 \%$ da composição do alquilado, dependendo das condições operacionais da unidade. O restante é dividido por pentanos (C5), hexanos (C6) e heptanos (C7). A Figura 5.12 apresenta a comparação entre os dados experimentais e os obtidos pelo modelo para a relação entre o TMP e o DMH. 


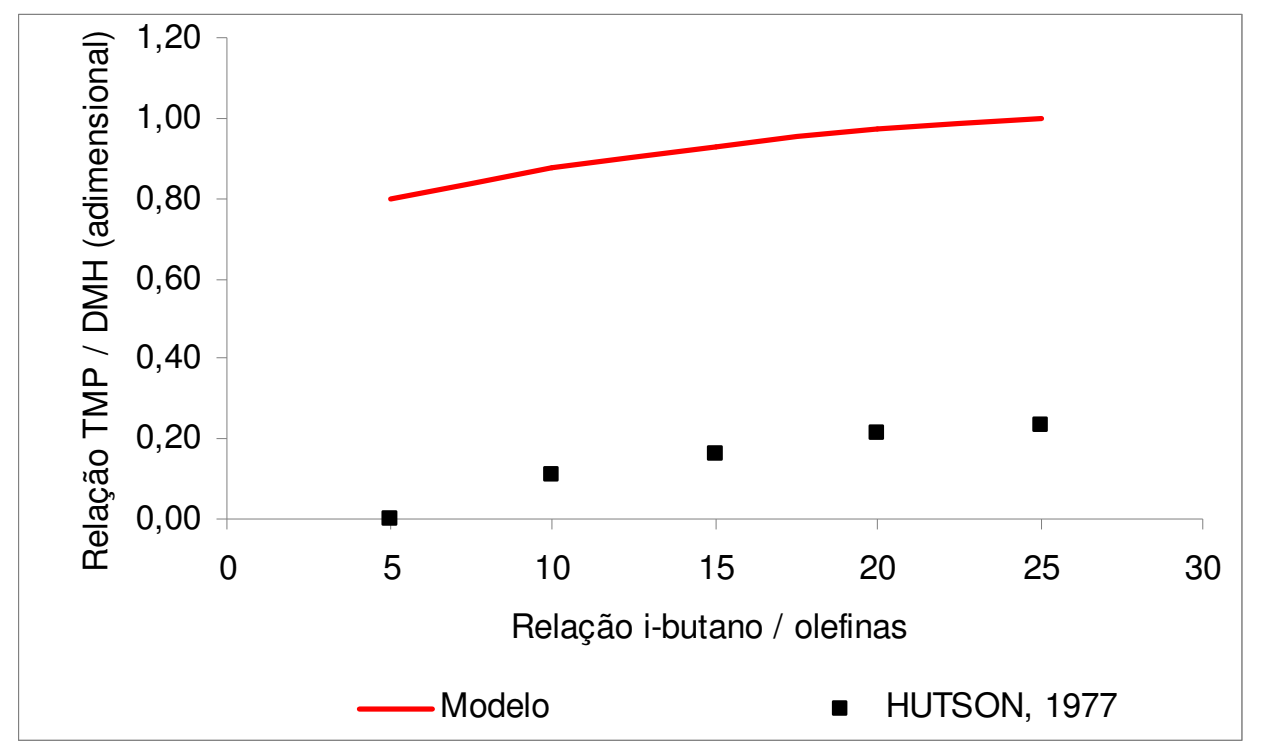

Figura 5.12: Comparação da relação entre TMP e DMH obtido experimentalmente e pelo modelo proposto.

Os resultados mostram que o modelo tende a prever uma formação muito superior de TMP em relação ao observado experimentalmente. A Figura 5.13, que apresenta o gráfico de paridade, comprova os resultados acima apresentados. Esse fato pode ser explicado pela obtenção de uma constante cinética de isomerização do $\mathrm{TMP}^{+}$inferior a real. Esse fenômeno pode ter ocorrido devido à adoção de limite superior, na etapa de calibração do modelo, para todas as constantes cinéticas envolvidas. Dessa maneira, as reações de isomerização que ocorrem no reator devem ser extremamente rápidas (instantâneas), com constante cinética da mesma ordem de grandeza da observada para as reações de iniciação de cadeia. 


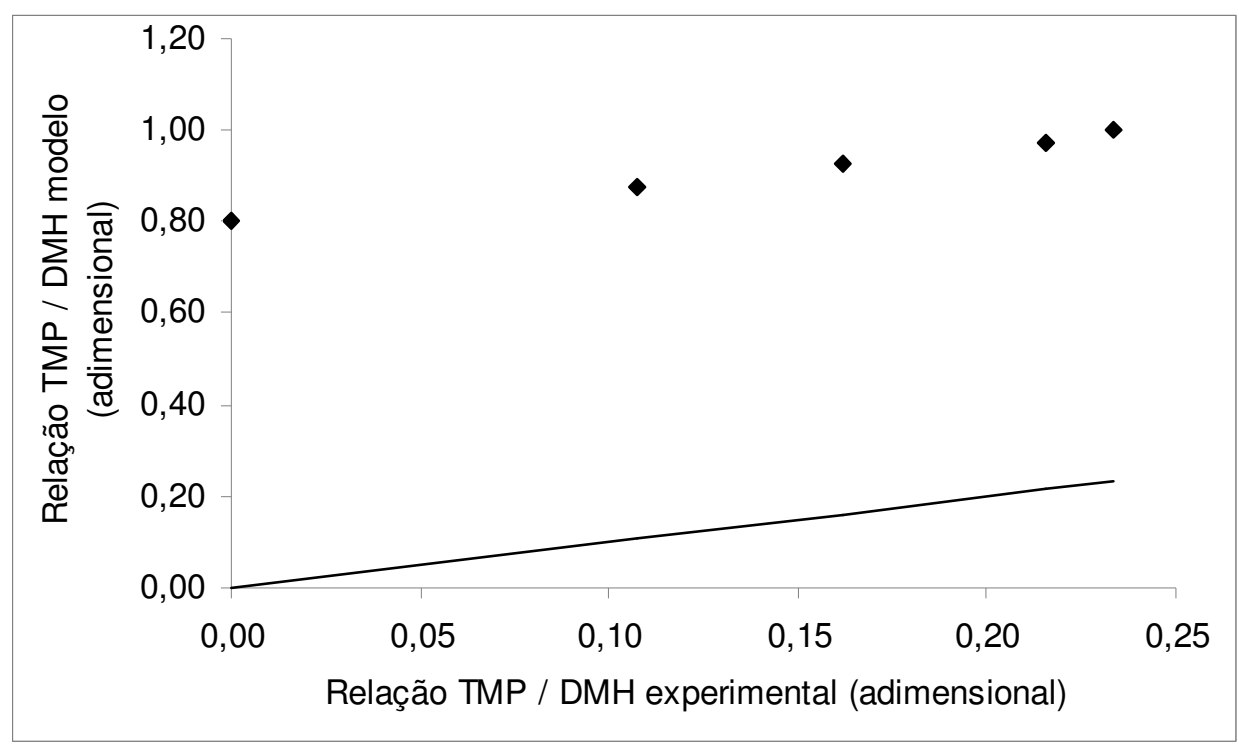

Figura 5.13: Gráfico de paridade para a relação entre TMP e DMH.

A análise dos resíduos, apresentados na Figura 5.14, permite afirmar que o resíduo do modelo não é função do dado experimental. Esse resultado demonstra que a hipótese da isomerização do $\mathrm{TMP}^{+}$ser instantânea pode explicar a diferença entre os dados experimentais e os obtidos pelo modelo.

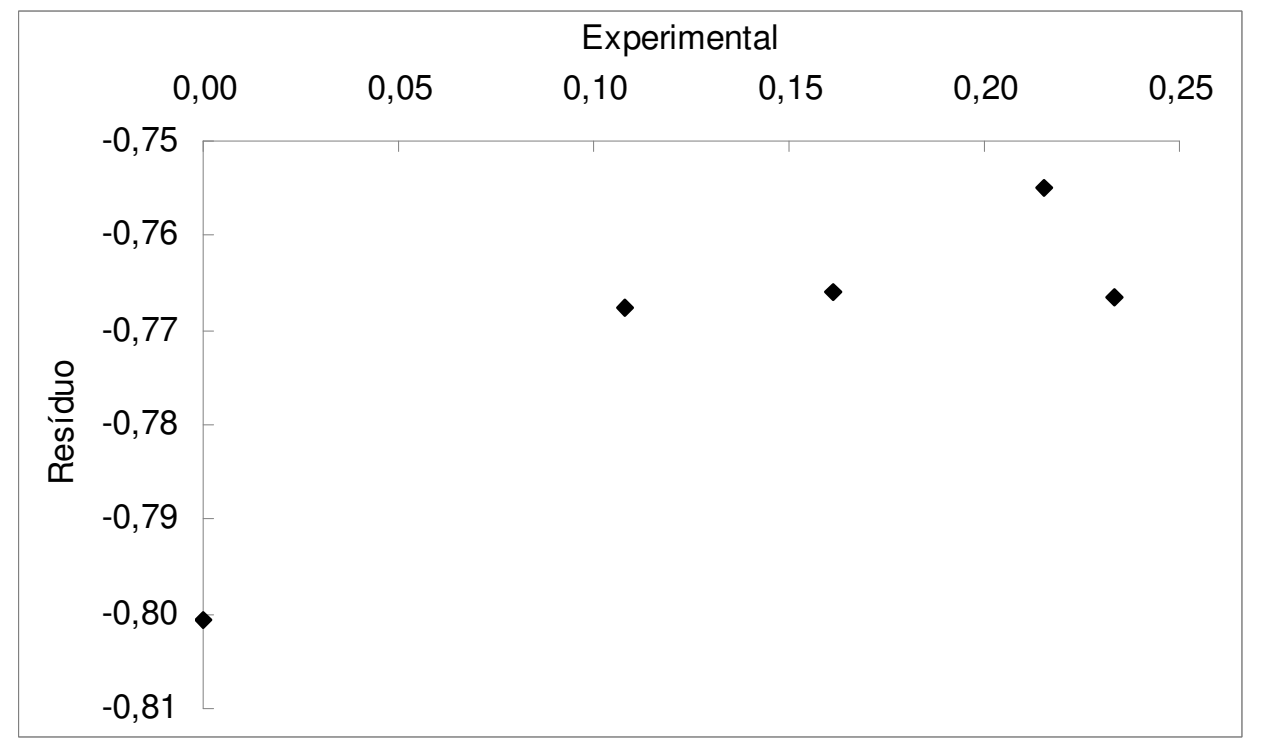

Figura 5.14: Análise de resíduos para a relação entre TMP e DMH.

De posse de todos os resultados obtidos durante a etapa de calibração do modelo cinético, é possível afirmar que este foi capaz de representar em grande parte os fenômenos que ocorrem no processo de alquilação. 


\subsection{Comparação com Dados Industriais}

Nesta seção são apresentadas as comparações entre condições operacionais normalmente vivenciadas em uma unidade de alquilação e os respectivos resultados dados pelo modelo matemático calibrado. Para realizar tal comparação foram coletados, na unidade industrial em estudo, dados das correntes de carga, ácido circulante e produtos da unidade. A maneira como estes dados foram coletados e tratados está apresentada na seção de metodologia deste trabalho. Os dados necessários para realizar a comparação estão apresentados na Tabela 5.2.

Tabela 5.2: Dados industriais necessários para avaliar adesão do modelo matemático.

\begin{tabular}{ccc}
\hline Carga do reator & Ácido circulante & Saída do reator \\
\hline Vazão & & Vazão \\
Temperatura & Temperatura & Temperatura \\
Composição & Composição & Composição \\
\hline
\end{tabular}

Todas as variáveis relacionadas à carga da unidade e ao ácido circulante são consideradas independentes. Também é uma variável independente a temperatura de saída do reator. Esse conjunto constitui os dados de entrada do modelo.

As variáveis dependentes são a vazão e composição de saída do reator, assim como a vazão de ácido circulante. Esses são os dados de saída do modelo. $A$ partir desses é possível calcular o consumo de reagentes (olefinas e i-butano); a vazão e composição do alquilado obtido, assim como o rendimento em frações pesadas do alquilado. Como a unidade não possui medição de vazão de ASO, vazão de ácido circulante (obtida pelo balanço de energia no sistema reacional), ou estimativa em tempo real do consumo de ácido, essas grandezas não puderam ser avaliadas.

Todos os resultados do modelo cinético foram obtidos utilizando-se os parâmetros cinéticos apresentados na etapa de calibração, sem nenhum ajuste adicional de parâmetros com os dados da unidade industrial. 
Em um reator industrial de alquilação toda a olefina alimentada é convertida a produtos e subprodutos da reação. A Figura 5.12 apresenta o gráfico de paridade para o consumo de olefinas verificado na unidade e o apresentado pelo modelo. Os resultados mostram uma boa aproximação do modelo aos dados industriais.

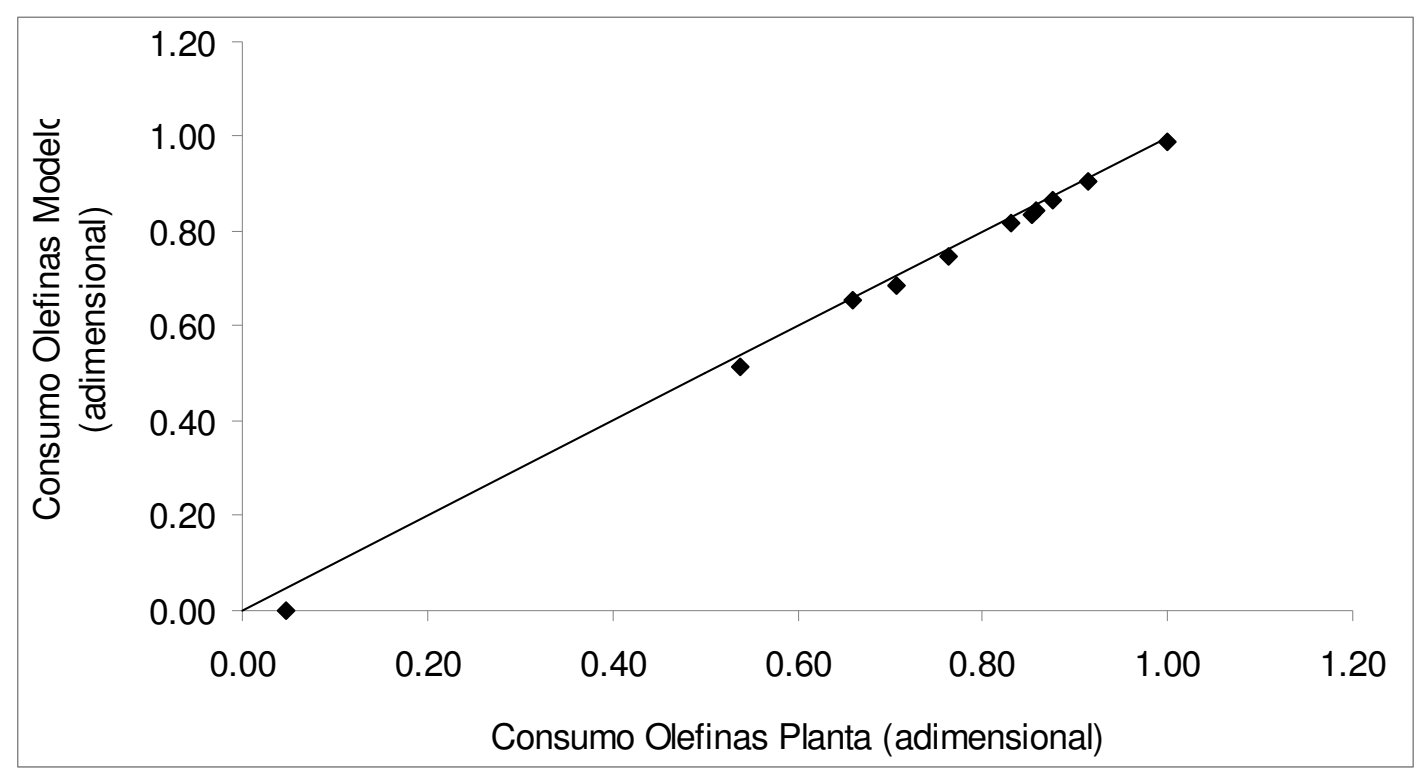

Figura 5.12: Gráfico de paridade para o consumo de olefinas: comparação entre dados industriais e modelo proposto.

O consumo de i-butano apresentado pelo modelo é levemente superior ao observado na unidade industrial, como apresentado pela Figura 5.13. Esse resultado pode ser explicado pela não inclusão, no modelo, da reação de isomerização dos carbocátions com 4 átomos e carbono e cadeia normal à sua forma ramificada. Essa isomerização faz com que menos i-butano seja consumido pelas reações de transferência de cadeia para os $\mathrm{nC}^{+}$. Essa etapa de reação é bastante citada na literatura como responsável pela baixa produção de n-butano das unidades de alquilação (HUTSON e HAYS, 1977). O modelo utilizado não considerou a possibilidade da reação de transferência de cadeia do carbocátion para o ASO, hipótese amplamente discutida na literatura (ALBRIGHT et al, 1988), uma vez que estudos mostram a existência de ligações $\mathrm{PI}$ na estrutura do ASO (ALBRIGHT, 2002;). Quando o ASO atua como agente de transferência de cadeia, o consumo de i-butano é reduzido. 


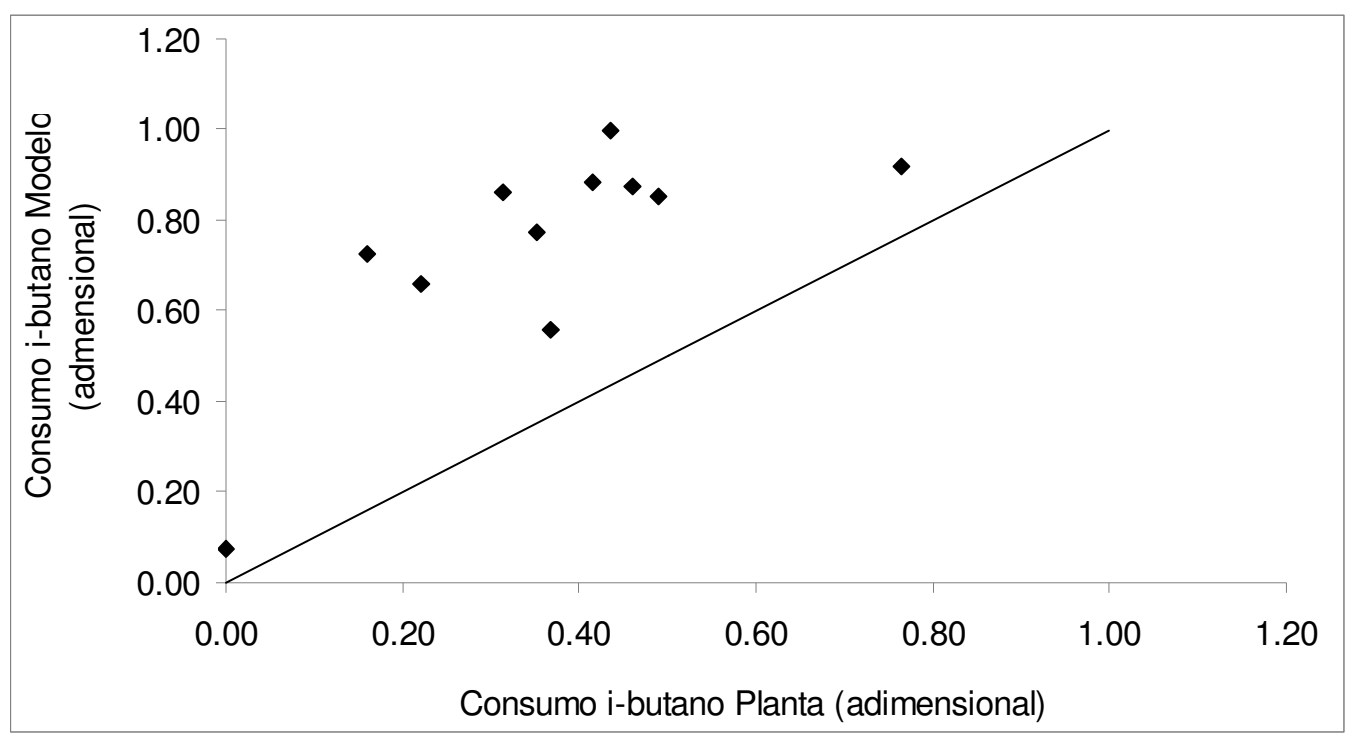

Figura 5.13: Gráfico de paridade para o consumo de i-butano: comparação entre dados industriais e modelo proposto.

Avaliando a diferença entre o valor da unidade industrial e o obtido pelo modelo mostra que não há correlação entre o resíduo e o dado industrial, como mostrado na Figura 5.14. Esse fato corrobora com a avaliação de que é necessária uma etapa de isomerização de carbocátions.

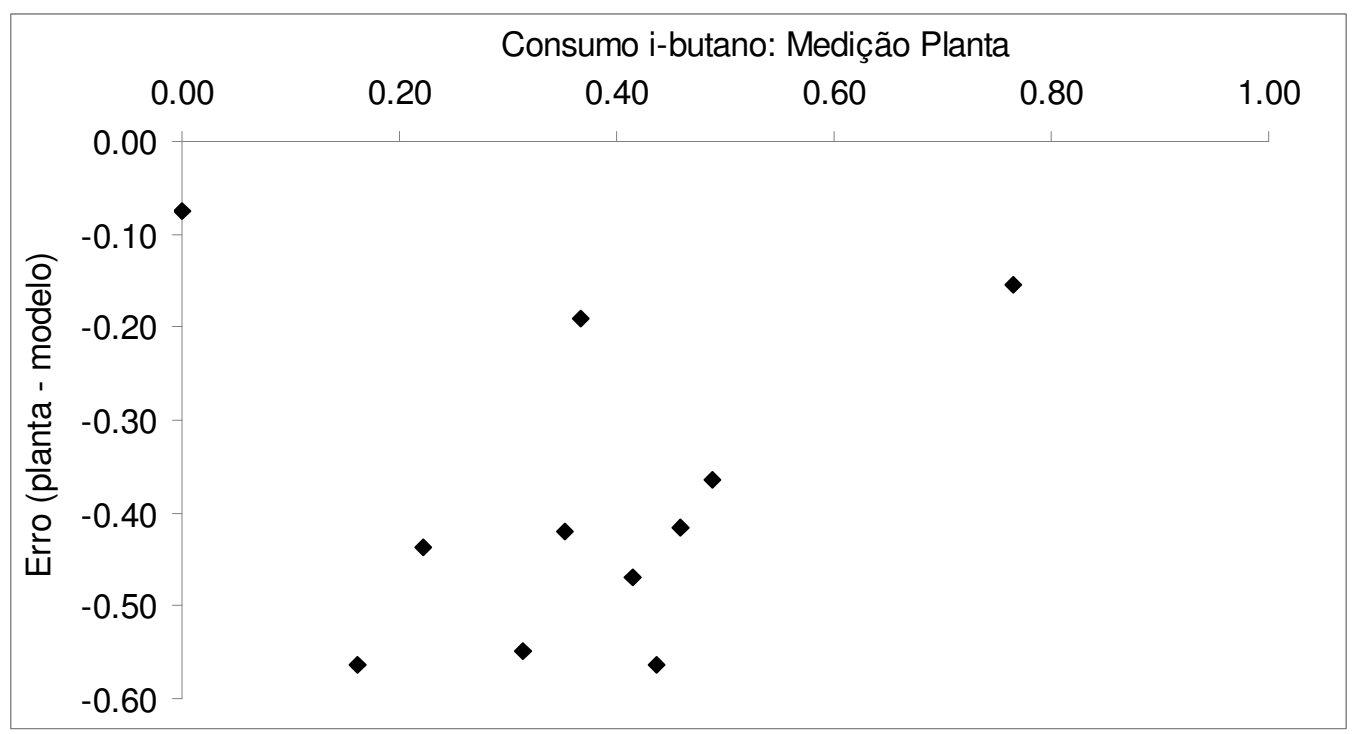

Figura 5.14: Análise de resíduos para a o consumo de i-butano: comparação entre dados industriais e dados obtidos pelo modelo proposto. 
O rendimento de alquilado dado pelo modelo apresentou boa correlação com os dados industriais, conforme mostrado na Figura 5.15.

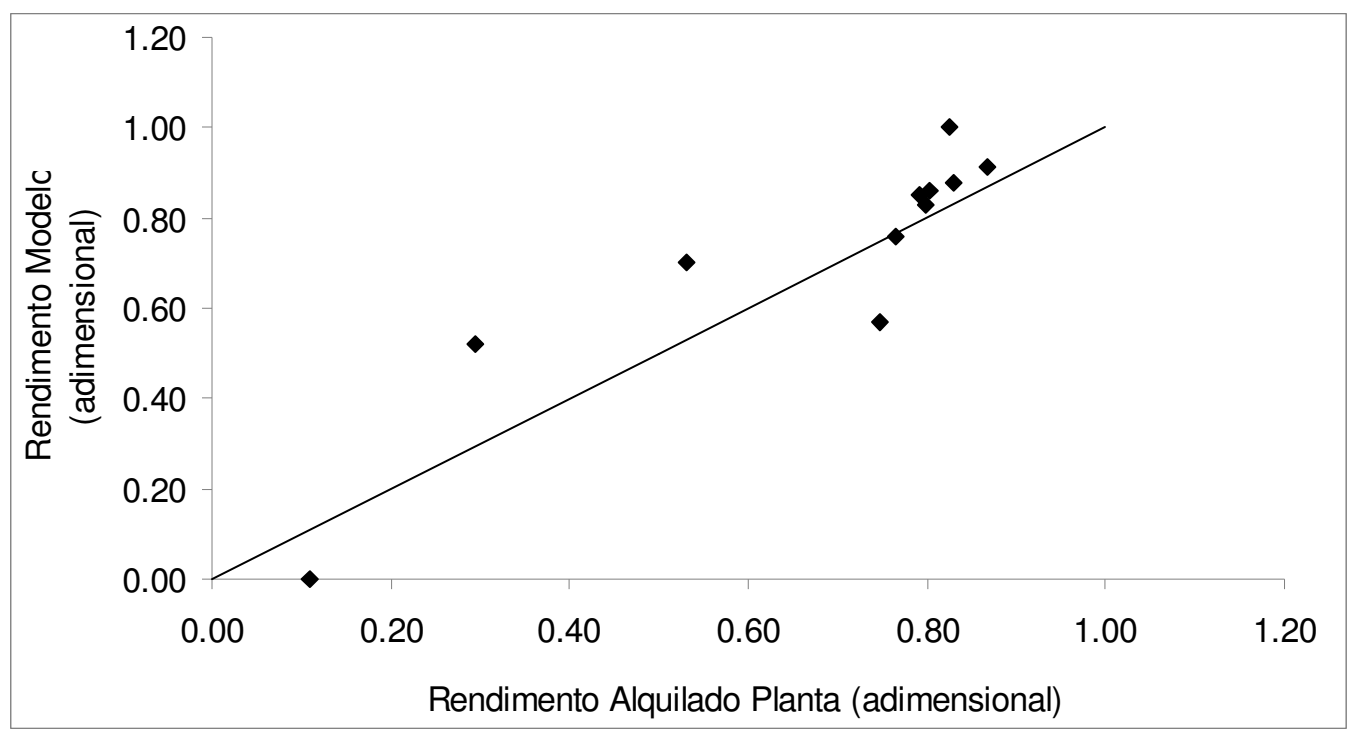

Figura 5.15: Gráfico de paridade para o rendimento em alquilado: comparação entre dados industriais e modelo proposto.

A composição do alquilado obtido, assim como na etapa de calibração, mostrou que o modelo tende a superestimar a produção de TMP, em detrimento ao de DMH, como mostrado na Figura 5.16. Esses resultados reforçam a hipótese que a constante cinética para a reação de isomerização do $\mathrm{TMP}^{+}$está subestimada.

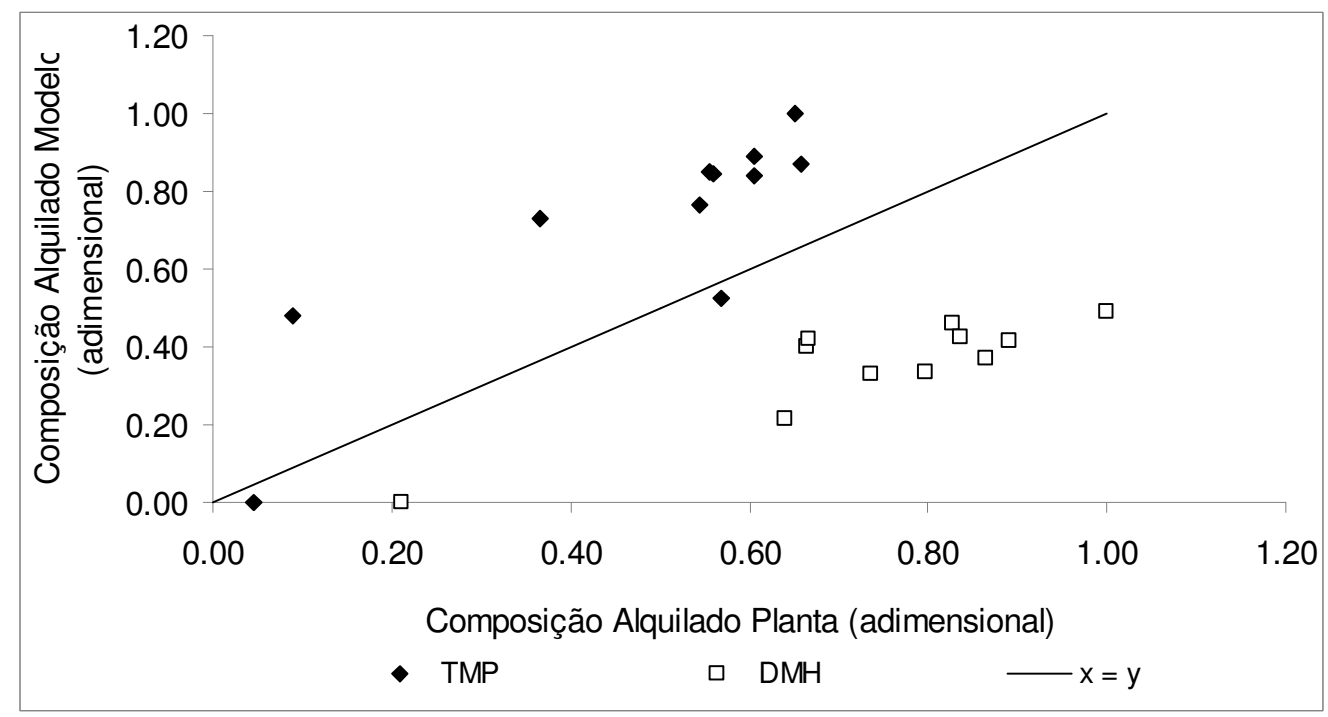

Figura 5.16: Gráfico de paridade para a composição do alquilado: comparação entre dados industriais e modelo proposto. 
A comparação entre os dados industriais e os obtidos pelo modelo para o rendimento em frações pesadas (alquilado pesado) está apresentado na Figura 5.17. Este resultado mostra que o modelo não foi capaz de representar o que de fato ocorreu na unidade industrial.

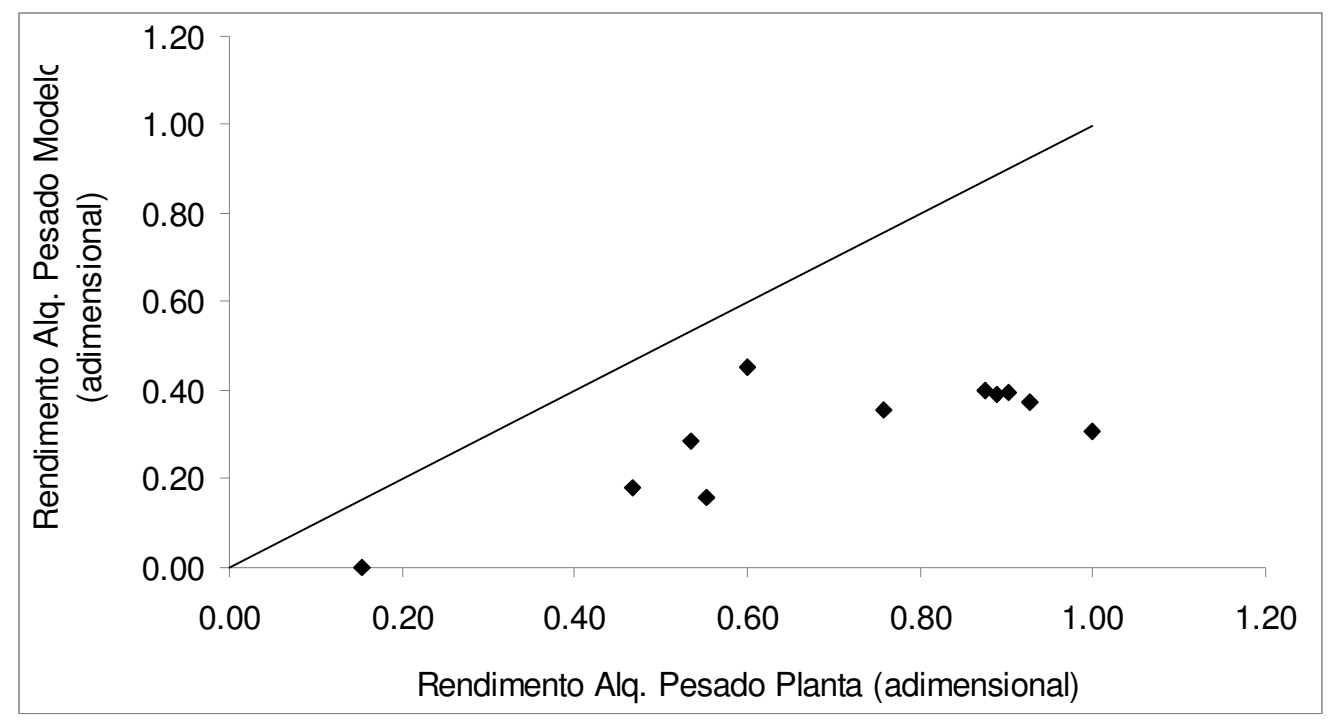

Figura 5.17: Gráfico de paridade para o rendimento em frações pesadas do alquilado: comparação entre dados industriais e modelo proposto.

A análise dos resíduos, apresentada na Figura 5.18, mostra uma forte relação entre o valor medido na planta e o erro apresentado pelo modelo. Isso indica que algum fenômeno que ocorre na planta não está representado pelo modelo. Três hipóteses simplificadoras que foram adotadas na fase de modelagem têm impacto direto no rendimento de frações pesadas.

A primeira desconsiderou a presença de butadieno e enxofre, contaminantes que reconhecidamente aumentam o rendimento em frações pesadas (AP) e subprodutos (ASO). O butadieno, por apresentar duas insaturações, ao entrar no meio reacional, irá reagir com duas outras moléculas de monômeros, levando a formação de frações pesadas (em um primeiro momento) e ASO (em uma segunda reação de propagação). 


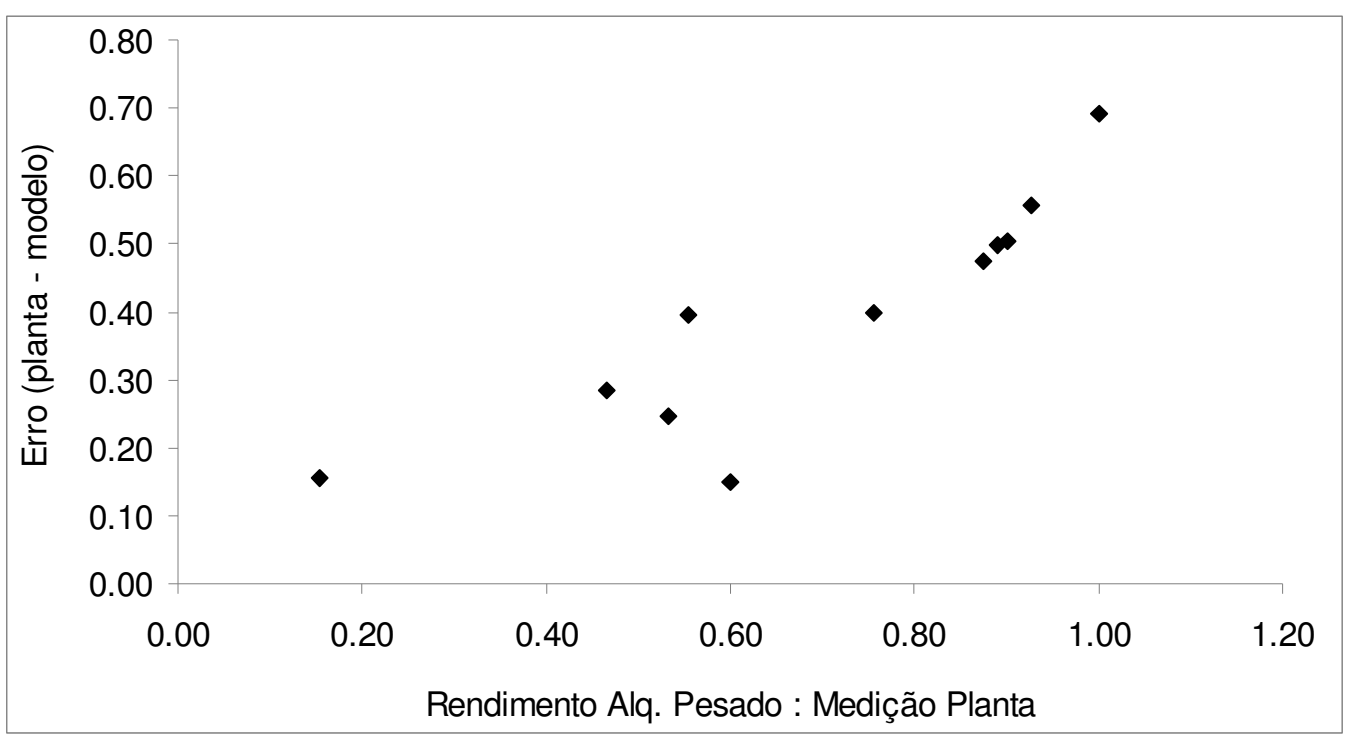

Figura 5.18: Análise de resíduos para a o rendimento em alquilado pesado: comparação entre dados industriais e dados obtidos pelo modelo proposto.

A segunda hipótese adotada foi que todo o hidrocarboneto que entra no reator está imediatamente disponível para reagir, isto é, foi desconsiderado o fato de que a reação ocorre na fase ácida e depende da quantidade de hidrocarbonetos solubilizados no HF. Quando o ácido apresenta elevada concentração de ASO em sua composição, pouco i-butano é transferido da fase hidrocarboneto para a fase ácida, reduzindo a atuação da etapa de transferência de cadeia, permitindo assim a formação de moléculas mais pesadas.

Por último considerou-se que a temperatura não tem influência sobre a cinética da reação. Essa aproximação foi baseada em dados de literatura, que mostram que a temperatura pouco afeta a octanagem do alquilado. Avaliando os dados industriais, nota-se uma tendência de aumento nas frações pesadas quando a temperatura de reação aumenta (Figura 5.19). 


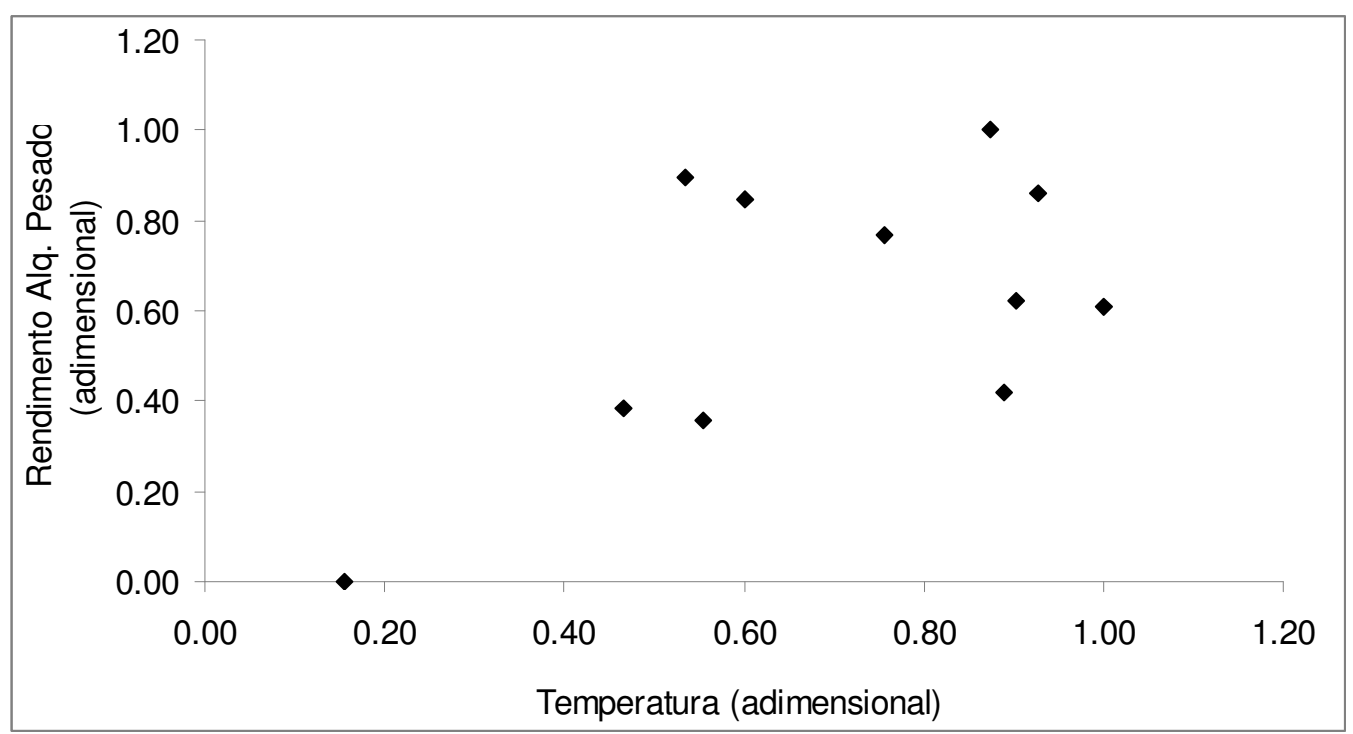

Figura 5.19: Dependência do rendimento em alquilado pesado com a temperatura: dados industriais.

Ao contrário do observado com os dados industriais, o modelo teve boa aderência aos dados de rendimento em frações pesadas apresentados na literatura. Esses dados foram coletados utilizando carga isenta de contaminantes, com composição constante para o HF (para cada grupo de experimentos) e temperatura controlada. Tendo isso em mente, infere-se que ambas as hipóteses adotadas na construção do modelo estão impactando seu desempenho.

Analisando todas as respostas do modelo às condições observadas na planta, é possível afirmar que seu desempenho foi positivo no que tange consumo de reagentes e rendimento em alquilado. Apesar da composição do alquilado não representar adequadamente os dados industriais, a correção do modelo pode ser feita através da alteração das constantes das reações de isomerização. O modelo não foi capaz de representar adequadamente o rendimento em frações pesadas do alquilado (conhecidas como alquilado pesado). Como a unidade industrial não possui medição de geração de ASO, não foi possível comparar os resultados do modelo com os dados da planta para esta variável.

Além das análises de consumo de matérias primas, rendimento e qualidade dos produtos e produção de subprodutos, o modelo apresentado permite avaliar o perfil de concentração dos reagentes, intermediários e produtos ao longo do reator. 
Também é possível visualizar o perfil de temperatura ao longo do riser da unidade. Estes dados estão apresentados na Figura 5.20.
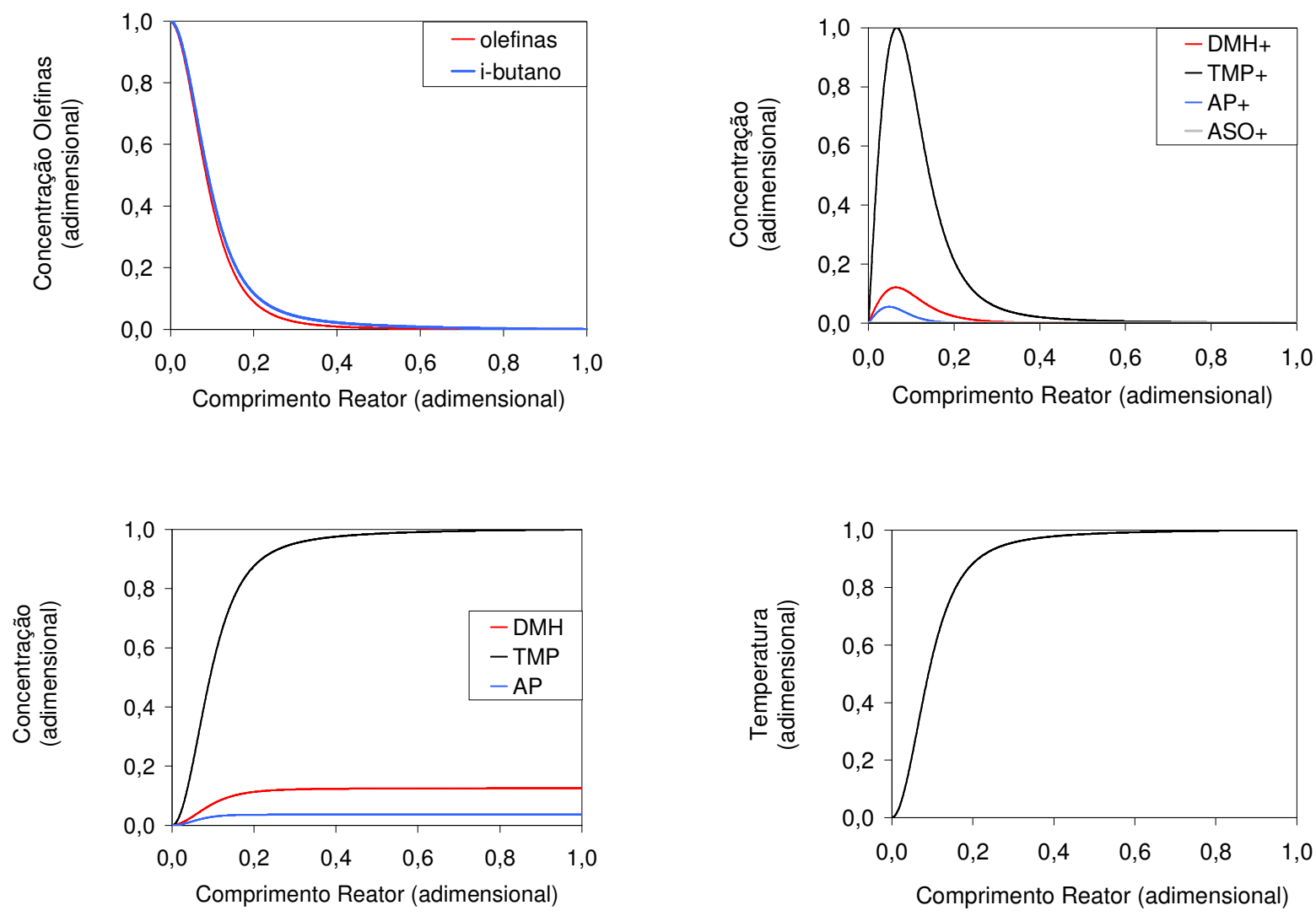

Figura 5.20: Perfil ao logo do reator para: (a) concentração de reagentes; (b) concentração de intermediários; (c) concentração de produtos e subprodutos; (d) temperatura.

A análise da Figura 5.20 permite afirmar que a maior parte das reações de alquilação ocorre nos primeiros $20 \%$ do reator e praticamente estão encerradas quando aproximadamente $60 \%$ do reator são percorridos. Isso se deve ao fato das reações de oligomerização ocorrerem de forma extremamente rápida, levando ao quase completo consumo das olefinas antes da metade do reator. Esse dado leva a crer que é possível aumentar a produtividade do reator adicionando uma nova entrada de butenos em um ponto intermediário do mesmo.

Segundo a empresa projetista da unidade em estudo, unidades de alquilação que apresentam o sistema de alimentação de reagentes somente pela base do reator, como é o caso aqui relatado, permitem a inserção de uma nova entrada de olefinas em um ponto intermediário do reator, fazendo com que a produção total de 
alquilado aumente. Portanto, os dados obtidos pelo modelo conseguem explicar o motivo de tal alteração no projeto, assim como permite localizar o melhor ponto para inserir a modificação do projeto. 


\section{SUGESTÕES DE TRABALHOS FUTUROS}

Os resultados acima apresentados mostram que a principal restrição ao uso do modelo foi o rendimento em frações pesadas, cujos dados ficam abaixo do observado na unidade industrial. A explicação para esse fenômeno baseou-se no fato do modelo desconsiderar os seguintes efeitos: presença de contaminantes na carga, influência da temperatura na cinética de reação e a presença de ASO no HF. Esses efeitos podem ser amenizados caso as seguintes ações sejam tomadas:

- Incluir os efeitos do enxofre no mecanismo cinético;

- Considerar cinética da reação dependente da temperatura;

- Inserir no mecanismo cinético a presença do butadieno.

Embora bastante conhecidos os efeitos do enxofre em unidades industriais de alquilação, os mecanismos pelos quais ele atua são pouco elucidados na literatura, portanto de difícil implementação em um modelo fenomenológico.

A inserção do efeito da temperatura na cinética da reação pode ser implementada utilizando-se, por exemplo, a equação de Arrhenius, apresentada na Equação 6.1.

$k_{i}=k_{i 0} \exp (-E A i / R T)$

Equação 6.1

Onde: $\mathrm{k}_{\mathrm{i}}$ : constante cinética da reação $\mathrm{i}$; $\mathrm{k}_{\mathrm{i} 0}$ : constante pré exponencial para a reação $\mathrm{i}$;

$E A_{i}$ : energia de ativação para a reação i;

$\mathrm{R}$ : constante dos gases;

T: temperatura.

A presença do butadieno no reator de alquilação altera bastante o mecanismo cinético das reações de alquilação, uma vez que ele apresenta duas insaturações em sua estrutura. Caso apenas uma insaturação seja protonada por vez, o número de intermediários presentes no reator aumenta exponencialmente, tornando muito complexa a modelagem por componente. Pode-se considerar a hipótese que ambas insaturações presentes no butadieno reagem ao mesmo tempo nas etapas de 
protonação (iniciação) e propagação Dessa maneira a modelagem por componente pode ser mantida.

Outra diferença observada entre os resultados do modelo e a resposta dos dados industriais foi o consumo de i-butano. O modelo previu um consumo ligeiramente superior ao observado na unidade industrial. Esse comportamento foi explicado pela ausência da etapa da isomerização dos carbocátions com 4 carbonos de cadeia normal a sua forma ramificada e pela ausência do mecanismo de transferência de cadeia do carbocátion para ASO. Também foi observado que o rendimento em TMP apresentado pelo modelo é superior ao apresentado pela unidade industrial. O contrário foi verificado para o DMH. A explicação adotada para esse comportamento foi o fato da constante cinética para a reação de isomerização do $\mathrm{TMP}^{+}$estar subestimada. Para corrigir essas observações, as seguintes alterações no modelo devem ser efetuadas:

- Inserir reação de isomerização do $\mathrm{nC}^{+}$a $\mathrm{iC}^{+}$no mecanismo de reação;

- Realizar nova calibração do modelo considerando que as reações de isomerização podem ser instantâneas;

- Prever mecanismo de transferência de cadeia para ASO.

O modelo matemático obtido considera que o alquilado é composto apenas TMP, DMH e frações pesadas (AP) devido à adoção das seguintes hipóteses: não haver reações de craqueamento e existirem apenas olefinas com 4 átomos de carbono no meio reacional. Para melhorar a representação da composição do alquilado pelo modelo, deve-se considerar as seguintes alterações:

- Caracterizar frações pesadas como hidrocarbonetos com 9 a 15 átomos de carbono, ao invés de agrupar sob um único produto (AP);

- Inserir reações de craqueamento.

A adoção das propostas acima apresentadas no mecanismo cinético utilizado para se obter o modelo fenomenológico da unidade resulta nas Reações 6.1 a 6.38. 
Dissociação do Ácido Fluorídrico

$H F \stackrel{k_{d} ; k_{i}}{\longleftrightarrow} H^{+}+F^{-}$

Reação 6.1

Iniciação

$\mathrm{C}_{n} \mathrm{H}_{2 n}+\mathrm{H}^{+} \stackrel{k_{1}}{\longrightarrow} \mathrm{C}_{n} \mathrm{H}_{2 n+1}^{+}$

Reação 6.2

$\mathrm{C}_{4} \mathrm{H}_{6}+2 \mathrm{H}^{+} \stackrel{k_{1}}{\longrightarrow} \mathrm{C}_{4} \mathrm{H}_{8}^{+2}$

Reação 6.3

Onde: $C_{n} H_{2 n}$ são buteno-1, buteno-2 e i-buteno.

A presença do butadieno no meio reacional e a possibilidade de moléculas grandes se quebrarem em outras moléculas menores alteram fortemente a etapa de propagação. As Reações 6.4 a 6.17 apresentam as reações envolvidas na etapa de propagação.

Propagação

$C_{n} H_{2 n+1}^{+}+C_{k} H_{2 k} \stackrel{k_{i}}{\longrightarrow} C_{j} H_{2 j+1}^{+}$

Reação 6.4

$\mathrm{C}_{n} \mathrm{H}_{2 n}^{+2}+\mathrm{C}_{k} \mathrm{H}_{2 k} \stackrel{k_{i}}{\longrightarrow} \mathrm{C}_{j} \mathrm{H}_{2 j}^{+2}$

Reação 6.5

$\mathrm{C}_{n} \mathrm{H}_{2 n-1}^{+3}+\mathrm{C}_{k} \mathrm{H}_{2 k} \stackrel{k_{i}}{\longrightarrow} \mathrm{C}_{j} \mathrm{H}_{2 j-1}^{+3}$

Reação 6.6

$C_{n} H_{2 n-2}^{+4}+C_{k} H_{2 k} \stackrel{k_{i}}{\longrightarrow} C_{j} H_{2 j-2}^{+4}$

Reação 6.7

$\mathrm{C}_{4} \mathrm{H}_{6}+\mathrm{C}_{n} \mathrm{H}_{2 n+1}^{+}+\mathrm{C}_{k} \mathrm{H}_{2 k+1}^{+} \stackrel{k_{i}}{\longrightarrow} \mathrm{C}_{j} \mathrm{H}_{2 j}^{+2}$

Reação 6.8

$\mathrm{C}_{4} \mathrm{H}_{6}+\mathrm{C}_{n} \mathrm{H}_{2 n+1}^{+}+\mathrm{C}_{k} \mathrm{H}_{2 k}^{+2} \stackrel{k_{i}}{\longrightarrow} \mathrm{C}_{j} H_{2 j-1}^{+3}$

Reação 6.9

$\mathrm{C}_{4} \mathrm{H}_{6}+\mathrm{C}_{n} \mathrm{H}_{2 n+1}^{+}+\mathrm{C}_{k} \mathrm{H}_{2 k-1}^{+3} \stackrel{k_{i}}{\longrightarrow} \mathrm{C}_{j} H_{2 j-2}^{+4}$

Reação 6.10

$\mathrm{C}_{4} \mathrm{H}_{6}+\mathrm{C}_{n} \mathrm{H}_{2 n+1}^{+}+\mathrm{C}_{k} \mathrm{H}_{2 k-2}^{+4} \stackrel{k_{i}}{\longrightarrow} \mathrm{C}_{j} H_{2 j-3}^{+5}$

Reação 6.11

$\mathrm{C}_{4} \mathrm{H}_{6}+\mathrm{C}_{n} \mathrm{H}_{2 n}^{+2}+\mathrm{C}_{k} \mathrm{H}_{2 k}^{+2} \stackrel{k_{i}}{\longrightarrow} \mathrm{C}_{j} \mathrm{H}_{2 j-2}^{+4}$

Reação 6.12

$\mathrm{C}_{4} \mathrm{H}_{6}+\mathrm{C}_{n} \mathrm{H}_{2 n}^{+2}+\mathrm{C}_{k} \mathrm{H}_{2 k-1}^{+3} \stackrel{k_{i}}{\longrightarrow} \mathrm{C}_{j} H_{2 j-3}^{+5}$

Reação 6.13

$\mathrm{C}_{4} \mathrm{H}_{6}+\mathrm{C}_{n} \mathrm{H}_{2 n}^{+2}+\mathrm{C}_{k} \mathrm{H}_{2 k-2}^{+4} \stackrel{k_{i}}{\longrightarrow} C_{j} H_{2 j-4}^{+6}$

Reação 6.14

$\mathrm{C}_{4} \mathrm{H}_{6}+\mathrm{C}_{n} \mathrm{H}_{2 n-1}^{+3}+\mathrm{C}_{k} \mathrm{H}_{2 k-1}^{+3} \stackrel{k_{i}}{\longrightarrow} \mathrm{C}_{j} H_{2 j-4}^{+6}$

Reação 6.15

$\mathrm{C}_{4} \mathrm{H}_{6}+\mathrm{C}_{n} \mathrm{H}_{2 n-1}^{+3}+\mathrm{C}_{k} \mathrm{H}_{2 k-2}^{+4} \stackrel{k_{i}}{\longrightarrow} \mathrm{C}_{j} \mathrm{H}_{2 j-5}^{+7}$

Reação 6.16

$\mathrm{C}_{4} \mathrm{H}_{6}+\mathrm{C}_{n} \mathrm{H}_{2 n-2}^{+4}+\mathrm{C}_{k} \mathrm{H}_{2 k-2}^{+4} \stackrel{k_{i}}{\longrightarrow} \mathrm{C}_{j} \mathrm{H}_{2 j-6}^{+8}$

Reação 6.17 
Como a hipótese da cadeia longa não pode ser adotada para o processo de alquilação, a constante cinética da etapa de propagação $\left(k_{i}\right)$ depende do número de carbonos (J) da cadeia formada. A relação está apresentada nas Equações 6.2 a 6.4.

$$
\begin{aligned}
& i=2 \text { para } 5 \leq j<10 \\
& i=3 \text { para } 10 \leq j<16 \\
& i=4 \text { para } j \geq 16
\end{aligned}
$$

Equação 6.2

Equação 6.3

Equação 6.4

Quando o tamanho de cadeia atinge 16 átomos de carbono, pode-se considerar que não há mais formação de produtos de interesse, alquilado e suas frações pesadas. Nesse caso, gera-se apenas o subproduto da reação, o ASO. Estudos mostram que o ASO tem diferentes tamanhos de cadeia, dispostos em estruturas cíclicas (MIRON e LEE, 1963). Para representar a formação de cadeias cíclicas, toda molécula de hidrocarboneto com mais de 16 átomos de carbono e com pares de cargas positivas disponíveis para reagir irá formar um composto cíclico. As Equações 6.5 a 6.12 mostram a representação do ASO para o modelo proposto.

$$
\begin{array}{lr}
C_{j} H_{2 j+1}^{+} \approx A S O^{+} & \text {Equação 6.5 } \\
C_{j} H_{2 j}^{+2} \approx A S O(1 N) & \text { Equação 6.6 } \\
C_{j} H_{2 j-1}^{+3} \approx A S O(1 N)^{+} & \text {Equação 6.7 } \\
C_{j} H_{2 j-2}^{+4} \approx A S O(2 N) & \text { Equação 6.8 } \\
C_{j} H_{2 j-3}^{+5} \approx A S O(2 N)^{+} & \text {Equação 6.9 } \\
C_{j} H_{2 j-4}^{+6} \approx A S O(3 N) & \text { Equação 6.10 } \\
C_{j} H_{2 j-5}^{+7} \approx A S O(3 N)^{+} & \text {Equação 6.11 } \\
C_{j} H_{2 j-6}^{+8} \approx A S O(4 N) & \text { Equação 6.12 }
\end{array}
$$

Onde: $\mathrm{N}$ representa o número de estruturas cíclicas na molécula.

para: $j \geq 16$.

Como as moléculas de ASO cíclicas já apresentam peso molecular bastante elevado no contexto de unidades de alquilação, considerou-se que as moléculas que ainda possuem cadeia viva não sofrem reação de propagação, mas somente 
reações de transferência de cadeia. Com essa hipótese é possível manter a modelagem molecular, que é a proposta deste trabalho.

Como o número de intermediários formados no meio reacional aumentou exponencialmente com a inserção do butadieno e das reações de craqueamento no modelo, a etapa de transferência de cadeia também é alterada. As Reações 6.18 a 6.25 apresentam a etapa de transferência de cadeia.

$$
\begin{array}{lr}
\text { Transferência de Cadeia } & \\
C_{n} H_{2 n+1}^{+}+i C_{4} H_{10} \stackrel{k_{5}}{\longrightarrow} C_{n} H_{2 n+2}+i C_{4} H_{9}^{+} & \text {Reação 6.18 } \\
C_{n} H_{2 n}^{+2}+i C_{4} H_{10} \stackrel{k_{5}}{\longrightarrow} C_{n} H_{2 n+1}^{+}+i C_{4} H_{9}^{+} & \text {Reação 6.19 } \\
C_{n} H_{2 n-1}^{+3}+i C_{4} H_{10} \stackrel{k_{5}}{\longrightarrow} C_{n} H_{2 n}^{+2}+i C_{4} H_{9}^{+} & \text {Reação 6.20 } \\
C_{n} H_{2 n-2}^{+4}+i C_{4} H_{10} \stackrel{k_{5}}{\longrightarrow} C_{n} H_{2 n-1}^{+3}+i C_{4} H_{9}^{+} & \text {Reação 6.21 } \\
C_{n} H_{2 n-3}^{+5}+i C_{4} H_{10} \stackrel{k_{5}}{\longrightarrow} C_{n} H_{2 n-2}^{+4}+i C_{4} H_{9}^{+} & \text {Reação 6.22 } \\
C_{n} H_{2 n-4}^{+6}+i C_{4} H_{10} \stackrel{k_{5}}{\longrightarrow} C_{n} H_{2 n-3}^{+5}+i C_{4} H_{9}^{+} & \text {Reação 6.23 } \\
C_{n} H_{2 n-5}^{+7}+i C_{4} H_{10} \stackrel{k_{5}}{\longrightarrow} C_{n} H_{2 n-4}^{+6}+i C_{4} H_{9}^{+} & \text {Reação 6.24 } \\
C_{n} H_{2 n-6}^{+8}+i C_{4} H_{10} \stackrel{k_{5}}{\longrightarrow} C_{n} H_{2 n-5}^{+7}+i C_{4} H_{9}^{+} & \text {Reação 6.25 }
\end{array}
$$

A Reação 6.26 apresenta o craqueamento que ocorre no reator da unidade de alquilação. Essa reação consiste na quebra de moléculas parafínicas em dois carbocátions de menor tamanho molecular. Em reatores de alquilação há relato de quebras de moléculas com tamanho de cadeia superior a 10 átomos de carbono, por isso nesse modelo só foi considerado a quebra dessas moléculas. Não foi considerada a possibilidade de quebra do ASO formado na reação.

$$
\begin{aligned}
& \text { Craqueamento } \\
& \mathrm{C}_{n} \mathrm{H}_{2 n+2} \stackrel{k_{z}}{\longrightarrow} \mathrm{C}_{(n-x)} H_{2(n-x)+1}^{+}+C_{x} H_{2 x+1}^{+}
\end{aligned}
$$

A constante cinética da reação de craqueamento, $k_{z}$, depende do número de carbonos presentes na molécula a ser quebrada. A relação das constantes cinética a serem adotadas em função do tamanho da cadeia a ser quebrada está apresentada 
nas Equações 6.13 a 6.18. Essa hipótese deve ser testada quando da calibração do modelo.

$$
\begin{aligned}
& z=13 \text { para } n=10 \\
& z=14 \text { para } n=11 \\
& z=15 \text { para } n=12 \\
& z=16 \text { para } n=13 \\
& z=17 \text { para } n=14 \\
& z=18 \text { para } n=15
\end{aligned}
$$

Equação 6.13

Equação 6.14

Equação 6.15

Equação 6.16

Equação 6.17

Equação 6.18

As etapas de terminação de cadeia, assim como dimerização do buteno-2 e ibuteno e formação de fluoreto orgânico são as mesmas do modelo apresentado anteriormente, conforme Reações 6.27 a 6.34. A etapa de isomerização, além de conter a isomerização dos carbocátions $\mathrm{TMP}^{+}$e $\mathrm{DMH}^{+}$, deve contemplar a isomerização dos carbocátions oriundos do buteno-1 e buteno-2. As Reações 6.35 a 6.38 apresentam essa etapa.

Terminação

$$
\begin{array}{lr}
C_{4} H_{9}^{+}-1 \stackrel{k_{6}}{\longrightarrow} C_{4} H_{8}-1+H^{+} & \text {Reação 6.27 } \\
C_{4} H_{9}^{+}-2 \stackrel{k_{6}}{\longrightarrow} C_{4} H_{8}-2+H^{+} & \text {Reação 6.28 } \\
i C_{4} H_{9}^{+} \stackrel{k_{6}}{\longrightarrow} i C_{4} H_{8}+H^{+} & \text {Reação 6.29 }
\end{array}
$$

Dimerização

$$
\begin{aligned}
& 2 \mathrm{C}_{4} \mathrm{H}_{8}-2+2 \mathrm{H}^{+} \stackrel{k_{9}}{\longrightarrow} \mathrm{DMH} \\
& 2 \mathrm{iC}_{4} \mathrm{H}_{8}+2 \mathrm{H}^{+} \stackrel{k_{10}}{\longrightarrow} \mathrm{DMH}
\end{aligned}
$$

Formação de Fluoreto Orgânico

$$
\begin{aligned}
& C_{4} H_{9}^{+}-1+F^{-} \stackrel{k_{11}}{\longrightarrow} C_{4} H_{9} F \\
& C_{4} H_{9}^{+}-2+F^{-} \stackrel{k_{11}}{\longrightarrow} C_{4} H_{9} F \\
& i C_{4} H_{9}^{+}+F^{-} \stackrel{k_{11}}{\longrightarrow} C_{4} H_{9} F
\end{aligned}
$$


Isomerização

$$
\mathrm{C}_{4} \mathrm{H}_{9}^{+}-1 \stackrel{k_{12}}{\longrightarrow} i \mathrm{C}_{4} \mathrm{H}_{9}^{+}
$$

Reação 6.35

$\mathrm{C}_{4} \mathrm{H}_{9}^{+}-2 \stackrel{k_{12}}{\longrightarrow} i \mathrm{C}_{4} \mathrm{H}_{9}^{+}$

Reação 6.36

$\mathrm{DMH}^{+} \stackrel{k_{7}}{\longrightarrow} \mathrm{TMP}^{+}$

Reação 6.37

$\mathrm{TMP}^{+} \stackrel{k_{8}}{\longrightarrow} \mathrm{DMH}^{+}$

Reação 6.38

Caso a hipótese de reator ideal tipo PFR e meio pseudo-homogêneo sejam mantidas, a Equação 5.4 pode ser aplicada para a construção do modelo fenomenológico. Neste caso, não é levada em consideração a existência de duas fases distintas no meio reacional e que as reações ocorrem somente em fase ácida.

$$
v_{z} \frac{d[A]}{d z}=\sum_{1}^{\text {reaç̃oes }} v_{A i} r_{i}
$$

Equação 5.4

Onde: $\mathrm{v}_{\mathrm{z}}$ : velocidade na direção do fluxo;

$[A]$ : concentração do componente $A$; $r_{i}$ : cinética da reação "i" onde o componente A participa; $v_{\mathrm{Ai}}$ : coeficiente estequiométrico.

Outra abordagem que pode ser dada a modelagem é considerar que o reator de alquilação não é homogêneo, e apresenta duas fases distintas (hidrocarboneto e ácido). Nesse caso os balanços deverão ser realizados para dois volumes de controle distintos: uma porção da fase contínua (HF) e uma gota da fase dispersa (hidrocarboneto); considerando a existência de fluxo de transferência de massa entre as fases. A solubilidade do hidrocarboneto na fase contínua será função da temperatura de reação e da quantidade de ASO presente no ácido. Pouco se conhece dos efeitos do ASO na solubilidade de hidrocarbonetos no ácido, o que pode dificultar a adoção dessa abordagem. 


\section{CONCLUSÕES}

$\mathrm{Na}$ literatura, os esforços para o desenvolvimento de modelos matemáticos complexos para o processo de alquilação têm se concentrado em sistemas que utilizam catalisadores sólidos ou líquidos iônicos; tecnologias incipientes, ainda sem aplicação industrial. Pouco foi desenvolvido para os processos catalisados por ácidos fortes, como o caso do sulfúrico e fluorídrico. Os principais modelos disponíveis na literatura para este tipo de unidade ainda estão baseados em propriedades intensivas (bulk) das correntes.

Este trabalho teve como objetivo construir e validar um modelo matemático fenomenológico para uma unidade de alquilação catalítica que utiliza o ácido fluorídrico (HF) como catalisador, capaz de representar adequadamente as principais reações químicas envolvidas no processo em questão, bem como estimar a quantidade de tri-metil-pentanos, di-metil-hexano e frações pesadas presentes na composição do alquilado. Esses podem ser considerados os componentes de maior importância na composição do alquilado, uma vez que conferem maior (caso TMP) e menor (DMH e frações pesadas) octanagem ao alquilado.

Analisando todas as respostas do modelo proposto às condições observadas na planta, é possível afirmar que seu desempenho foi positivo no que tange consumo de reagentes, rendimento em alquilado. Com relação a composição do alquilado, o modelo tendeu a superestimar a produção de TMP em detrimento a de DMH. O modelo não foi capaz de representar adequadamente o rendimento em frações pesadas do alquilado (conhecidas como alquilado pesado). Como a unidade industrial não possui medição de geração de ASO, não foi possível comparar os resultados do modelo com os dados da planta para essa variável.

O consumo de iso-butano ligeiramente superior ao observado na unidade industrial previsto pelo modelo obtido é explicado pela ausência da etapa da isomerização dos carbocátions com 4 carbonos de cadeia normal a sua forma ramificada. Outro fator que contribuiu para o elevado consumo de iso-butano foi a 
não consideração do ASO como agente de transferência de cadeia, recentemente citado na literatura. A explicação adotada para o comportamento do rendimento superestimado do TMP foi o fato da constante cinética para a reação de isomerização do TMP+ estar subestimada.

A principal restrição ao uso do modelo foi o rendimento em frações pesadas, cujos dados ficam abaixo do observado na unidade industrial. A explicação para esse fenômeno está baseada no fato do modelo desconsiderar os seguintes efeitos: presença de contaminantes na carga, influência da temperatura na cinética de reação e a presença de ASO no HF.

A análise dos perfis de concentração e temperatura ao longo do reator permite afirmar que a maior parte das reações de alquilação ocorre nos primeiros $20 \%$ do reator e praticamente estão encerradas quando aproximadamente $60 \%$ do reator são percorridos. Esse dado leva a crer que é possível aumentar a produtividade do reator adicionando uma nova entrada de butenos em um ponto intermediário do mesmo. Segundo a empresa que projetou a unidade em estudo, unidades de alquilação que apresentam o sistema de alimentação de reagentes somente pela base do reator, como é o caso aqui relatado, permitem a inserção de uma nova entrada de olefinas em um ponto intermediário do reator, fazendo com que a produção total de alquilado aumente. Portanto, os dados obtidos pelo modelo conseguem explicar o motivo de tal alteração no projeto, assim como permite localizar o melhor ponto para inserir a modificação do projeto.

No capítulo de sugestão de trabalhos futuros sugere-se uma nova abordagem para o modelo, visando corrigir as distorções encontradas. Também fica como sugestão de modelar o reator de alquilação como um meio heterogêneo, que permita melhor visualizar os efeitos da solubilidade dos hidrocarbonetos na fase ácida e como isso afeta o rendimento da unidade. 


\section{BIBLIOGRAFIA}

ALBRIGHT, L. F. Present and Future Alkylation Process in Refineries. Industrial \& Engineering Chemistry Research, vol. 48, № 3, 1409 - 1413, 2009.

ALBRIGHT, L. F. Alkylation of Isobutane with C3 - C5 Olefins to Produce High Quality Gasolines: Physicochemical Sequence of Events. Industrial \& Engineering Chemistry Research, vol. 42, № 19, 4283 - 4289, 2003.

ALBRIGHT, L. F. Alkylation - Homogeneous. In HORVATH, I. T. Encyclopedia of Catalysis. $1^{\text {st }}$ ed, vol 1, $191-210$, New Jersey: John Willey \& Sons, 2003.

ALBRIGHT, L. F. Alkylation - Industrial. In HORVATH, I. T. Encyclopedia of Catalysis. $1^{\text {st }}$ ed, vol 1, $262-281$, New Jersey: John Willey \& Sons, 2003.

ALBRIGHT, L. F. Alkylation of Isobutane with C3 - C5 Olefins: Feedstock Consumption, Acid Usage and Alkylate Quality for Different Processes. Industrial \& Engineering Chemistry Research, vol. 41, no 23, 5627 - 5631, 2002.

ALBRIGHT, L. F.; ECKERT, R. E. Formation and Separation of Sulfuric Acid / nHeptane Dispersions: Applications to Alkylation. Industrial \& Engineering Chemistry Research, vol. 40, № 19, $4032-4039,2001$.

ALBRIGHT, L. F.; WOOD, K. V. Alkylation of Isobutane with C3 - C4 Olefins: Identification and Chemistry of Heavy-End Production. Industrial \& Engineering Chemistry Research, vol. 36, № 6, $2110-2120,1997$.

ALBRIGHT, L. F. Alkylation of Isobutane with Light Olefins: Yields of Alkylates for Different Olefins. Industrial \& Engineering Chemistry Research, vol. 32, 꾸 12, 2991 - 2996, 1993.

ALBRIGHT, L. F.; SPALDING, M. A.; NOWINSKI, J. A.; YBARRA, R. M.; ECKERT, R. E. Alkylation of Isobutane with C4 Olefins. 1. First-Step Reactions Using Sulfuric Acid Catalyst. Industrial \& Engineering Chemistry Research, vol. 27, № 3, 381 386, 1988.

ALBRIGHT, L. F.; SPALDING, M. A.; KOPSER, C. G.; ECKERT, R. E. Alkylation of Isobutane with $\mathrm{C} 4$ Olefins. 2. Production and Characterization of Conjunct Polymers. Industrial \& Engineering Chemistry Research, vol. 27, n 3, 386 - 391, 1988. 
ALBRIGHT, L. F.; Li, K. W.. Alkylation of Isobutane with Light Olefins Using Sulfuric Acid: reaction Mechanism and Comparison with HF Alkylation. Industrial \& Engineering Chemistry Process Design and Development, vol. 9, nํ 3, 447 454, 1970.

AM ENDE, D. J.; ALBRIGHT, L. F. Degradation and Isomerization of Isoparaffins While in Contact with Sulfuric Acid in Alkylation Units: Chemistry and Reaction kinetics. Industrial \& Engineering Chemistry Research, vol. 33, no 4, 840 - 848, 1994.

BOX, G. E. P.; HUNTER, W. G.; HUNTER, J. S. Statistics for Experimenters - An Introduction to Design, Data Analysis and Model Building. $1^{\text {st }}$ ed. New York: John Willey \& Sons, 1978. 653p. (Wiley Series in Probability and Mathematical Statistics).

BUI, T. L. T.. Investigations on Alkylation of Isobutane with 2-Butene Using Highly Acidic Ionic Liquids as Catalysts. 2007. 181p. Tese (Doutorado) -. Universität Bayreuth. Alemanha, 2007.

CAMERON, I. T.; HANGOS, K. M. Process Modelling and Model Analysis. $1^{\text {st }}$ ed. London: Academic Press, 2001. 542p. (Process Systems Engineering, Volume 4).

CIAPETTA, F. G. Alkylation of Isoparaffins: Aplication of the Carbonium - Ion Theory. Industrial and Engineering Chemistry, vol. 37, nํ12, 1210-1216, 1945.

CORMA, A.; MARTINEZ, A. Alkylation - Heterogeneous. In HORVATH, I. T. Encyclopedia of Catalysis. $1^{\text {st }}$ ed, vol 1, $210-262$, New Jersey: John Willey \& Sons, 2003.

CUPIT, C. R.; GWYN, J. E.; JERNIGAN, E. C. Catalytic Alkylation part 1. Petro/Chem Engineer, December, 204-215, 1961.

CUPIT, C. R.; GWYN, J. E.; JERNIGAN, E. C. Catalytic Alkylation part 2. Petro/Chem Engineer, January, 207-217, 1962.

DAUZACKER, E. R.; PALOMBO, F.. "Impacto das Futuras Especificações na Formulação da Gasolina Brasileira". Boletim Técnico Petrobras, 46, (3/4), 256-269. Rio de Janeiro, 2003. 
DE JONG, K.P.; MESTERS, C. M. A. M.; PEFEROEN, D. G. R.; VAN BRUGGE, P. T. M.; DE GROOTE, C. Paraffin Alkylation Using Zeolitie Catalysts in a Slurry Reactor: Chemical Engineering Principles to Extend Catalyst Life Time. Chemical Engineering Science, vol 51, № 10, 2053 - 2060, 1996.

DE KLERK, A.; VAAL, P. L. Alkylate Technology Selection for Fischer Tropsch Refining. Industrial \& Engineering Chemistry Research, vol. 47, oㅡ 18, 6870 6877, 2008.

DOSHI, B.; ALBRIGHT, L. F. Degradation and Isomerization Reactions Occurring During Alkylation of Isobutane with Olefins. Industrial \& Engineering Chemistry Process Design and Development, vol. 15, № 1, 53-60, 1976.

DURRETT. L. R.; TAYLOR, C. F.; WANTLAND, C. F.; DVORETZKY, I. Component Analysis of Isoparaffin - Olefin Alkylate by Capillary Gas Chromatography. Analytical Chemistry, vol 35, no 6, $637-641,1963$.

FIORE, I. K.; MORGADO JR., E. Optimizing Defluorinator Catalyst Bed Changeout: A Case Study from A HF Alkylation Plant In Brazil. In: UOP 2011 HF Alkylation Symposium, 2011, San Diego, CA.

FIORE, I. K.; CARRAPIÇO, O. L.; OGINO, W. T. On the Level. Hydrocarbon Engineering, vol. 15, № 10, 83- 87, 2010.

FLORY, P. J. Principles of Polymer Chemistry. $1^{\text {st }}$ ed. Ithaca: Cornel University Press, 1953. 672p.

FOGLER, H. S. Elementos de Engenharia das Reações Químicas. $3^{\mathrm{a}}$ ed. Rio de Janeiro: LTC, 2002. $892 \mathrm{p}$.

GARY, J. H.; HANDWERK, G. E. Petroleum Refining: Technology and Economics. $4^{a}$ ed. New York: Marcel Dekker Inc, 2001. 399 p.

GROSSE, A. V.; LINN, C., B. The Addition of Hydrogen Fluoride to the Double Bound. Journal of Organic Chemistry, vol. 03, no 1, 26-32, 1938.

HAMIELEC, A.E.; TOBITA, H. Polymerization Process. In Ullmann's Encyclopedia of Industrial Chemistry, vol A.21, $305-428,1992$. 
HANDLER, L. H.; SMITH, E. W. The Analysis of Carbon - 14 Labeled Butane Isobutane Alkylation Reactions. International Journal of Applied Isotopes, vol 25, $521-533,1974$.

HIMES, J. F.; MEHLBERG, R. L. Motor Fuel Alkylation. In JONES, D. S. J.; PUJADÓ, P.R. Handbook of Petroleum Processing. $2^{\text {nd }}$ ed. Chicago: Springer, 2008. 1353 p.

HIMMELBLAU, D. M.; RIGGS, J. B. Engenharia Química - Princípios e Cálculos. $7^{\underline{a}}$ ed. Rio de Janeiro: LTC, 2006. 846 p.

HOFMANN, J. E.; SCHRIESHEM, A. Ionic Reactions Occurring During Sulfuric Acid Catalyzed Alkylation. I. Alkylation of Isobutane with Butenes. Journal of American Chemical Society, vol. 84, ํㅜ 6, 953 - 957, 1962.

HOFMANN, J. E.; SCHRIESHEM, A. Ionic Reactions Occurring During Sulfuric Acid Catalyzed Alkylation. II. Alkylation of Isobutane with $\mathrm{C}^{14}$ Labeled Butenes. Journal of American Chemical Society, vol 84, n 6, 957 - 961, 1962.

HOMMELTOFT, S. I. Isobutane Alkylation: Recent Developments and Future Perspectives. Applied Catalysis A: General, vol 221, no $1-2,421-428,2001$.

HUTSON, T., LOGAN, R.S. Estimate Alky Yield and Quality. Hydrocarbon Processing, $\mathrm{n}$ ㅇ 9, $107-110,1975$.

HUTSON, T.; HAYS, G. E. Reaction Mechanisms for Hydrofluoric Acid Alkylation. In ALBRIGHT, L. F.; Goldsby, A. R. Industrial and Laboratory Alkylations. $1^{\text {st }}$ ed. New Orleans: ACS Symposium Series 55. American Chemical Society, 1977. 462 p.

HUTSON, T. HF Alkylation in the 1980's: The Role of Isobutane/Olefin Ratio. In: Symposium on Octane in the 1980's, 1978, Miami Beach, FL. American Chemical Society Meeting.

HYDROCARBON PUBLISHING COMPANY. Worldwide Refinery Processing Review: Hydrocracking and Alkylation. 207 - 332. Houston, 2008.

HYMAN, H. H.; KILPATRICK, M.; KATZ, J. J. The HAMMETT Acidity Funtion Ho for Hydrofluoric Acid Solutions. Journal of American Chemical Society, vol. 79, $n^{\circ} 14$, $3668-3671,1957$. 
IPATIEFF, V. N., GROSSE, A. V. Reaction of Paraffins with Olefins. Journal of American Chemical Society, vol. 57, no 9, 1616 - 1621, 1935.

KRAMER, G. M. Alkylation Studies. In ALBRIGHT, L. F.; Goldsby, A. R. Industrial and Laboratory Alkylations. $1^{\text {st }}$ ed. New Orleans: ACS Symposium Series 55. American Chemical Society, 1977. 462 p.

LITTLE, D. M. Catalytic Reforming. $1^{\text {st }}$ ed. Tulsa: Penn Well Books, 1985.

MAKOVEC, D. J.; HASKELL, D. M. HF Alkylation of Cat-Craker Butenes. In ALBRIGHT, L. F.; Goldsby, A. R. Industrial and Laboratory Alkylations. $1^{\text {st }}$ ed. New Orleans: ACS Symposium Series 55. American Chemical Society, 1977. 462 p.

MIRON, S.; LEE, J. R. Molecular Structure of Conjunct Polymers. Journal of Chemical and Engineering Data, vol. 8, nำ1, 150 - 160, 1963.

MOLNAR, A. Acids and Acid Catalysis - Homogeneous. In HORVATH, I. T. Encyclopedia of Catalysis. $1^{\text {st }}$ ed, vol 1, $40-86$, New Jersey: John Willey \& Sons, 2003.

NAYAK, S. V.; RAMACHANDRAN, P. A.; DUDUKOVIC, M. P. Modeling of Key Reaction Pathways: Zeolite Catalyzed Alkylation Process. Chemical Engineering Science, vol 65, no 1, $335-342,2010$.

PETERSON, A. H.; PHILLIPS, B. L.; KELLY, J. T. Hidroisomerization of Normal Olefins Under Alkylation Conditions. I\&EC Product Research and Development, vol. 4, no 4, $261-265,1965$.

PRICKETT, S. E.; MAVROVOUNIOTIS, M. L. Construction of Complex Reaction Systems - III An Example: Alkylation of Olefins. Computers and Chemical Engineering, vol. 21, no 12, 1325 - 1337 , 1997.

OLAH, G. A. 100 Years of Carbocations and their Significance in Chemistry. The Journal of Organic Chemistry, vol. 66, no 18, 5943 - 5957, 2001.

SCHMERLING, L. Reactions of Hydrocarbons: Ionic Mechanisms. Industrial and Engineering Chemistry, vol. 45, № 7, 1447 - 1455, 1953. 
SCHMERLING, L. The Mechanism of the Alkylation of Paraffins. II. Alkylation of Isobutane with Propene, 1-Butene and 2-Butene. Journal of American Chemical Society, vol 68, no 2, $275-281,1946$.

SCHMERLING, L. The Mechanism of the Alkylation of Paraffins. Journal of American Chemical Society, vol 67, no 10, 1778 - 1783, 1945.

SHIMIDT, R.; WELCH, M. B.; ANDERSON, R. L.; SARDASHTI, M.; RANDOLPH, B B. Disproportionation of Light Paraffins. Energy and Fuels, vol 22, $n^{\circ} 3,1812-1823,2008$.

SIMPSON, M. F.; WEI, J.; SUNDARESAN, S. Kinetic Analysis of Isobutane / Butene Alkylation over Ultrastable $\mathrm{H}-\mathrm{Y}$ Zeolite. Industrial \& Engineering Chemistry Research, vol. 36, no 11, $3861-3873,1996$.

WESTON, N.; CLIFT, R.; BASSON, L.; POUTON, A.; WHITE, N. Assessment of Cleaner Process Options: A Case Study from Petroleum Refining. The Canadian Journal of Chemical Engineering, vol. 86, $302-315,2008$.

ZIMMERMAN, C. A.; KELLY, J. T.; DEAN, J. C. Dimethylhexane Formation in Butene Alkylation. I\&EC Product Research and Development, vol. 1, no 2, $124-126$, 1962.

CHEMICAL AND PROCESS ENGINEERING RESOUCES. Green Gasoline. Disponível em: <http://www.cheresources.com/greengas.shtml>. Acesso em 17 out. 2010.

FLUORIDE ACTION NETWORK. Hydrofluoric Acid Leak in Texas Leaves a Residue of Questions. Disponível em: <http://www2.fluoridealert.org/Pollution/OilRefineries/Hydrofluoric-Acid-Leak-in-Texas-Leaves-a-Residue-of-Questions>. Acesso em 24 out. 2010

WIKIPEDIA. Disponível em: <http://en.wikipedia.org/wiki/File:RefineryFlow.png>. Acesso em 23 out. 2010.

PORTAL LABORATÓRIOS VIRTUAIS DE PROCESSOS QUÍMICOS. Disponível em: <http://labvirtual.eq.uc.pt>. Acesso em 06 nov. 2010. 